\title{
HIGH EFFICIENCY GENERATION OF HYDROGEN FUELS USING NUCLEAR POWER
}

\author{
ANNUAL REPORT TO THE \\ U.S. DEPARTMENT OF ENERGY
}

AUGUST 1, 2000 THROUGH JULY 31, 2001

\author{
by \\ L.C. BROWN, J.F. FUNK, and A.C. MARSHALL
}

\author{
Prepared under \\ Nuclear Energy Research Initiative (NERI) \\ Grant No. DE-FG03-99SF21888 \\ for the U.S. Department of Energy
}

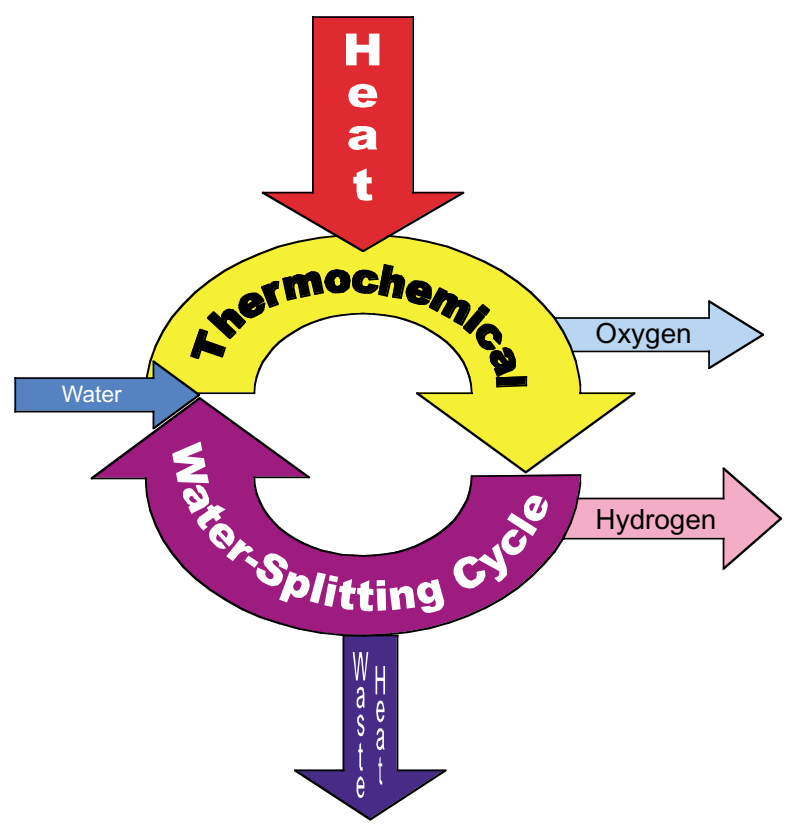

DATE PUBLISHED: NOVEMBER 2002 


\section{DISCLAIMER}

This report was prepared as an account of work sponsored by an agency of the United States Government. Neither the United States Government nor any agency thereof, nor any of their employees, makes any warranty, express or implied, or assumes any legal liability or responsibility for the accuracy, completeness, or usefulness of any information, apparatus, product, or process disclosed, or represents that its use would not infringe privately owned rights. Reference herein to any specific commercial product, process, or service by trade name, trademark, manufacturer, or otherwise, does not necessarily constitute or imply its endorsement, recommendation, or favoring by the United States Government or any agency thereof. The views and opinions of authors expressed herein do not necessarily state or reflect those of the United States Government or any agency thereof. 


\section{HIGH EFFICIENCY GENERATION OF HYDROGEN FUELS USING NUCLEAR POWER \\ ANNUAL REPORT TO THE U.S. DEPARTMENT OF ENERGY}

AUGUST 1, 2000 THROUGH JULY 31, 2001

by

L.C. BROWN, J.F. FUNK, ${ }^{\star}$ and A.C. MARSHALL†

*University of Kentucky, Lexington, Kentucky

tSandia National Laboratories, Albuquerque, New Mexico

Prepared under

Nuclear Energy Research Initiative (NERI)

Grant No. DE-FG03-99SF21888

for the U.S. Department of Energy 


\section{EXECUTIVE SUMMARY}

Currently no large scale, cost-effective, environmentally attractive hydrogen production process is available for commercialization nor has such a process been identified. Hydrogen is a promising energy carrier, which potentially could replace the fossil fuels used in the transportation sector of our economy. Carbon dioxide emissions from fossil fuel combustion are thought to be responsible for global warming.

The purpose of this work is to determine the potential for efficient, cost-effective, largescale production of hydrogen utilizing high temperature heat from an advanced nuclear power station. The benefits of this work will include the generation of a low-polluting transportable energy feedstock in an efficient method that has little or no implication for greenhouse gas emissions from a primary energy source whose availability and sources are domestically controlled. This will help to ensure energy for a future transportation/energy infrastructure that is not influenced/controlled by foreign governments.

This report describes work accomplished during the second year (Phase 2) of a three year project whose objective is to "define an economically feasible concept for production of hydrogen, by nuclear means, using an advanced high temperature nuclear reactor as the energy source." The emphasis of the first year (Phase 1) was to evaluate thermochemical processes which offer the potential for efficient, cost-effective, large-scale production of hydrogen from water, in which the primary energy input is high temperature heat from an advanced nuclear reactor and to select one (or, at most, three) for further detailed consideration. Phase 1 met its goals and did select one process, the sulfur-iodine process, for investigation in Phases 2 and 3. The combined goals of Phases 2 and 3 were to select the advanced nuclear reactor best suited to driving the selected thermochemical process and to define the selected reactor and process to the point that capital costs, operating costs and the resultant cost of hydrogen can be estimated. During original contract negotiation, it was necessary to reduce work scope to meet funding limits. As a result, the reactor interface and process will not be iterated to the point that only hydrogen is produced. Rather, hydrogen and electricity will be co-generated and the hydrogen cost will be stated as a function of the electricity sales price.

Division of tasks between Phases 2 and 3 is somewhat arbitrary. The originally assumed division was based on funding and the assumed progress during year two. The main elements comprising Phase 2 as originally conceived are:

- Carry out a detailed evaluation of the processes remaining under consideration at the end of Phase 1 and select one for detailed consideration in Phases 2 and 3. 
- Define the reactor thermal interface.

- Perform preliminary engineering design of the selected process.

- Develop chemical flow sheets for the selected process.

- Prepare preliminary equipment specifications.

- Report on the results of Phase 2.

The first task was, to a large extent, completed during Phase 1 of this project where the sulfur-iodine thermochemical water-splitting cycle was chosen for study during Phases 2 and 3. The effort allocated to this task was expended in investigating process alternatives.

Definition of the reactor thermal interface was primarily a Sandia National Laboratory (SNL) task. Nine broad classifications of reactors were considered and, for each of the five classifications deemed feasible, a preferred implementation was examined in detail. Three reactors, lead-bismuth cooled, lithium-beryllium fluoride cooled and helium gas cooled were judged to be promising candidates for which relative development risks were considered. The helium gas-cooled reactor was selected to be matched to the sulfur-iodine process in Phase 3 as it was rated highest of the three finalists in terms of suitability to the task and has minimal development risks compared with the other two finalists.

Process engineering and development tasks were carried out at the University of Kentucky (UK) and at General Atomics (GA). The effort was split between the two institutions. GA was responsible for overall process design and thermodynamic modeling while the UK emphasized development of process flow sheets. The UK was responsible for the sulfuric acid processing portion of the flow sheet and GA was responsible for the remainder of the flow sheet. The UK provided student support to both the GA efforts and their own.

A significant effort was required in the development of consistent thermodynamic models that could be used with a chemical process simulator. The original work on the process was almost completely based on hand calculations [1]. Part of the present work being described in this report was subcontracted to Aspen Technologies, the developers of AspenPlus, the process simulator chosen for this work.

The final process design bears similarity to those developed in the 1980s. Significant differences are found in that section of the process where hydrogen iodide is separated from iodine and water and decomposed to produce hydrogen. At this point, we are still considering two options. (1) A relatively minor modification to the previous flow sheet replaces low temperature heat, obtained by vapor recompression of otherwise waste heat, with reject heat from co-generation of electricity. (2) A radical process modification replaces a large section of the process with a combination distillation column chemical reactor. 
The various flow sheet options have been explored allowing us to proceed with flow sheet matching. Some additional effort is required to develop thermodynamic models which will produce reliable flow sheets but we can proceed using hand calculations if necessary. Remaining process design decisions will be made on the basis of the lowest overall cost of the hydrogen produced.

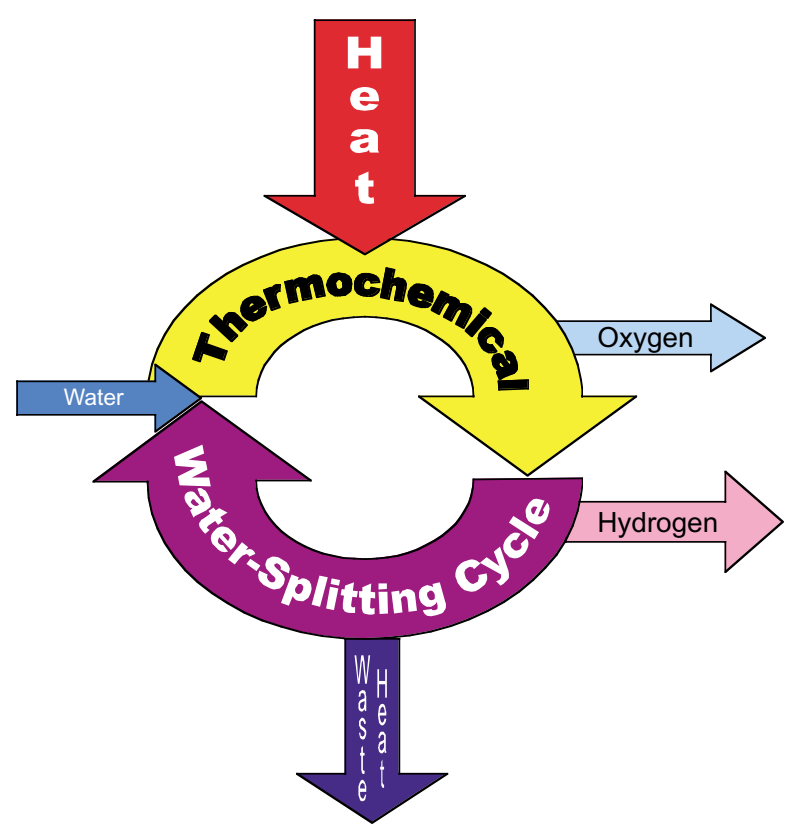




\section{TABLE OF CONTENTS}

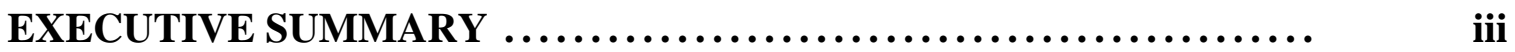

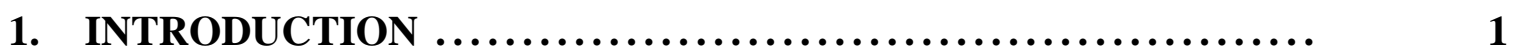

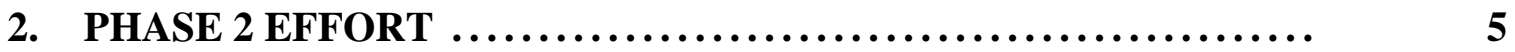

2.1. Process Evaluation …....................................... 5

2.1.1. Sulfer-Iodine Thermochemical Process ................... 5

2.1.2. Process Alternatives ..................................... 7

2.2. Reactor Definition .......................................... 11

2.3. Preliminary Process Engineering ............................... 12

2.3.1. Evaluation of Chemical Thermodynamic Data and Models .. 12

2.4. Chemical Flow Sheet Development ….......................... 15

2.4.1. Overall Flow Sheet Development ........................ 15

2.4.2. Section 2 .............................................. 15

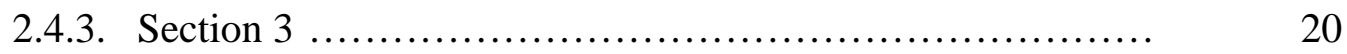

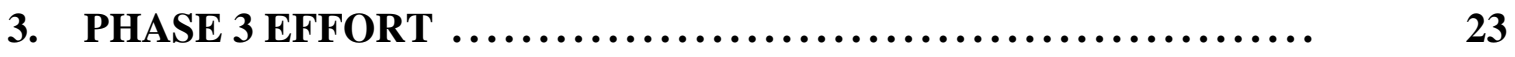

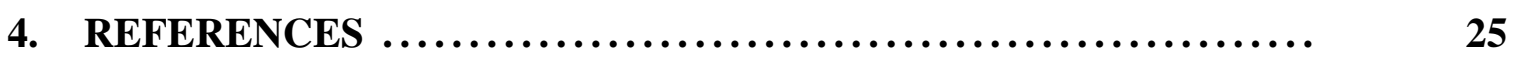

5. ACKNOWLEDGEMENTS .............................. 27

APPENDIX: A.C. MARSHALL, "AN ASSESSMENT OF REACTOR TYPES FOR THERMOCHEMICAL HYDROGEN PRODUCTION,"

SANDIA NATIONAL LABORATORY REPORT SAND2002-0513 (2002)

\section{LIST OF FIGURES}

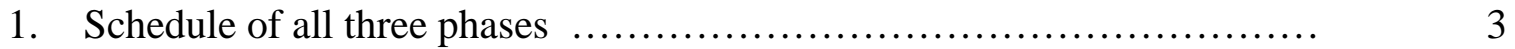

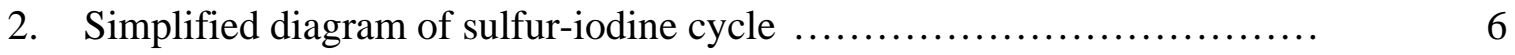

3. Simplified flow diagram of Section 1 from 1979 flow sheet ............... 8

4. Simplified flow diagram of Section 1 from 1981 flow sheet ............... 8

5. Vapor recompression flash stage .................................. $\quad 10$

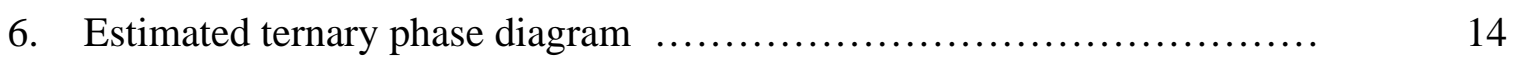

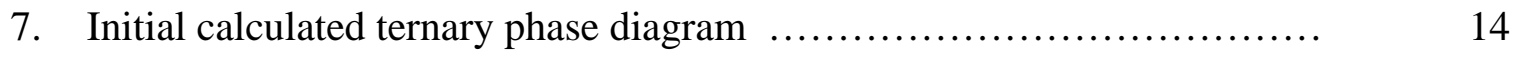


8. Section 2 flow sheet based on flash concentration to $60 \%$ sulfuric acid. .. $\quad 17$

9. Section 2 flow sheet based on flash concentration to $90 \%$ sulfuric acid ... 18

10. Section 2 flow sheet based on distillation to $90 \%$ sulfuric acid ............. 19

11. Modified Roth and Knoche scheme ............................... 21

12. Phosphoric acid version of Section 3 flow sheet ...................... 22

\section{LIST OF TABLES}

1. Schedule, performance and responsible organization for Phase 2 tasks $\ldots .2$

2. Schedule and responsible organization for Phase 3 tasks ................ 4

3. Effect of heat recovery on efficiency for Section $2 \ldots \ldots \ldots \ldots \ldots \ldots \ldots \ldots \ldots$ 


\section{INTRODUCTION}

Combustion of fossil fuels, used to power transportation, generate electricity, heat homes and fuel industry provides $86 \%$ of the world's energy [2,3]. Drawbacks to fossil fuel utilization include limited supply, pollution, and carbon dioxide emissions. Carbon dioxide emissions, thought to be responsible for global warming, are now the subject of international treaties [4]. Together, these drawbacks show a need for the replacement of fossil fuels with a less-polluting and potentially renewable primary energy such as nuclear energy. Conventional nuclear plants readily generate electric power but fossil fuels are firmly entrenched in the transportation sector. Hydrogen is an environmentally attractive transportation fuel that has the potential to displace fossil fuels. Hydrogen will be particularly advantageous when coupled with fuel cells. Fuel cells are more efficient than conventional battery/internal combustion engine combinations and do not produce nitrogen oxides during low-temperature operation. Contemporary hydrogen production is primarily based on fossil fuels and, more specifically, on steam reforming of natural gas. When hydrogen is produced using energy derived from fossil fuels, there is little or no environmental advantage.

There is currently no large scale, cost-effective, environmentally attractive hydrogen production process available for commercialization, nor has such a process been identified. The objective of this work is to find an economically feasible process for the production of hydrogen, by nuclear means, using an advanced high-temperature nuclear reactor as the primary energy source. Hydrogen production is a chemical process that accomplishes the decomposition of water into hydrogen and oxygen using only heat or, in the case of a hybrid thermochemical process, by a combination of heat and electrolysis. Hydrogen production by thermochemical water-splitting could meet these goals.

Hydrogen produced from fossil fuels has trace contaminants (primarily carbon monoxide) that are detrimental to precious metal fuel cells as is now recognized by many of the world's largest automobile companies. Thermochemical hydrogen will not contain contaminating carbon monoxide at any level. Electrolysis, the alternative process for

producing hydrogen using nuclear energy, suffers from thermodynamic inefficiencies in both the production of electricity and in electrolytic parts of the process. The efficiency of electrolysis (electricity to hydrogen) is currently about $80 \%$. To ensure the efficiency of electric power, the generated power would need to be in the range of 59\%-65\% (thermal to electrical) in order for the combined efficiency to reach the $47 \%-52 \%$ (thermal to hydrogen) calculated for the sulfur-iodine thermochemical cycle. 
For the past 35 years and at various levels of effort, thermochemical water-splitting cycles have been studied. They were extensively studied in the late 1970s and early 1980s but have received little attention in the U.S. for the past 15 years. While there is no question about the technical feasibility and the potential for high efficiency, cycles with proven low cost and high efficiency have yet to be developed commercially. Over 100 cycles have been proposed, but substantial research has been executed on only a few.

This report describes work accomplished during the second year (Phase 2) of a three year project whose objective is to "define an economically feasible concept for the production of hydrogen, by nuclear means, using an advanced high temperature nuclear reactor as the energy source." The emphasis of the first phase was to evaluate thermochemical processes that offer the potential for efficient, cost-effective, large-scale production of hydrogen from water and to select one (or, at most, three) for further detailed consideration.

The result of the first year (Phase 1) [5] was the selection of the sulfur-iodine process for detailed evaluation during Phases 2 and 3. The division of tasks between Phase 2 and Phase 3 is as follows:

1. Phase 2 emphasized the selection of the nuclear reactor and development of the chemical flow sheet. (The primary energy input to the process is to be high temperature heat from an advanced nuclear reactor.)

2. Phase 3 will emphasize matching the process to the reactor and estimating cost and efficiency.

The work of Phase 2 was divided into several tasks (Table 1, Fig. 1). Technical tasks, with the exception of Task 2.5, were completed as indicated. Task 2.5 was postponed, with

Table 1

Schedule, Performance and Responsible Organization for Phase 2 Tasks

\begin{tabular}{|c|c|c|c|c|}
\hline Task & Description & $\begin{array}{l}\text { Planned } \\
\text { Completion }\end{array}$ & $\begin{array}{l}\text { Actual Completion } \\
\text { or Comment }\end{array}$ & $\begin{array}{c}\text { Lead } \\
\text { Organization }\end{array}$ \\
\hline 2.1 & $\begin{array}{l}\text { Carry out detailed evaluation of a few } \\
\text { processes to select one }\end{array}$ & Fri., $1 / 26 / 01$ & Fri., $1 / 26 / 01$ & GA \\
\hline 2.2 & Define reactor thermal interface & Fri., 3/2/01 & Tue., $7 / 31 / 00$ & SNL \\
\hline 2.3 & $\begin{array}{l}\text { Preliminary engineering design of } \\
\text { selected process }\end{array}$ & Fri., 3/2/01 & Tue., $7 / 31 / 00$ & GA \\
\hline 2.4 & Develop flow sheet & Fri., 6/29/01 & Tue., $7 / 31 / 00$ & UK \\
\hline 2.5 & Conceptual equipment specifications & Fri., 6/29/01 & $\begin{array}{l}\text { Work postponed to } \\
\text { Phase } 3 \text { as task } 3.3\end{array}$ & SNL \\
\hline 2.6 & Write Phase 2 Report & Fri., 8/31/01 & This report & GA \\
\hline
\end{tabular}




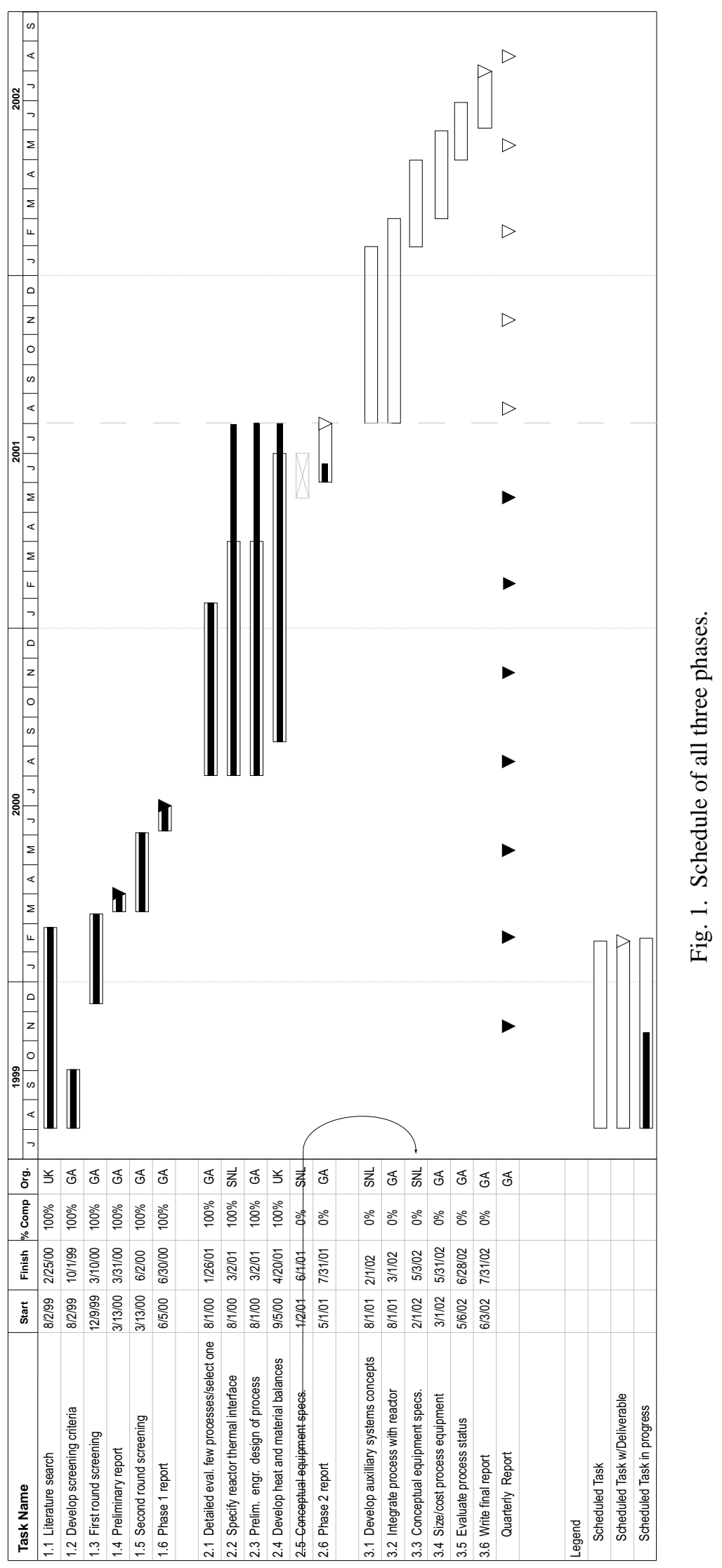


DOE concurrence, to Phase 3. The work was performed as a collaborative effort between GA, the UK and SNL under the Department of Energy, Nuclear Energy Research Initiative (NERI). GA was the lead laboratory for this work but all of the collaborators were involved in every task and one organization was responsible for the task.

In Phase 3, preliminary engineering estimates will be made of the cost of hydrogen produced from nuclear energy using the sulfur-iodine thermochemical cycle. The flow sheets from Phase 2 will be refined and these refined flow sheets will be used to both estimate the efficiency of the sulfur-iodine cycle and the size of the major pieces of process equipment. Based on equipment size and construction material, the cost of the equipment and the total capital cost of the process plant may be estimated. Combining this information with an estimated reactor capital cost and estimated operating costs, the cost of hydrogen can be calculated. The Phase 3 effort will perform the work scope and follow the schedule of the original proposal as amended prior to contract award. The schedule for Phase 3 is given in Table 2.

Table 2

Schedule and Responsible Organization for Phase 3 Tasks

\begin{tabular}{|c|c|c|c|c|}
\hline Task & Description & $\begin{array}{l}\text { Planned } \\
\text { Completion }\end{array}$ & $\begin{array}{l}\text { Actual Completion } \\
\text { or Comment }\end{array}$ & $\begin{array}{c}\text { Lead } \\
\text { Organization }\end{array}$ \\
\hline 3.1 & $\begin{array}{l}\text { Develop concepts for auxiliary } \\
\text { systems }\end{array}$ & Fri., 2/1/02 & Phase 3 effort & SNL \\
\hline 3.2 & Refine flow sheet & Fri., 3/1/02 & Phase 3 effort & UK \\
\hline 3.3 & $\begin{array}{l}\text { Conceptual equipment } \\
\text { specifications }\end{array}$ & Fri., 4/26/02 & Was task 2.5 & SNL \\
\hline 3.4 & Size/cost process equipment & Fri., 5/31/02 & Was task 3.3 & $\mathrm{GA}$ \\
\hline 3.5 & Evaluate process status & Fri., 6/28/02 & Was task 3.4 & $\mathrm{GA}$ \\
\hline 3.6 & Write Final Report & Fri., 7/31/02 & Was task 3.5 & $\mathrm{GA}$ \\
\hline
\end{tabular}




\section{PHASE 2 EFFORT}

\subsection{PROCESS EVALUATION}

\subsubsection{Sulfur-lodine Thermochemical Process}

The sulfur-iodine thermochemical cycle was chosen during Phase 1 of this project [5] to be matched to a high temperature nuclear reactor. The cycle consists of three chemical reactions, which amount to the dissociation of water:

$$
\begin{array}{cc}
\mathrm{I}_{2}+\mathrm{SO}_{2}+2 \mathrm{H}_{2} \mathrm{O} \rightarrow 2 \mathrm{HI}+\mathrm{H}_{2} \mathrm{SO}_{4} & \left(120^{\circ} \mathrm{C}\right) \\
\mathrm{H}_{2} \mathrm{SO}_{4} \rightarrow \mathrm{SO}_{2}+\mathrm{H}_{2} \mathrm{O}+1 / 2 \mathrm{O}_{2} & \left(850^{\circ} \mathrm{C}\right) \\
2 \mathrm{HI} \rightarrow \mathrm{I}_{2}+\mathrm{H}_{2} & \left(350^{\circ} \mathrm{C}\right) \\
\mathrm{H}_{2} \mathrm{O} \rightarrow \mathrm{H}_{2}+1 / 2 \mathrm{O}_{2} & \left(4000^{\circ} \mathrm{C}\right)
\end{array}
$$

The three chemical reactions that form the cycle occur at much lower temperatures than the dissociation reaction.

The simplified flow diagram shown in Fig. 2 indicates how these three chemical reactions are linked to form the cycle. Most of the heat input to the sulfur-iodine cycle goes into item (2), the dissociation of sulfuric acid, which generates oxygen. Considerably less heat is required in item (3) to decompose hydrogen iodide and generate hydrogen. The Bunsen reaction in item (1), which produces the sulfuric acid and hydrogen iodide, is endothermic. Viewed as a heat engine, high temperature heat enters the process through reaction (2) and the waste heat leaves via reaction (1) while the converted energy leaves through reaction (3) as the higher heating value of hydrogen. The converted energy can be regained through the reverse of reaction (4).

The Bunsen reaction is carried out in excess water. This water circulates through both branches of the cycle. The presence of water increases the heat requirements, either to concentrate the acids or to recuperate the excess material to the reaction temperature. A key discovery, made at GA in 1974, was that an excess of iodine in the Bunsen reaction causes the formation of two liquid phases. The light phase is composed of sulfuric acid and water, with only a trace of the iodine containing components. The heavy phase is composed of hydrogen iodide, iodine and water, with only a trace of sulfur containing components. 
Without this discovery, there would be no sulfur-iodine cycle as hydrogen iodide cannot be separated from aqueous sulfuric acid by thermal means. Ultimately, the sulfuric acid and hydrogen iodide react to form iodine and sulfur dioxide. Again, the excess iodine results in increased heat requirements, either to separate the iodine from the hydrogen iodide or to heat to the reaction temperature.

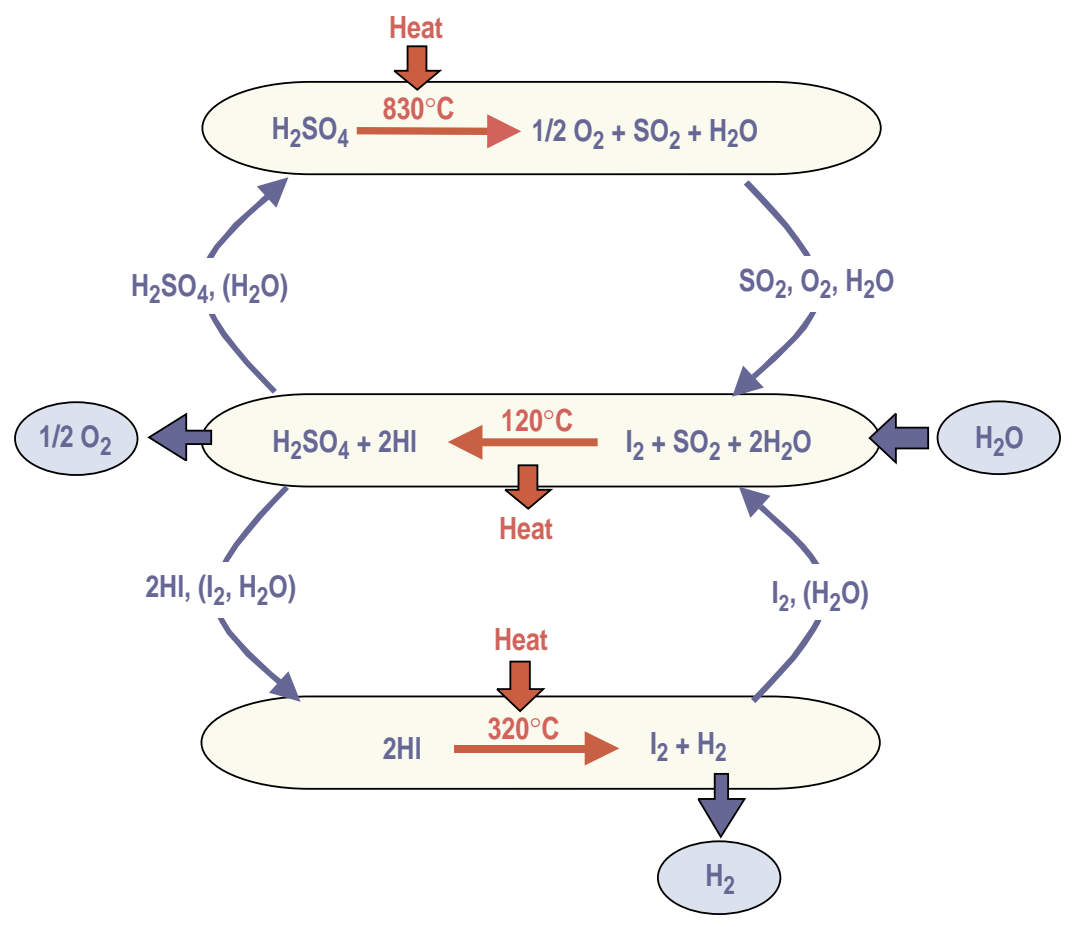

Fig. 2. Simplified diagram of sulfur-iodine cycle.

The sulfur-iodine cycle was extensively studied in the 1970s and 1980s at GA. This work included fundamental chemical investigations, chemical process engineering studies [1] and material compatibility experiments [6]. The energetics of the chemical reaction is fixed, therefore, much of the chemical and process engineering effort was aimed at understanding the separation processes. Maximizing the efficiency of these processes maximizes the overall process efficiency. In these and subsequent efforts, the process has been divided into "sections" corresponding roughly to the three reactions. Section 1 includes the Bunsen reaction and all process associated with it. Also included in Section 1 are the separation of the immiscible phases, scrubbing the excess sulfur dioxide from the $\mathrm{HI}_{\mathrm{x}}$, boosting the sulfuric acid concentration by reaction with fresh iodine and sulfur dioxide and scrubbing the last traces of sulfur dioxide from the oxygen so it can be vented. Section 2 is concerned with concentrating and decomposing the sulfuric acid. Treatment of the $\mathrm{HI}_{\mathrm{x}}$ phase is termed Section 3. The treatment of the $\mathrm{HI}_{\mathrm{x}}$ can either decompose the hydrogen iodide content or separate it. If the hydrogen iodide is separated, the processes associated with its decomposition are called Section 4. 
Two different variations of the flow sheet were presented: the 1979 flow sheet was optimized for maximum thermal efficiency; whereas, the 1981 flow sheet accepted lower efficiency in order to reduce capital equipment cost. The 1981 flow sheet was incomplete due to the absence of Section 2. Section 2 was completed separately to match the cycle to either a concentrated solar energy source or a fusion energy source [7]. The fusion flow sheet or MARS flow sheet is very similar to a fission reactor flow sheet. We used the MARS adaptation of the 1981 flow sheet as a starting point for this work.

Having an efficient process is not sufficient for the process to be economic, the capital and operating costs must also be reasonable. Once materials of construction were identified for each service, process engineering studies were undertaken to estimate the size and cost of the process equipment and the operating cost of the hydrogen plant.

\subsubsection{Process Alternatives}

The 1979 and 1981 flow sheets have many detailed differences. One major difference on the 1981 flow sheet shows a significantly higher iodine recycle between Sections 1 and 3 . This is result of a transition from a counter-current chemical reactor to a co-current reactor in order to reduce capital costs. Figures 3 and 4 are simplified flow diagrams for the 1979 and 1981 Section 1 flow sheets. In both versions, the Bunsen reaction takes place in both the main reactor and in the boost reactor. It also takes place in the cleanup columns (not shown) where the oxygen is purified before venting. Assuming chemical equilibrium is reached in the chemical reactors, the compositions of the acid streams are determined by the conditions at the phase separators. For a given set of conditions, the counter-current main reactor of the 1979 flow sheet produced higher acid concentrations due to higher sulfur dioxide concentration. The 1981 flow sheet counteracted this problem by increasing the iodine flow and thus decreasing the hydrogen iodide concentration in the liquid phases and ending up with the same sulfuric acid concentration and hydrogen iodide concentration (on an iodinefree basis).

The counter-current reactor of the 1979 flow sheet is not standard chemical process equipment. The design places a high duty heat exchanger in the middle of a counter-current mass transfer device. Under these conditions, heat transfer would likely be very poor and thus the heat transfer area would be large. Since niobium and tantalum are about the only heat transfer materials usable in this service, the cost of this equipment would dominate the cost of all of Section 1. Fortunately, there are other means to shift the equilibrium, which we will continue to explore. Among these are raising the operating pressure so that the sulfur dioxide partial pressure remains high even with co-current operation. Lowering the exit temperature of the heat exchanger reactor will also shift the equilibrium but care must be taken not to precipitate iodine from the solutions. Finally, it may be possible to use membrane technology to partially separate the sulfur dioxide from the oxygen and further 
increase the sulfur dioxide concentration at the reactor exit. If pure sulfur dioxide were used in the reactor, there would be no difference in chemical equilibria between co-current and counter-current operation.

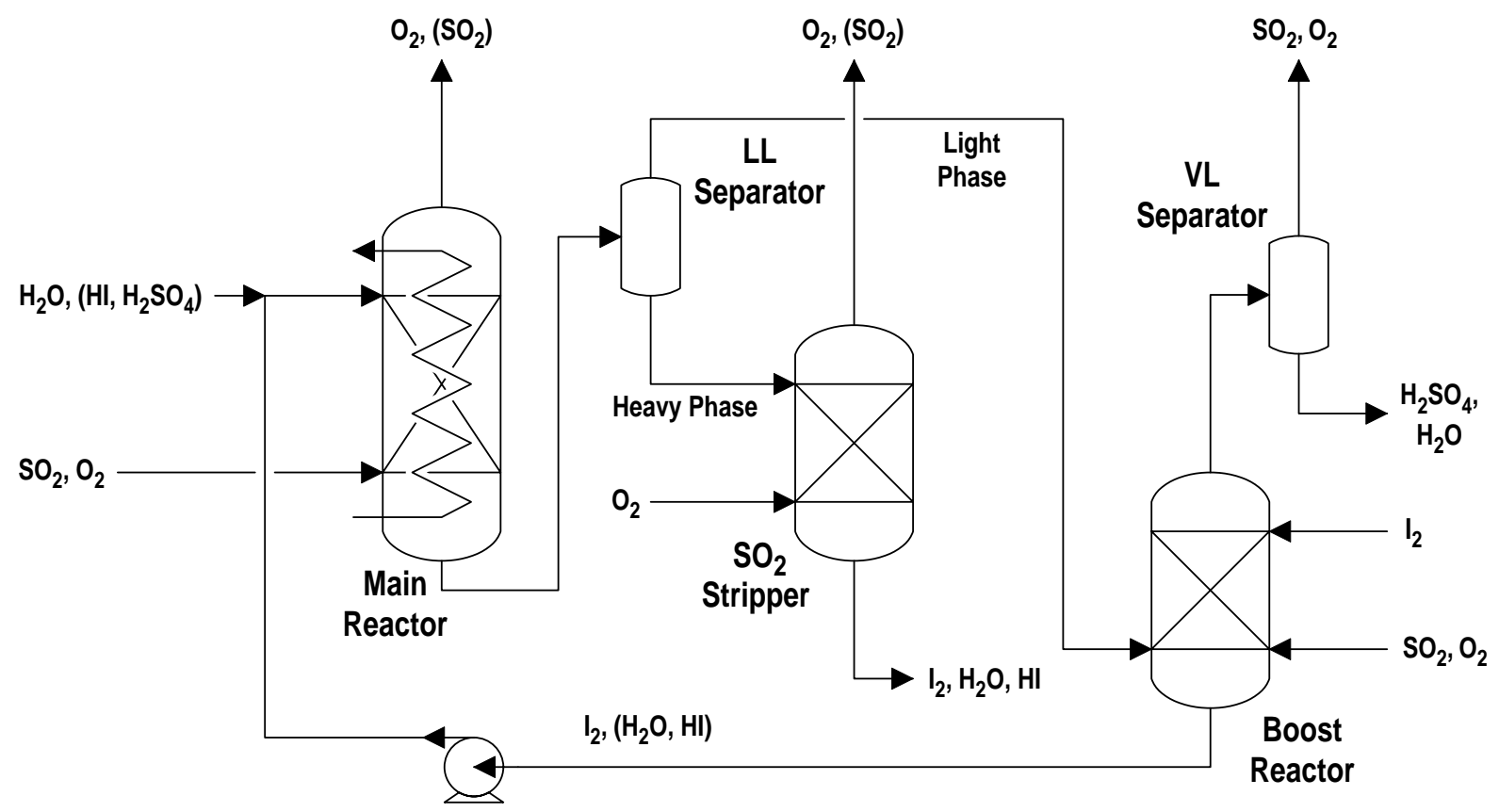

Fig. 3. Simplified flow diagram of Section 1 from 1979 flow sheet.

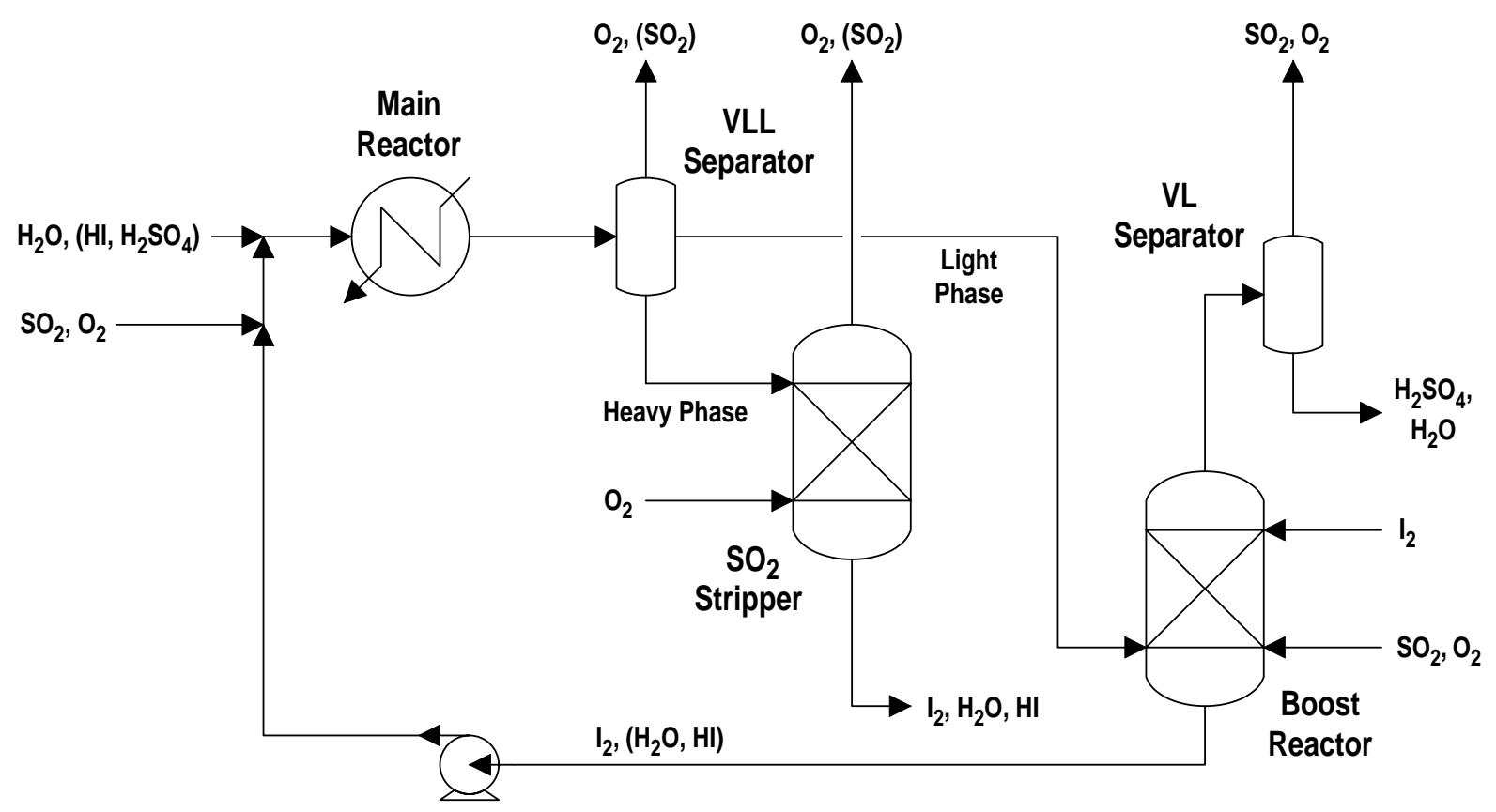

Fig. 4. Simplified flow diagram of Section 1 from 1981 flow sheet. 
For both versions of Section 1, it is important to coordinate the pressures so that the oxygen used to strip the sulfur dioxide from the heavy phase can flow from the reactor offgases, through a pressurized oxygen cleanup column, through the $\mathrm{SO}_{2}$ stripper and through a low-pressure cleanup column to the atmospheric oxygen vent. Gas compressors must be avoided as they are both expensive and energy gluttons.

Separating the products of the Bunsen reaction, hydrogen iodide and sulfuric acid, is the first of the chemical separations. Each mole of sulfuric acid in the light phase is initially accompanied by $5 \mathrm{~mol}$ of water. This may be reduced to $4 \mathrm{~mol}$ of water in what is called the boost reactor. The remaining water should be separated from the sulfuric acid to minimize the amount of material cycled to high temperature and thus increase the efficiency. Water can be removed from sulfuric acid by vaporization and, if the heat gained upon condensing the water can be effectively reused, the process can be quite efficient.

Separation is even more of a concern for the heavy phase. Each mole of hydrogen iodide in the heavy phase is accompanied by $5 \mathrm{~mol}$ of water and four to $6 \mathrm{~mol}$ of iodine. The solution is very impractical, thus the usual simplifying assumptions and approximations cannot be made. There appears to be a chemical complex formation that involves all three species: hydrogen iodide, iodine, and water. The original GA flow sheets for the process uses concentrated phosphoric acid to break the complex. Concentrated phosphoric acid is added to the heavy phase and the water is extracted into the phosphoric acid phase leaving hydrogen iodide and iodine as a separate phase. The solution of hydrogen iodide and iodine is well behaved and may be separated by distillation. Once the water and iodine are gone, decomposition of the hydrogen iodide is relatively straightforward. Purification of the hydrogen requires several process steps but the equipment is small and relatively inexpensive. Separating the water from the phosphoric acid requires a large amount of lowgrade thermal energy. This energy is efficiently provided by several vapor recompression flash stages (Fig. 5) in series. The water/phosphoric acid solution is heated and a portion of the water is flashed to steam. The steam is compressed so that its condensation temperature is sufficient to vaporize water from the inlet stream. Effectively, the vapor recompression stage acts as a heat pump. A small amount of high grade heat is used to generate shaft work which then drives a heat pump. This process can lead to very high overall thermal efficiencies, but rotating equipment is very expensive and leads to high capital costs.

The "ground rules" used when developing the phosphoric acid-based process were that the nuclear reactor and hydrogen plant were to be a self contained; i.e., the nuclear reactor was to exactly match the energy requirements of the hydrogen plant. The nuclear reactor was to produce both the heat and shaft work required by the hydrogen plant and no electricity could be either imported or exported. Relaxing this requirement allows additional flexibility in the design. Rather than providing the heat required for phosphoric acid concentration by 
vapor recompression which is driven by shaft work, the heat source could be the waste heat of a Brayton cycle power plant.

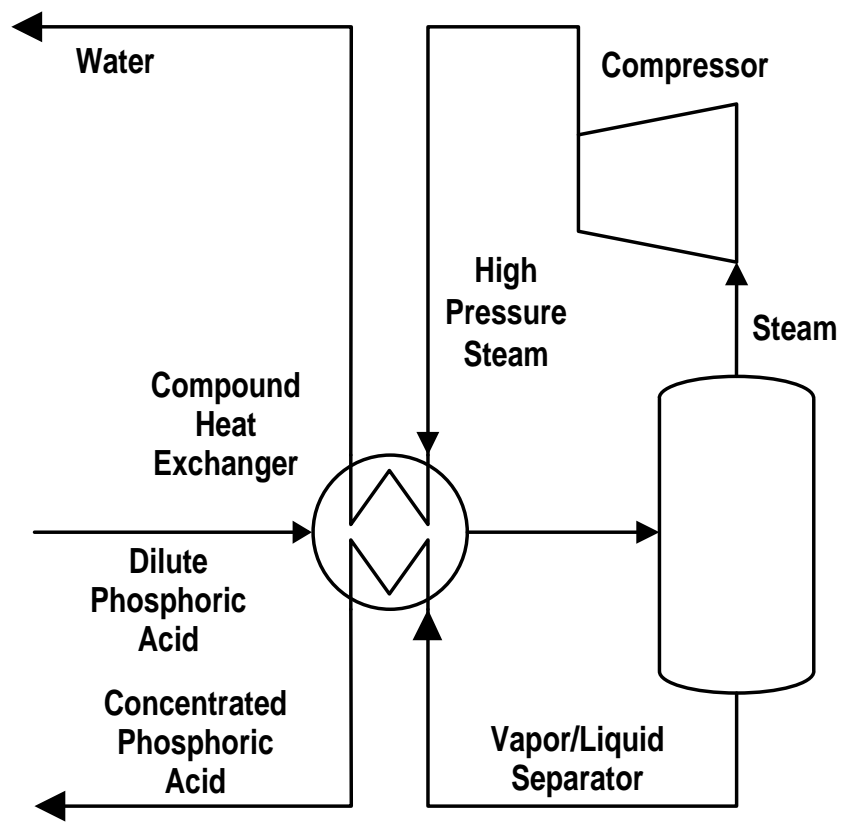

Fig. 5. Vapor recompression flash stage.

Over the years, there have been several attempts to improve the efficiency of the process or, at least, reduce the capital costs of the hydrogen iodide separation step. Dr. Norman [1], of GA, proposed that hydrogen bromide be added to the system. Preliminary indications show vaporization of the water could be eliminated but there would be a significant recycle of hydrogen bromide through the Bunsen reactor. Hydrogen bromide is advantageous over phosphoric acid due to its inability to accumulate in the sulfuric acid vaporizer. On the other hand, phosphoric acid is insoluble in iodine and should not get to the Bunsen reactor nor to the sulfuric acid system.

Roth and Knoche [8] proposed that hydrogen iodide be decomposed in a reactive distillation column at high pressure. They developed a flow sheet for the hydrogen iodide decomposition section of the sulfur iodide process using the feed composition from the 1979 GA flow sheet. This flow sheet avoids both the use of any additional compounds and evaporation of the water in the $\mathrm{HI} / \mathrm{I}_{2} / \mathrm{H}_{2} \mathrm{O}$ phase. The flow sheet does lead to liberal recycling of material between the Bunsen reactor and the reactive distillation column. It has been estimated that the Roth and Knoche scheme, as compared with the phosphoric acid flow sheet, would result in a 2\%-3\% efficiency increase and a $20 \%$ decrease in the plant capital cost [9]. 


\subsection{REACTOR DEFINITION}

The leading effort of Phase 2 was to develop processing concepts for the sulfur-iodine thermochemical cycle so that the cycle can be matched to an advanced nuclear reactor during the Phase 3 effort. The second effort was to define the advanced reactor. Once the high temperature heat input was defined for the process and the requirement of an intermediate heat transfer loop was specified, the process development tasks and reactor specification task could be undertaken with minimal interaction. The reactor specification task was completed by SNL (see Appendix).

Nine broad classifications of reactors were considered. Four reactor types were deemed unsuitable during the initial evaluation. The coolants of organic-cooled reactors break down far below the $900^{\circ} \mathrm{C}$ temperature required for thermochemical water-splitting. This temperature is also too high for pressurized water reactors (PWR) and boiling water reactors (BWR) as it is above the $374^{\circ} \mathrm{C}$ critical point of water. Most of the energy in the BWR would be as a nuclear superheat and the PWR would have to be pressurized far above the 218 atm, the critical pressure water. Finally, although a gas core reactor would have no problem reaching the required temperature, the approach is basically unproven technology and the required development work and the development risks are too significant to merit further consideration for this study.

Five reactor classes warranted more detailed consideration: alkali metal-cooled reactors, heavy-metal cooled reactors, gas-cooled reactors, molten-salt cooled reactors and liquid-core reactors. A preferred implementation of each of these reactor classes was examined in detail; these were the lithium-cooled reactor, the lead-bismuth-cooled reactor, the helium-cooled reactors, the lithium-beryllium fluoride-cooled reactor and the molten salt-core reactor. Each reactor was evaluated against a number of criteria: materials compatibility, coolant stability, reasonable operating pressures, nuclear compatibility, basic feasibility, development requirements, safety, operational issues, capital costs, intermediate loop compatibility, and other merits and issues. The top three candidate reactors (lead-bismuth cooled, lithiumberyllium fluoride cooled and helium gas cooled) were further evaluated relative to development risks. The helium-cooled reactor was highest rated of the three finalists in terms of suitability to the task and has minimal development risks compared with the other two finalists and was selected to power the sulfur-iodine process.

The analysis did not extend to a determination of which type of helium-cooled reactor to use. The selection between the pebble bed reactor and the various types of prismatic block reactor will be made in Phase 3. 


\subsection{PRELIMINARY PROCESS ENGINEERING}

\subsubsection{Evaluation of Chemical Thermodynamic Data and Models}

The key to developing an efficient thermochemical process is found in thermal matching of the reactor heat source to the process steps which require high temperature heat and efficiently reusing heat from high temperature heat sources in the process in lower temperature heat requirements. To do this heat matching, one must have a good model of the thermodynamics of the chemical species and their mixtures and a process simulation program capable of calculating the heat and material flows in the process. Thermodynamic models must also describe the phase equilibria encountered in the process. The chemical systems found in the sulfur-iodine cycle tend to be highly non-ideal and thus very difficult to model. A considerable effort was expended to evaluate the available thermodynamic data and to develop thermodynamic models applicable to the S-I process.

The nascent work on the cycle was based on experiments. Chemical compositions in the flow sheets were based on experimental measurements. Thermodynamic calculations for pure components were based on the JANAF tables [10] but, as the JANAF tables did not include liquid water, a JANAF-compatible table for water was generated based on the best available data. Thermodynamic models, suitable for hand calculations, were developed and these models were used in developing flow sheets for the process. Attempts were made to use the chemical process simulators available at that time, but without success. Details of the calculation methods used in the early flow sheets have not survived. Significant advances have been made in chemical process simulators and in thermodynamic models of electrolytic systems in the last 20 years: it is our intent to use these modern tools in the current calculations.

The chemical process simulator AspenPlus, available from Aspen Technologies of Cambridge, Massachusetts is most suitable for calculating the heat and material balances for very deficient chemical process. AspenPlus includes a thermodynamic model ELECNRTL, which is capable of describing aqueous and nonaqueous ionic solutions. Additionally, AspenPlus includes the capability of regressing experimental data, so as to generate the bestfit parameters for a thermodynamic model. As a starting point, the AspenPlus includes an ELECNRTL model for sulfuric acid that is valid for all concentrations, up to the azeotrope, and for temperatures up to $200^{\circ} \mathrm{C}$. Unfortunately the vapor pressure of the azeotrope is only 11 Torr at $200^{\circ} \mathrm{C}$ so this thermodynamic package is unable to describe the process steps necessary to concentrate and vaporize the sulfuric acid. The ELECNRTL sulfuric acid model has been extended, in proprietary versions, into the oleum region (beyond $100 \%$ sulfuric acid into the $\mathrm{H}_{2} \mathrm{~S}_{2} \mathrm{O}_{7}$ regime) indicating that the sulfuric acid model is extendible. 
Vapor-liquid equilibrium (VLE) data for sulfuric acid, in the region of interest, had been measured in Germany but the existence of this data was not generally known outside the thermochemical water-splitting community. We contracted with Aspen Technologies to extend the ELECNRTL model for sulfuric acid up to $300^{\circ} \mathrm{C}$ using this data.

Before contracting with Aspen Technologies and while awaiting its completion (the new model was not received until July 2001), flow sheet alternatives were investigated which only partially concentrated the sulfuric acid and thus did not require temperatures beyond the range of the standard ELECNRTL model for sulfuric acid.

We assumed that AspenPlus would be able to handle sulfuric acid "out of the box" but we knew that we would have to develop a thermodynamic model for the system $\mathrm{HI} / \mathrm{I}_{2} / \mathrm{H}_{2} \mathrm{O}$. Our overall strategy was to develop a broadly applicable ELECNRTL model for $\mathrm{HI} / \mathrm{I}_{2} / \mathrm{H}_{2} \mathrm{O}$ and then combine it with a broadly applicable ELECNRTL model for $\mathrm{H}_{2} \mathrm{SO}_{4} / \mathrm{H}_{2} \mathrm{O}$ adding only interactions terms not present in either model to fit the system $\mathrm{H}_{2} \mathrm{SO}_{4} / \mathrm{HI}_{2} / \mathrm{I}_{2} / \mathrm{H}_{2} \mathrm{O}$. The full model would only need to be valid over the relatively small temperature range where the Bunsen reaction produces two liquid phases.

The available VLE data and liquid-liquid equilibria (LLE) data, upon which to base the $\mathrm{HI} / \mathrm{I}_{2} / \mathrm{H}_{2} \mathrm{O}$ model was extremely limited. The system is known to be miscible over a wide range of compositions but to form two separate two-liquid regions (Fig. 6). The actual amount of data under the conditions of interest is quite meager. In fact, for the HI lean region, only the two-component endpoints of the immiscibility curve are known. Significantly, more information is available at temperatures below the melting point of iodine and much of what is surmised about the high temperature equilibria is an extrapolation of the low temperature data.

VLE data for the system $\mathrm{HI} / \mathrm{I}_{2} / \mathrm{H}_{2} \mathrm{O}$ is very limited. A fair amount of total pressure data is available, at high pressure and temperature, but only over a fairly limited range of liquid compositions. The data is further compromised; to obtain a stable measurement, it was necessary to wait until the pressure drift due to HI decomposition ceased. The total pressure measured is thus the sum of the partial pressures of hydrogen iodide, iodine, water and hydrogen, where the hydrogen partial pressure is, in turn, the result of the equilibrium decomposition of hydrogen iodide to hydrogen and iodine. Although the VLE data is sparse, it is possible to regress this data to generate a thermodynamic model for the system, especially since it is possible to include the LLE data in the same regression. Aspen Technologies was contracted to regress the data and generate an ELECNRTL model for the system $\mathrm{HI} / \mathrm{I}_{2} / \mathrm{H}_{2} \mathrm{O}$ to cover the range up to 50 bar and $400^{\circ} \mathrm{C}$. A first cut at the model was obtained but it contained obvious flaws as evident in the LLE phase diagram shown in Fig. 7. Work on the model is continuing. 


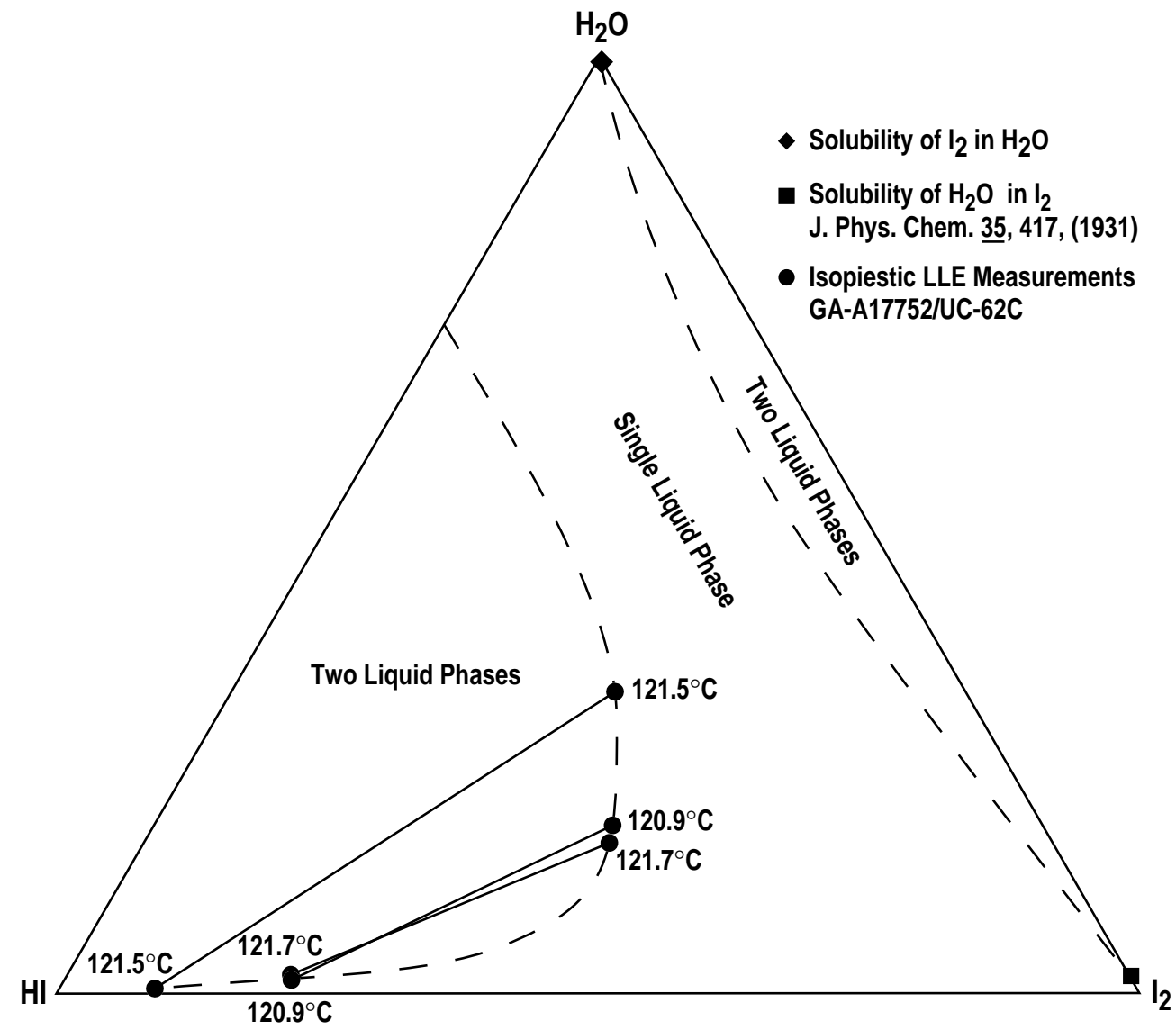

Fig. 6. Estimated ternary phase diagram for $\mathrm{HI} / \mathrm{I}_{2} / \mathrm{H}_{2} \mathrm{O}$ at $120^{\circ} \mathrm{C}$.

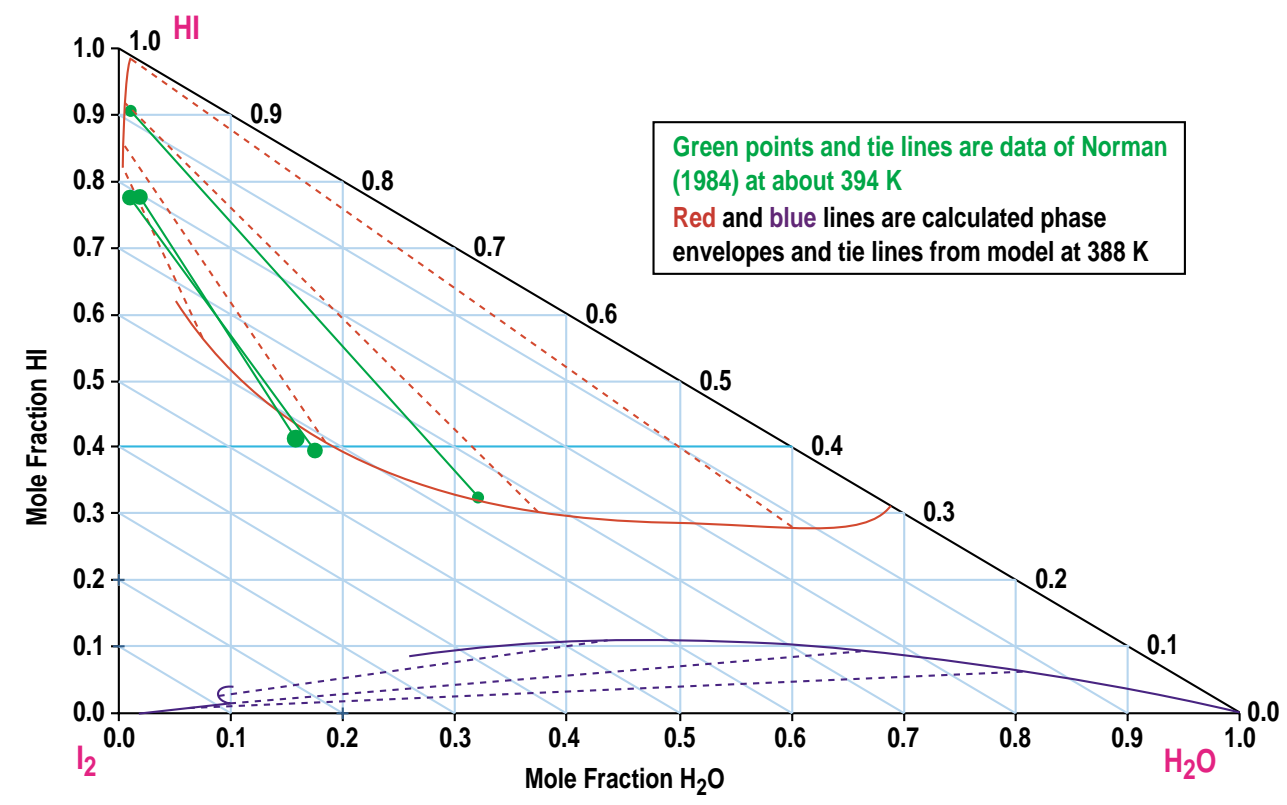

Fig. 7. Initial calculated ternary phase diagram for $\mathrm{HI} / \mathrm{I}_{2} / \mathrm{H}_{2} \mathrm{O}$ at $120^{\circ} \mathrm{C}$. $\mathrm{HI}-\mathrm{I}_{2}-\mathrm{H}_{2} \mathrm{O}$ ternary diagram at about $390 \mathrm{~K}$. 


\subsection{CHEMICAL FLOW SHEETS DEVELOPMENT}

\subsubsection{Overall Flow Sheet Development}

The overall flow sheet for the SI process is usually divided into three (or four sections) for ease of comprehension. The three sections correspond roughly to the three chemical reactions. In some analyses, where the hydrogen iodide is completely separated from the $\mathrm{HI}_{\mathrm{x}}$ before decomposition, separation and decomposition are considered as two sections. For our analysis Section 2, sulfuric acid decomposition, was set up on flow sheets by the UK and the remaining sections were set up on flow sheets by GA. As Section 2 uses the highest temperature heat, it will be discussed first.

\subsubsection{Section 2}

The inlet stream (the light phase) to Section 2 is a 20 mol \% solution of sulfuric acid water containing essentially no significant amount of iodine containing species. The sulfuric acid is heated to a high temperature to decompose the sulfuric acid according to reaction (2).

$$
\begin{array}{cl}
\mathrm{H}_{2} \mathrm{SO}_{4} \rightarrow \mathrm{SO}_{2}+\mathrm{H}_{2} \mathrm{O}+1 / 2 \mathrm{O}_{2} & \left(850^{\circ} \mathrm{C}\right) \\
\mathrm{H}_{2} \mathrm{SO}_{4} \rightarrow \mathrm{SO}_{3}+\mathrm{H}_{2} \mathrm{O} & \left(400^{\circ} \mathrm{C}-650^{\circ} \mathrm{C}\right) \\
\mathrm{SO}_{3} \rightarrow \mathrm{SO}_{2}+1 / 2 \mathrm{O}_{2} & \left(700^{\circ} \mathrm{C}-1000^{\circ} \mathrm{C}\right)
\end{array}
$$

Reaction (2) is actually composed of two reactions - the decomposition of sulfuric acid to sulfur trioxide, at moderate temperatures, followed by the higher temperature decomposition of the sulfur trioxide to sulfur dioxide. That reaction (2) is really two reactions has important consequences to the design and operation of Section 2 and to the overall efficiency of the SI process.

The wide temperature range over which reactions $(2 a)$ and $(2 b)$ adsorb heat permits the SI cycle produce high efficiency even when the heat source must deliver heat over a wide temperature range, as is the case with a helium-cooled nuclear reactor. Both reaction (2a) and (2b) are endothermic and adsorb heat over a wide temperature range: as heat is adsorbed, the temperature rises and the equilibrium is shifted toward the right. Both reactions show an increase in the number of moles of gas with increasing reaction so both are suppressed by increased pressure. This effect is more pronounced for reaction (2a) as the increase in number of moles is greater. The fact that water is not involved in reaction ( $2 b)$ shows additional water with the sulfuric acid does not suppress oxygen formation. Moreover, added water reduces the effect of pressure on reaction $(2 b)$. 
Reaction (2a) proceeds without catalysis but reaction (2b) requires a catalyst over the temperature range of interest. The requirement of a catalyst for reaction $(2 b)$ is actually very beneficial as the chemical equilibrium is frozen at the temperature of the catalytic reactor outlet. There is no necessity of quenching the reaction nor separating the products at high temperature. The product stream can be cooled in conventional heat exchangers and the sensible heat reused elsewhere in the process. The necessity of performing reaction (2b) with a catalyst places an upper limit on the useful temperature of the SI cycle. The upper temperature limit is certainly above $950^{\circ} \mathrm{C}$ and may be in excess of $1100^{\circ} \mathrm{C}$.

Together, these considerations mean that the high temperature portion of Section 2 can be operated over a wide range of conditions and that a wide range of conditions must be explored in order to find the optimum conditions.

Early SI cycle flow sheets were based on removing as much water as possible from the sulfuric acid before taking it to high temperature for decomposition. As indicated in the previous discussion, water should not have a deleterious effect on the decomposition reaction but additional water will increase the total gas flow through the decomposition system and thus increase the capital cost of the decomposer. The additional material flow will also increase the amount of heat that must be recuperated, increasing both capital cost of recuperation and the irreversibilities associated with heat transfer. The temperature limit of the ELECNRTL model for sulfuric acid, which was available at the beginning of this work, does not permit concentrating the sulfuric acid beyond $60 \mathrm{~mol} \%$.

The initial flow sheeting effort was limited by the $200^{\circ} \mathrm{C}$ temperature limit of the stock $\mathrm{H}_{2} \mathrm{SO}_{4} / \mathrm{H}_{2} \mathrm{O}$ ELECNRTL thermodynamic package provided with AspenPlus. Figures 8,9 and 10 show three variations on the flow sheet for sulfuric acid concentration and decomposition. In each, the inlet stream to Section 2 is a 20 mol \% solution of sulfuric acid in water. (Note: $20 \mathrm{~mol} \%$ sulfuric acid corresponds to $57 \mathrm{wt} \%$ sulfuric acid.)

The flow sheet shown in Fig. 8 uses only the low temperature $\mathrm{H}_{2} \mathrm{SO}_{4} / \mathrm{H}_{2} \mathrm{O}$ model. Sulfuric acid is concentrated to $60 \mathrm{~mol} \%$ in a series of five flashes, four heated flashes at 7.5 bar and one adiabatic flash to 3 bar. Essentially, pure water is removed in the overhead of the flashes and this is returned to Section 1 . The $60 \%$ acid then passes to a $1 \mathrm{~atm}$ vaporizer and then to the decomposition system. The stock thermodynamic package describes the system well through the concentration stages and after the stream is completely vaporized. In particular, the stock package cannot predict the vaporization temperature but if the temperature is given from other sources, it does give the correct enthalpy for the fully vaporized stream. 


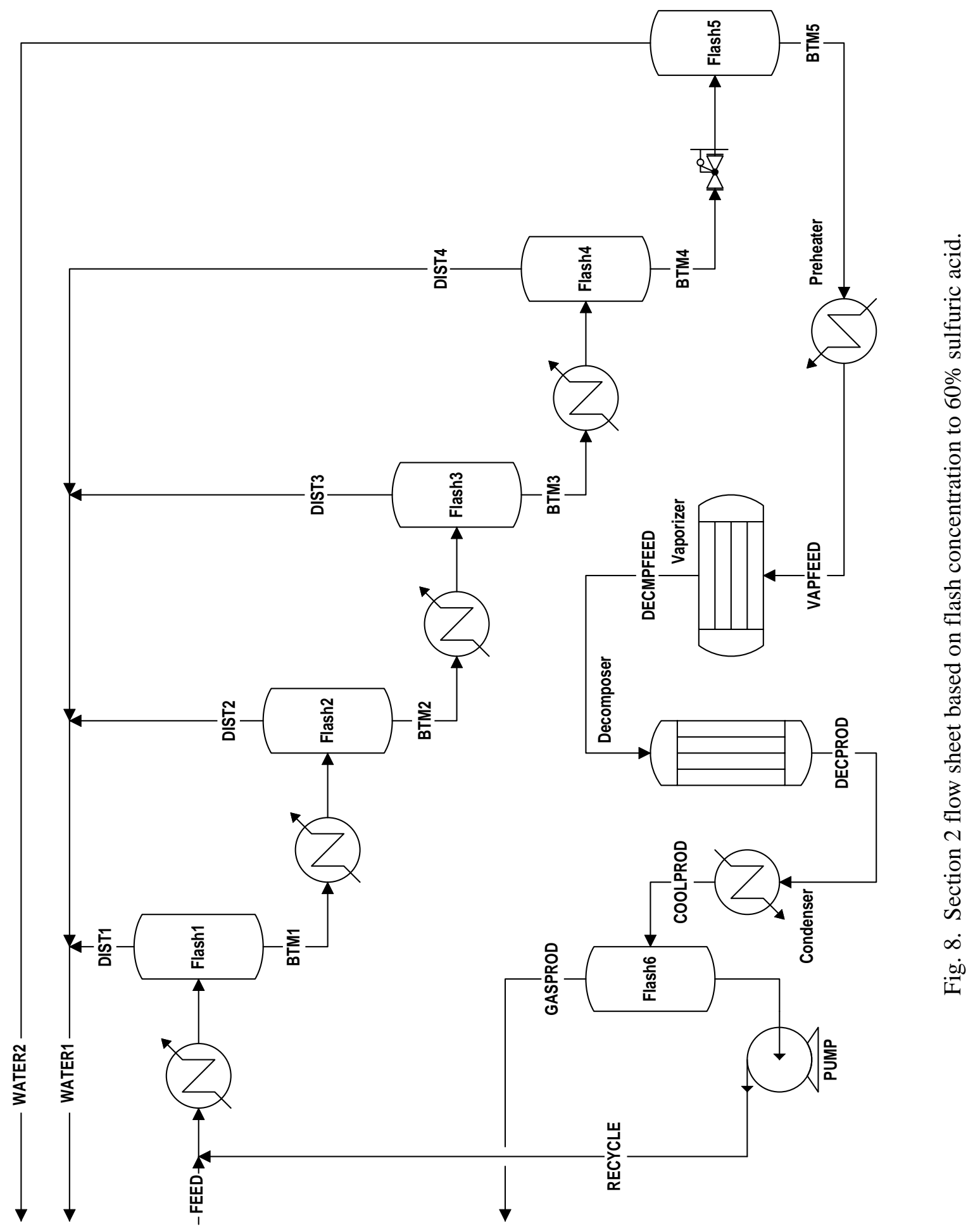




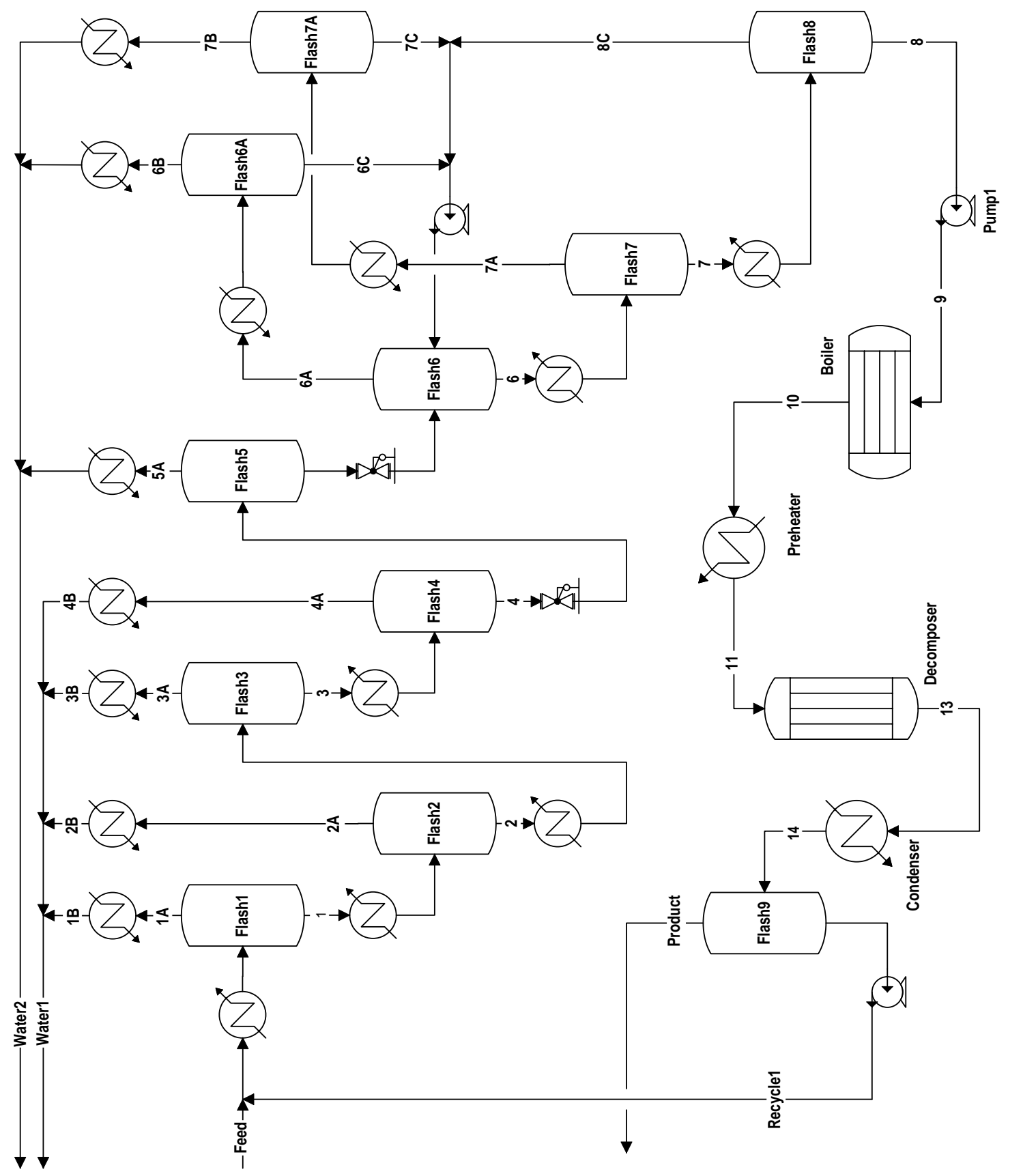

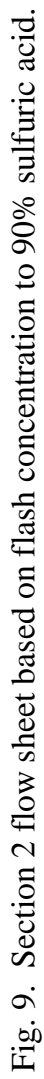




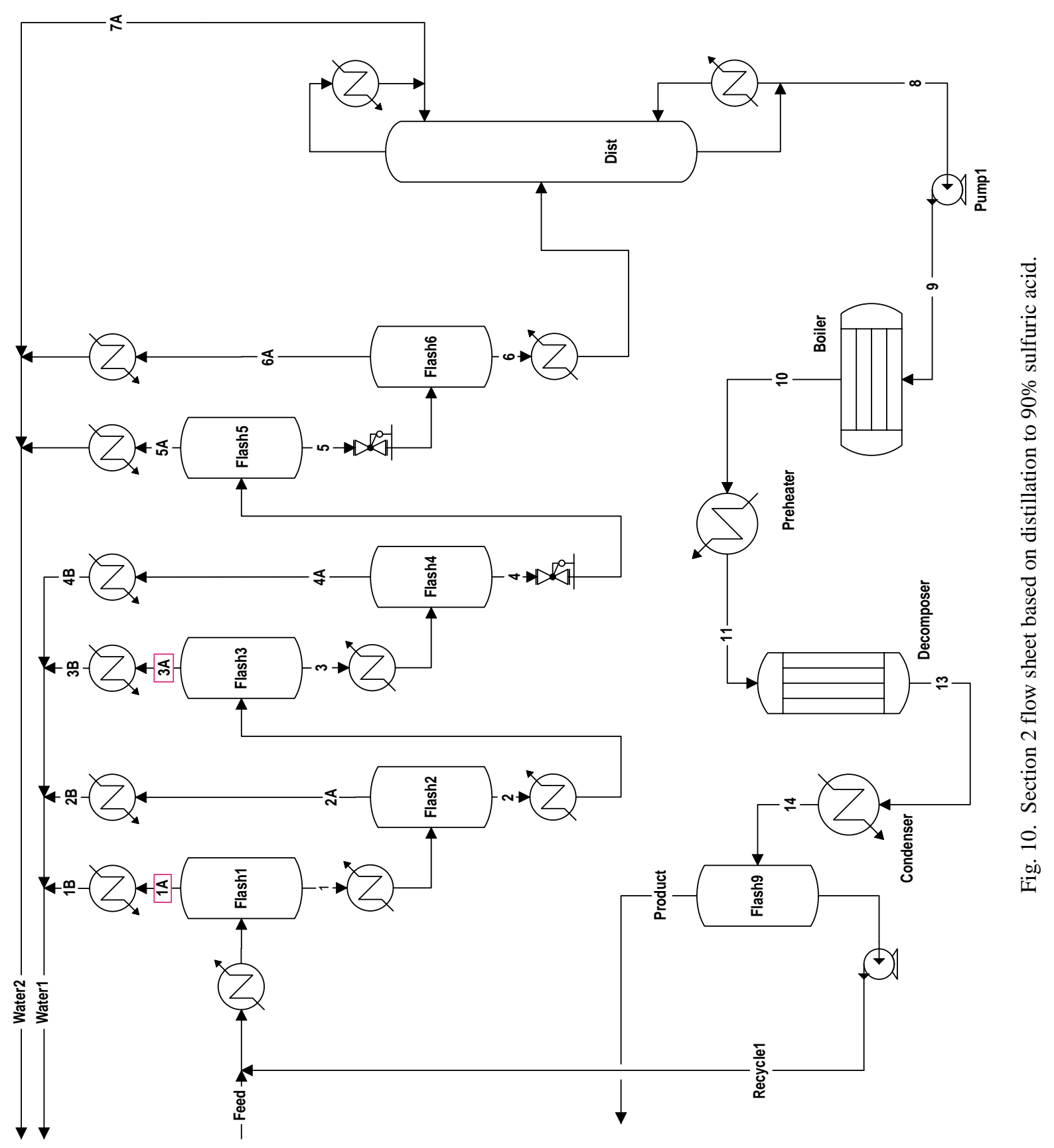


Note that although $60 \%$ acid is fed to the vaporizer and $60 \%$ acid exits the vaporizer, the solution in the vaporizer is that solution which is in equilibrium with $60 \%$ vapor. The solution in the vaporizer is thus an $88 \%$ solution of sulfuric acid in water, which is slightly below the azeotropic composition of $90.3 \%$. All the heat necessary to vaporize the $60 \%$ sulfuric must be delivered at a constant temperature which is higher than the reversible enthalpy for the vaporization. This further reduces the possible efficiency of the $60 \%$ flow sheet.

The atmospheric pressure operation of the decomposer in the $60 \%$ flow sheet means that the heat recovered from condensing the decomposer product maintains too low a temperature to be fully utilized elsewhere in the process. If the decomposer is operated at higher pressure, the heat can be used in the flash concentrators. Figures 8 and 9 are two alternative flow sheets operating with a pressurized decomposer. These flow sheets also concentrate the sulfuric acid to the azeotropic composition to minimize irreversibilities. In Fig. 9, additional heated flashes and partial condensers perform the additional concentration duty and in Fig. 10 a distillation column is used. With the stock $\mathrm{H}_{2} \mathrm{SO}_{4} / \mathrm{H}_{2} \mathrm{O}$ thermodynamics, good thermodynamics exist only up to $60 \%$ concentration and after vaporizing the total stream. Note that after the decomposer, the sulfuric acid concentration is reduced to below $60 \%$ so we can use the stock thermodynamics to describe the thermal energy recovery process.

Using these flow sheets, we can make some estimates as to the effect of heat recovery on the final efficiency of the overall process. The difference in enthalpy between the $60 \%$ acid at $3 \mathrm{bar}$ and the $90 \%$ acid at $7 \mathrm{bar}$ is about $68 \mathrm{~kJ} / \mathrm{mole}$ of sulfuric acid. Together, the flow sheets indicate that for each mole of hydrogen produced, $636 \mathrm{~kJ}$ will be needed and about $350 \mathrm{~kJ}$ will be available for recovery. The difference is approximately the higher heating value for hydrogen. Table 3 indicates the final overall efficiency as a function of the fraction the $350 \mathrm{~kJ}$ recovered, assuming that no other heat is required by the process. Of course, heat is required elsewhere in the process, specifically in Section 3, but these results do indicate the importance of heat recovery and recuperation.

Table 3

Effect of Heat Recovery on Efficiency for Section 2

\begin{tabular}{lrcccr}
\hline Heat recovery fraction & 0 & 0.25 & 0.5 & 0.75 & 1 \\
Efficiency & 45 & 52 & 62 & 77 & 100 \\
\hline
\end{tabular}

\subsubsection{Section 3}

Although sulfuric acid decomposition involves the highest temperatures, the chemistry of hydrogen iodide separation and decomposition is more difficult. The hydrogen iodide is 
accompanied by a great deal of water and iodine. Separating the hydrogen iodide so that it could be efficiently decomposed led to significant process complexities and capital costs in previous flow sheets. We selected the Roth and Knoche reactive distillation method of processing the $\mathrm{HI}_{\mathrm{x}}$ mixture as the basis for our major effort. Since this method involves complex solution thermodynamics and some poorly defined VLE, we continue to consider the phosphoric acid treatment scheme as a backup.

Roth and Knoche took the 1979 GA flow sheet as a starting point. The inlet composition was taken to be that produced by the Bunsen reaction section (Section 1) of that flow sheet but the flow rate is increased to account for the hydrogen iodide that is not reacted but recycled to Section 1. Figure 11 shows the Roth and Knoche scheme with two minor additions. The Section 1 flow sheet requires some pure iodine in order to obtain the maximum possible sulfuric acid composition. We have added an iodine distillation column to purify enough iodine for the boost reactor of Section 1. The Roth and Knoche flow sheet left a small amount of hydrogen iodide in the hydrogen product. A water scrubber was added to strip the remaining hydrogen iodide from the product.

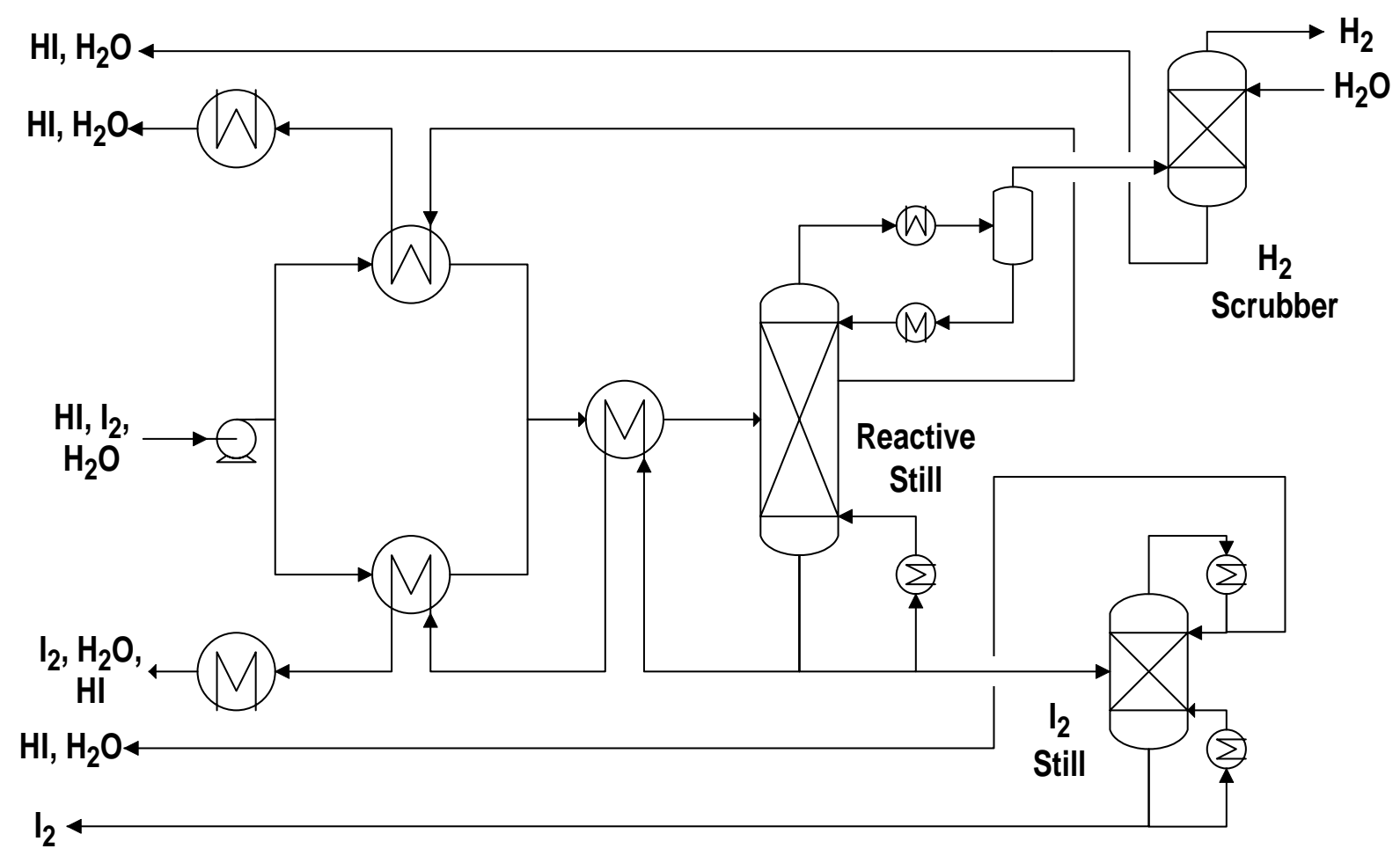

Fig. 11. Modified Roth and Knoche scheme.

The phosphoric acid-based flow sheets remain a backup to the Roth and Knoche scheme. Figure 12 shows the co-generation version of the phosphoric acid flow sheet generated by AspenPlus. Note that the directions of the heat flow streams (dashed lines) are 
the direction of information flow within the simulation. The reject heat actually flows from the turbine exhaust coolers to the phosphoric acid concentrators.

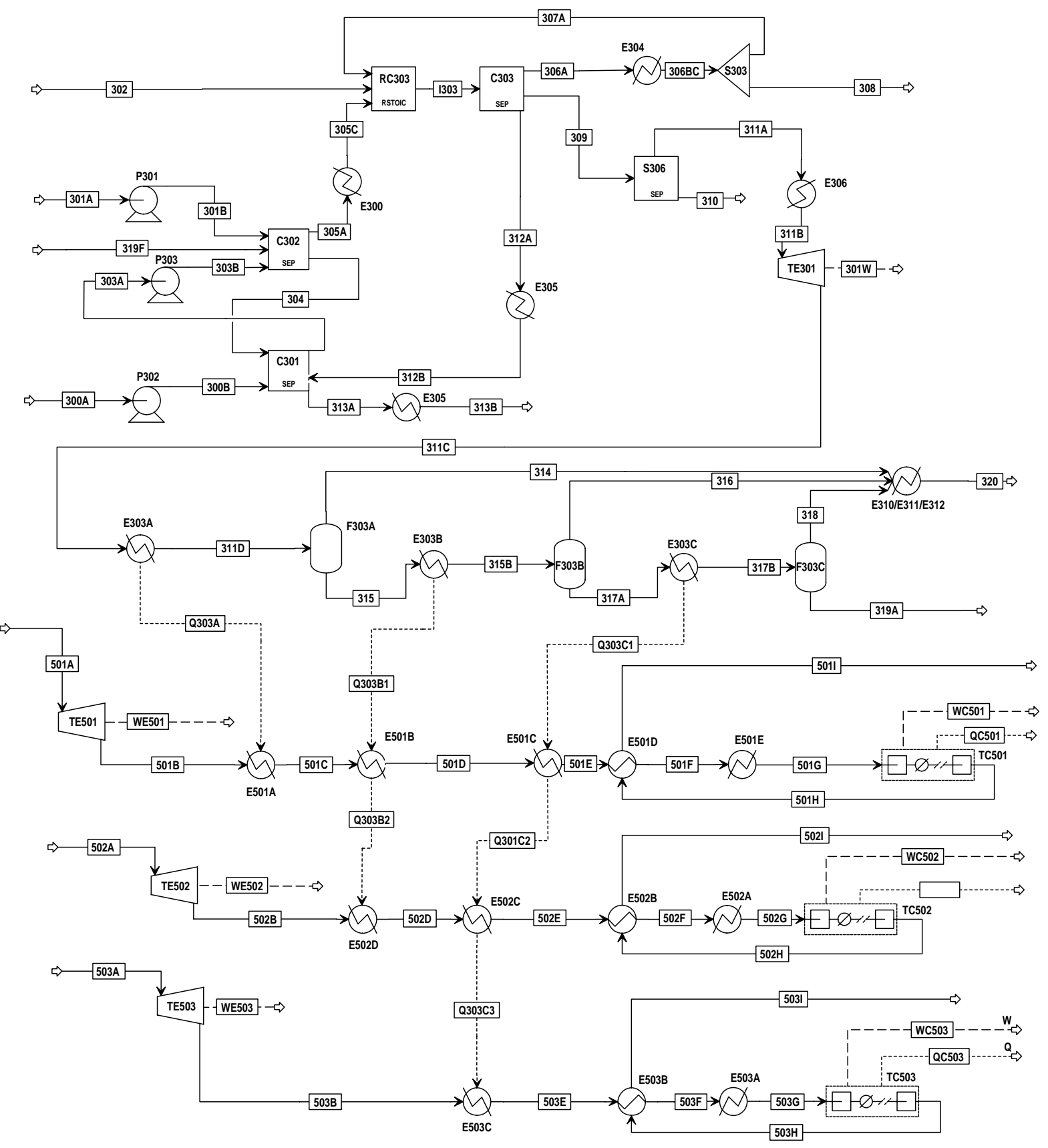

Fig. 12. Phosphoric acid version of Section 3 flow sheet with electrical co-generation. 


\section{PHASE 3 EFFORT}

The major tasks remaining for Phase 3 are to complete an integrated flow sheet for the process matched to a high temperature helium-cooled nuclear reactor, determine the cost of the chemical plant based on preliminary equipment sizing calculations, and calculate the cost of hydrogen from the combined nuclear reactor and chemical plant. Two potential versions of the flow sheet will be considered The phosphoric acid version and the reactive distillation version differ in how the hydrogen iodide phase is treated. In the phosphoric acid version, water is extracted from the $\mathrm{HI} / \mathrm{I}_{2} / \mathrm{H}_{2} \mathrm{O}$ phase allowing the $\mathrm{HI}$ to be separated and decomposed. The reactive distillation version decomposes a portion of the hydrogen iodide from the $\mathrm{HI} / \mathrm{I}_{2} / \mathrm{H}_{2} \mathrm{O}$ in a distillation column and recycles most of the hydrogen iodide back to the Bunsen reaction along with the water. The decision between the two flow sheets will be based on overall economics. The main tradeoff is expected to be between the expense of the vapor recompression equipment of the phosphoric acid flow sheet and the cost associated with the large $\mathrm{HI}$ recycle of the reactive distillation scheme. The improved thermodynamic models for sulfuric acid and $\mathrm{HI} / \mathrm{I}_{2} / \mathrm{H}_{2} \mathrm{O}$, which should be available shortly, will permit optimization of the two designs. 


\section{REFERENCES}

[1] J.H. Norman, G.E. Besenbruch, L.C. Brown, D.R. O'Keefe, C.L. Allen, "Thermochemical Water-Splitting Cycle, Bench-Scale Investigations and Process Engineering: Final Report for the Period February 1977 through December 31, 1981," U.S. Department of Energy Report DOE/ET/26225-1; General Atomics Report GA-A16713 (1982).

[2] U.S. Energy Information Administration, International Energy Outlook 2000, U.S. Department of Energy Report DOE/EIA-0484(2000) (http://www.eia.doe.gov).

[3] U.S. Energy Information Administration, Annual Energy Outlook 2000 with Projections to 2020, U.S. Department of Energy Report DOE/EIA-0383(2000) (http://www.eia.doe.gov).

[4] U.S. Energy Information Administration, Impacts of the Kyoto Protocol on U.S. Energy Markets and Economic Activity, U.S. Department of Energy Report SR/OIAF/98-03 (Washington, DC, October 1998) (http://www.eia.doe.gov).

[5] L.C. Brown, J.F. Funk, S.K. Showalter, "High Efficiency Generation of Hydrogen Fuels Using Nuclear Power: Annual Report to the U. S. Department of Energy, August 1, 1999 through July 31, 2000," General Atomics Report GA-A23451 (2000).

[6] P.W. Trester, H.G. Staley, "Assessment and Investigation of Containment Materials for the Sulfur-Iodine Thermochemical Water-Splitting Process for Hydrogen Production: Final Report July 1979 - December 1980," Gas Research Institute Report GRI80/0081; General Atomics Report GA-A16328 (1981).

[7] B.G. Logan, et al., "Mirror Advanced Reactor Study: Final Report Volume 2, Commercial Fusion Synfuels Plant," Lawrence Livermore National Laboratory Report UCRL-53480 (1984).

[8] M. Roth, K.F. Knoche, "Thermochemical Water-Splitting Through Direct HIDecomposition from $\mathrm{H}_{2} \mathrm{O} / \mathrm{HI} / \mathrm{I}_{2}$ Solutions," Int. J. Hydrogen Energy 14, 545 (1989).

[9] H. Engels, J.E. Funk, K. Hesselmann, K.F. Knoche, "Thermochemical Hydrogen Production,” Int. J. Hydrogen Energy 12, 291 (1987).

[10] D.R. Stull, H. Prophet, JANAF Thermochemical Tables, Second Edition, Office of Standard Reference Data National Bureau of Standards Report NSRDS-NBS 37 (Washington, 1971). 


\section{ACKNOWLEDGEMENTS}

This work was performed as a collaborative effort between GA, the UK and SNL. Work at GA and the UK was supported by the Department of Energy, Nuclear Energy Research Initiative (NERI) Grant No. DE-FG03-99SF21888. Work at SNL, a multiprogram laboratory operated by Sandia Corporation, a Lockheed Martin Company, was funded by the Department of Energy through Contract No. DE-AC04-94AL85000 under NERI Award No. 99-238. 


\section{APPENDIX \\ A.C. MARSHALL, "AN ASSESSMENT OF REACTOR \\ TYPES FOR THERMOCHEMICAL HYDROGEN PRODUCTION," SANDIA NATIONAL LABORATORY REPORT SAND2002-0513 (2002)}


SAND2002-0513

Unlimited Release

February 2002

\title{
An Assessment of Reactor Types for Thermochemical Hydrogen Production
}

\author{
Albert C. Marshall
}

Prepared by

Sandia National Laboratories

Albuquerque, New Mexico 87185 and Livermore, CA 94550

Sandia is a multiprogram laboratory operated by Sandia Corporation a Lockheed Martin Company, for the United States Department of Energy under Contract DE-AC04-94AL85000.

\section{Sandia National Laboratories}


Issued by Sandia National Laboratories, operated for the United States Department of Energy by Sandia Corporation.

NOTICE: This report was prepared as an account of work sponsored by an agency of the United States Government. Neither the United States Government nor any agency thereof, nor any of their employees, nor any of their contractors, subcontractors, or their employees, makes any warranty, express or implied, or assumes any legal liability or responsibility for the accuracy, completeness, or usefulness of any information, apparatus, product, or process disclosed, or represents that its use would not infringe privately owned rights. Reference herein to any specific commercial product, process, or service by trade name, trademark, manufacturer, or otherwise, does not necessarily constitute or imply its endorsement, recommendation, or favoring by the United States Government, any agency thereof, or any of their contractors or subcontractors. The views and opinions expressed herein do not necessarily state or reflect those of the United States Government, any agency thereof, or any of their contractors.

Printed in the United States of America. This report has been reproduced directly from the best available copy.

Available to DOE and DOE contractors from

Office of Scientific and Technical Information

P.O. Box 62

Oak Ridge, TN 37831

Prices available from (615) 576-8401, FTS 626-8401

Available to the public from

National Technical Information Service

U.S. Department of Commerce

5285 Port Royal Rd

Springfield, VA 22161

NTIS price codes

Printed copy: A03

Microfiche copy: A01 


\title{
SAND2002-0513
}

Unlimited Release

February 2002

\section{An Assessment of Reactor Types for Thermochemical Hydrogen Production}

\author{
Albert C. Marshall \\ Advanced Nuclear Concepts Department \\ P.O. Box 5800 \\ Sandia National Laboratories \\ Albuquerque, New Mexico 87185-0425
}

\begin{abstract}
Nuclear energy has been proposed as a heat source for producing hydrogen from water using a sulfur-iodine thermochemical cycle. This document presents an assessment of the suitability of various reactor types for this application. The basic requirement for the reactor is the delivery of $900 \mathrm{C}$ heat to a process interface heat exchanger. Ideally, the reactor heat source should not in itself present any significant design, safety, operational, or economic issues. This study found that Pressurized and Boiling Water Reactors, Organic-Cooled Reactors, and Gas-Core Reactors were unsuitable for the intended application. Although Alkali Metal-Cooled and Liquid-Core Reactors are possible candidates, they present significant development risks for the required conditions. Heavy Metal-Cooled Reactors and Molten Salt-Cooled Reactors have the potential to meet requirements, however, the cost and time required for their development may be appreciable. Gas-Cooled Reactors (GCRs) have been successfully operated in the required $900 \mathrm{C}$ coolant temperature range, and do not present any obvious design, safety, operational, or economic issues. Altogether, the GCRs approach appears to be very well suited as a heat source for the intended application, and no major development work is identified. This study recommends using the Gas-Cooled Reactor as the baseline reactor concept for a sulfur-iodine cycle for hydrogen generation.
\end{abstract}




\section{Acknowledgments}

This work was performed for and funded by the U.S. Department of Energy for DOE Nuclear Energy Research Project number 99-238. The author is grateful for the suggestions and guidance provided by Paul Pickard, Dana Powers, and Steve Showalter of Sandia National Laboratories, and Lloyd Brown from General Atomics. 


\section{Table of Contents}

Nomenclature ................................................................................................................................ 7

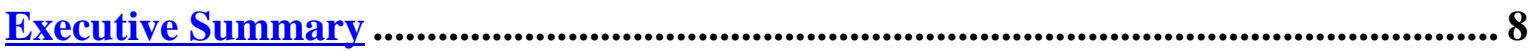

An Assessment of Reactor Types for Thermochemical Hydrogen Production ........... 10

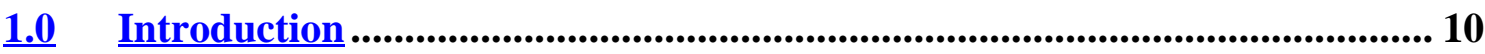

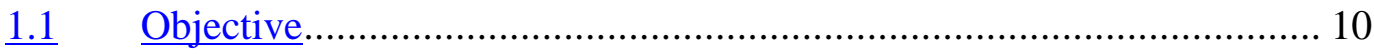

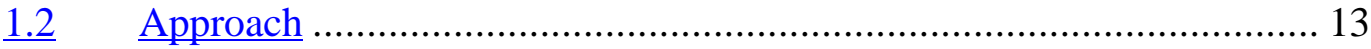

2.0 Stage 1: Status of Reactor Types........................................................................... 17

2.1 Pressurized Water-Cooled Reactors....................................................... 17

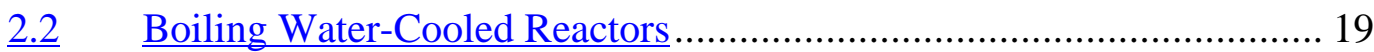

$2.3 \quad$ Organic-Cooled Reactors ……………………....................................... 19

$2.4 \quad$ Alkali Metal-Cooled Reactors …………………................................... 20

$2.5 \quad$ Heavy Metal-Cooled Reactors............................................................... 20

$2.6 \quad$ Gas-Cooled Reactors ........................................................................ 22

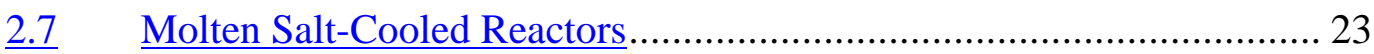

$2.8 \quad$ Liquid-Core Reactors ............................................................................. 23

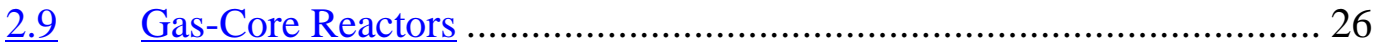

3.0 Stage 2: Coolant Properties.................................................................................... 27

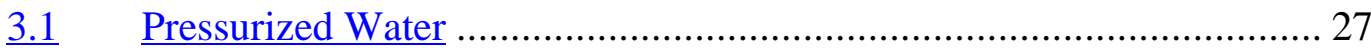

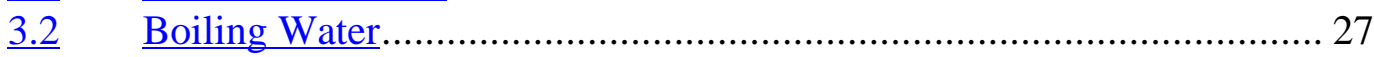

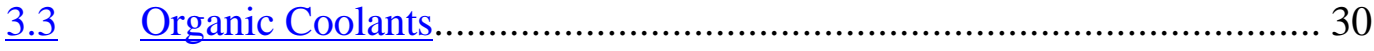

$\underline{3.4} \quad$ Alkali-Metal Coolants ....................................................................... 30

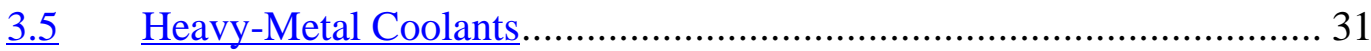

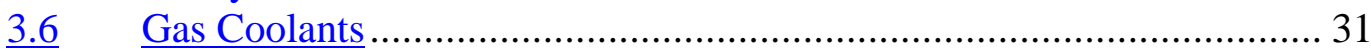

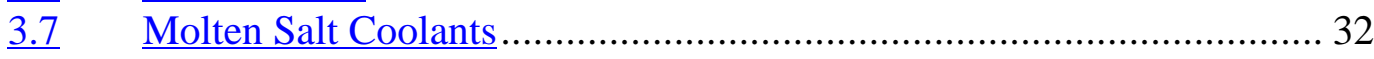

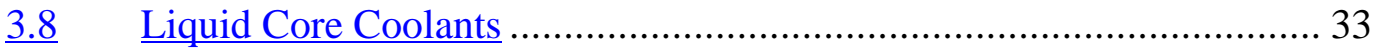

4.0 Stage 3:Attribute Assessments .......................................................................... 33

$4.1 \quad$ Pressurized Water-Cooled Reactors...................................................... 36

4.2 Boiling Water-Cooled Reactors.............................................................. 36

$4.3 \quad$ Organic-Cooled Reactors ………………………................................. 36

$4.4 \quad$ Alkali metal-Cooled Reactors................................................................. 36

4.5 Heavy Metal-Cooled Reactors................................................................ 38

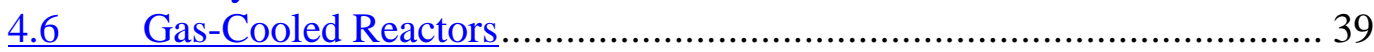

$4.7 \quad$ Molten Salt-Cooled Reactors................................................................. 41

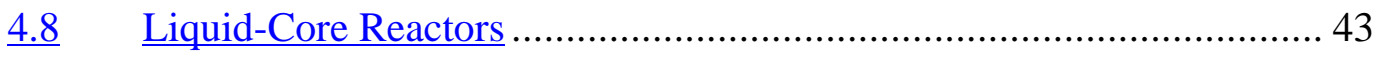

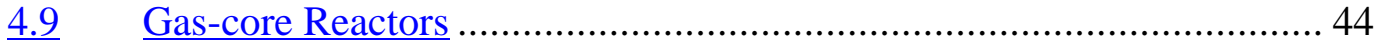

5.0 Stage 4: Development COSTs .............................................................................. 45

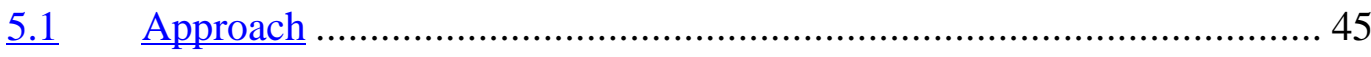




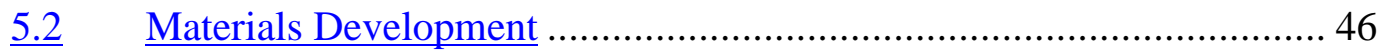

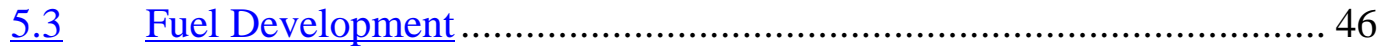

5.4 Component Development ............................................................ 46

$\underline{5.5}$ System Design Development....................................................... 47

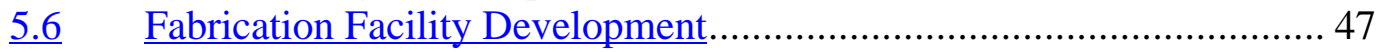

5.7 Development Assessment ........................................................ 47

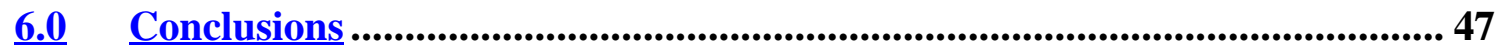

References: ............................................................................................................................50

\section{List of Figures}

Figure 1 Sulfur-iodine thermochemical cycle for hydrogen production......................... 11

Figure 2 Schematic of nuclear reactor heat source with a water/thermochemical hydrogen production system. ................................................................. 12

Figure 3 PWR containment building and system components ................................. 18

Figure 4 Clinch River Breeder Reactor liquid metal cooled reactor............................ 21

Figure 5 HTGR primary system cross section................................................... 24

Figure 6 Pebble Bed Reactor vessel cross section. ............................................. 25

\section{List of Tables}

Table 1 Reactor Types Considered in the Assessment .......................................... 15

Table 2 Attribute Requirements and Criteria........................................................ 16

Table 3 Reactor Coolant Basic Properties......................................................... 28

Table 4 Reactor Coolant Thermal and Chemical Properties ...................................... 29

Table 5 Assessment of Reactor Concepts for Sulfur-Iodine Thermochemical Cycle ...... 35

Table 6 Development Cost Scores Relative to GCRs.......................................... 46 


\section{Nomenclature}

$\begin{array}{ll}\text { AVR } & \text { Arbeitsgemeinschaft Versuchsreaktor } \\ \text { BWR } & \text { Boiling Water Reactor } \\ \text { CRBR } & \text { Clinch River Breeder Reactor } \\ \text { DOE } & \text { Department of Energy } \\ \text { ES\&H } & \text { Environmental Safety and Health } \\ \text { FSV } & \text { Fort St. Vrain } \\ \text { GCR } & \text { Gas-Cooled Reactor } \\ \text { HMR } & \text { Heavy Metal-Cooled Reactor } \\ \text { HTGR } & \text { High Temperature Gas Cooled Reactor } \\ \text { HTGR } & \text { High Temperature Graphite Reactor (when used for a MSCR core design) } \\ \text { MSCR } & \text { Molten Salt-Cooled Reactor } \\ \text { NERI } & \text { Nuclear Energy Research Initiative } \\ \text { PBR } & \text { Pebble Bed Reactor } \\ \text { PWR } & \text { Pressurized Water Reactor }\end{array}$




\section{Executive Summary}

A broad range of reactor categories was reviewed to assess the suitability of various concepts as a heat source for the sulfur-iodine thermochemical production of hydrogen from water. The principal requirement is that heat must be supplied at $900 \mathrm{C}$ in order to dissociate sulfuric acid into $\mathrm{SO}_{2}, \mathrm{H}_{2} \mathrm{O}$, and $\mathrm{O}_{2}$. The assessment was carried out in four stages, as follows:

\section{Stage 1: Status of reactor types}

For this stage, nine basic types of reactors were identified and their development status was assessed. The basic reactor types include pressurized water-cooled reactors, boiling water-cooled reactors, organic-cooled reactors, alkali metal-cooled reactors, heavy metal-cooled reactors, gas-cooled reactors, molten salt-cooled reactors, liquid-core reactors, and gas-core reactors. Based on this review, gas-core reactors were eliminated from consideration because, given the objectives of the program, the development requirements for this reactor category is unacceptably high.

\section{Stage 2: Coolant property assessment}

For stage 2 the properties of reactor coolants were reviewed to determine their suitability for the proposed application. Pressurized water-cooled reactors were eliminated from consideration because the required system pressure would be extremely high, and boiling water-cooled reactors were eliminated due the severe corrosion issues associated with $900 \mathrm{C}$ steam. Organic-cooled reactors were dropped from consideration because organic coolants dissociate at temperatures well below $900 \mathrm{C}$. During this stage, baseline

coolants were selected for each reactor category. For example, lithium was selected as the baseline coolant for the alkali metal-cooled reactor category.

\section{Stage 3: Attribute assessment}

A list of five requirements and five criteria was developed and used to further assess the suitability of the various reactor types for the sulfur-iodine cycle. The five requirements included (1) materials compatibility, (2) coolant stability, (3) reasonable operating pressures, (4) nuclear compatibility, and (5) basic feasibility and development requirements. The five criteria were (1) safety, (2) operational issues, (3) capital costs, (4) intermediate loop compatibility, and (5) other merits and issues. Guidelines were then established for rating each reactor category for each requirement and criterion with a score of 0 through 4 (with 4 indicating best achievable and 0 indicating unacceptable). Based on this assessment, liquid-core and alkali metal-cooled reactors were identified as possibilities, but were judged to present significant technology development risks. The 
issues for the liquid-core approach focus on the radiological challenges presented by a circulating fuel in the primary loop. For alkali metals, the general corrosiveness of the coolant and the potential impact on development cost were the principal issues. Gascooled, heavy metal-cooled, and molten salt-cooled reactors were identified as promising candidates.

\section{Stage 4: Development COST requirements}

A comparison of the relative development cost requirements was made for the top three candidate approaches from stage 3. Based on this assessment, helium gas-cooled reactors appear to require the least development work and present the lowest development risk. The underlying reasons for their suitability for the high temperature sulfur-iodine cycle are: (1) helium is chemically inert, and (2) gas cooled reactors have been successfully operated for a number of years in the required temperature range. Based on this assessment helium gas-cooled reactors are recommended as the baseline choice as a reactor heat source for a sulfur-iodine thermochemical cycle for hydrogen production. 


\section{An Assessment of Reactor Types for Thermochemical Hydrogen Production}

\subsection{Introduction}

The Department of Energy has awarded a Nuclear Energy Research Initiative (NERI) Grant to General Atomics, the University of Kentucky, and Sandia National Laboratories to explore the possibility of using a reactor heat source combined with a thermochemical cycle for the production of hydrogen from water [1]. The sulfur-iodine thermochemical cycle was selected during the first phase of this project as the baseline approach. For this cycle, a heat supply temperature of $850 \mathrm{C}$ permits optimum operation; however, temperatures as low as $750 \mathrm{C}$ may be acceptable [2], and by operating at higher pressures, higher temperatures may be utilized. The cycle reactions and operating temperatures are:

$$
\begin{array}{lr}
\mathrm{H}_{2} \mathrm{SO}_{4} \rightarrow \mathrm{SO}_{2}+\mathrm{H}_{2} \mathrm{O}+1 / 2 \mathrm{O}_{2} & 850 \mathrm{C} \\
2 \mathrm{HI} \rightarrow \mathrm{I}_{2}+\mathrm{H}_{2} . & 300 \mathrm{C} \\
2 \mathrm{H}_{2} \mathrm{O}+\mathrm{SO}_{2}+\mathrm{I}_{2} \rightarrow 2 \mathrm{HI}+\mathrm{H}_{2} \mathrm{SO}_{4} & 100 \mathrm{C}
\end{array}
$$

The cyclical relationship of the chemical reactants is illustrated in Fig. 1, and a schematic illustration of a reactor based hydrogen production system is illustrated in Fig. 2 . Reaction 1 is highly endothermic, requiring most of the heat input to the process. Reaction 2 is slightly endothermic and Reaction 3 is very exothermic.

For the second phase of this project, one of the tasks is to define the thermal characteristics of the advanced nuclear reactor heat source. This definition includes a specification of the reactor coolant/heat transfer medium. Several types of nuclear reactors are capable of producing process heat in the temperature range of interest. Sandia was tasked with analyzing the characteristics of the various types of reactors and recommending reactor concepts best suited as a heat source for a sulfur-iodine cycle. This report provides the findings of the Sandia study.

\subsection{Objective}

The objectives of this study are to identify the most promising reactor concepts for use as the heat source in a sulfur-iodine thermochemical system for producing hydrogen from water, and to select one reactor concept as the baseline design for Phase 3 of this project. 


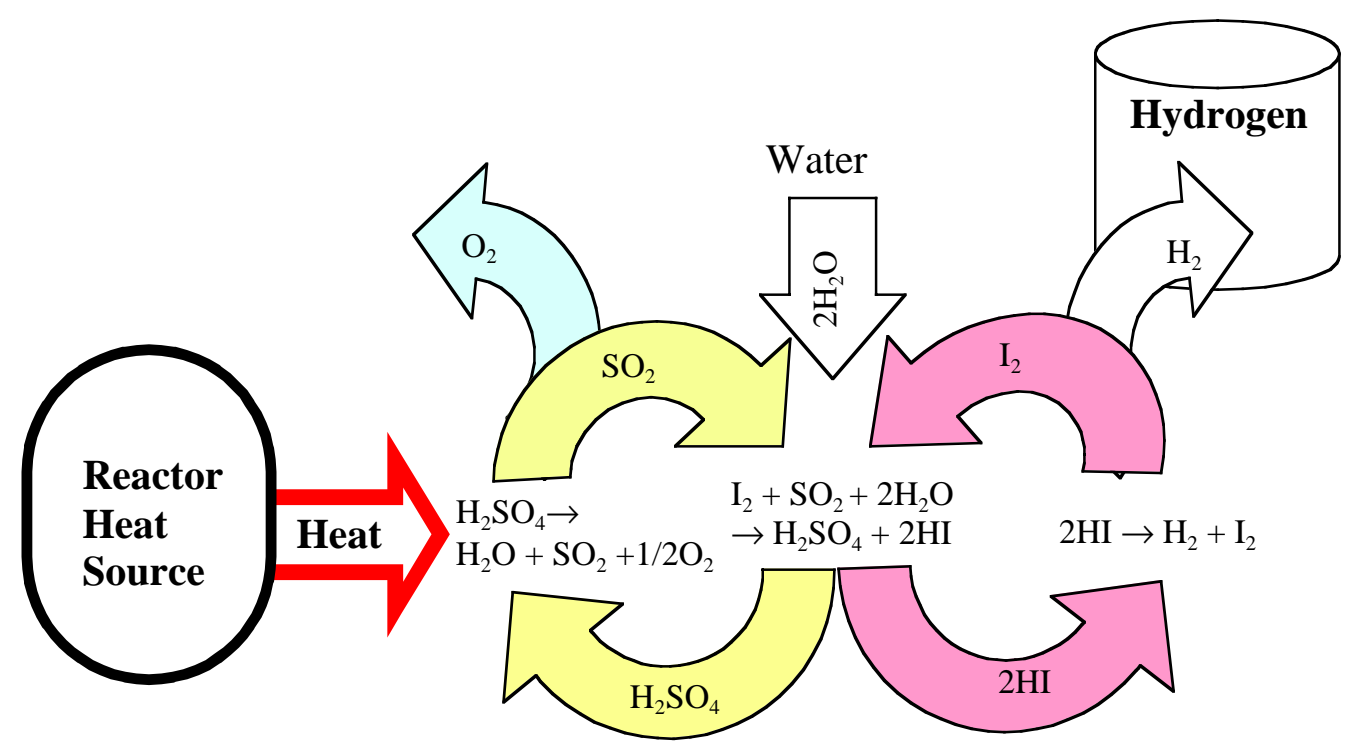

Figure 1 Sulfur-iodine thermochemical cycle for hydrogen production 


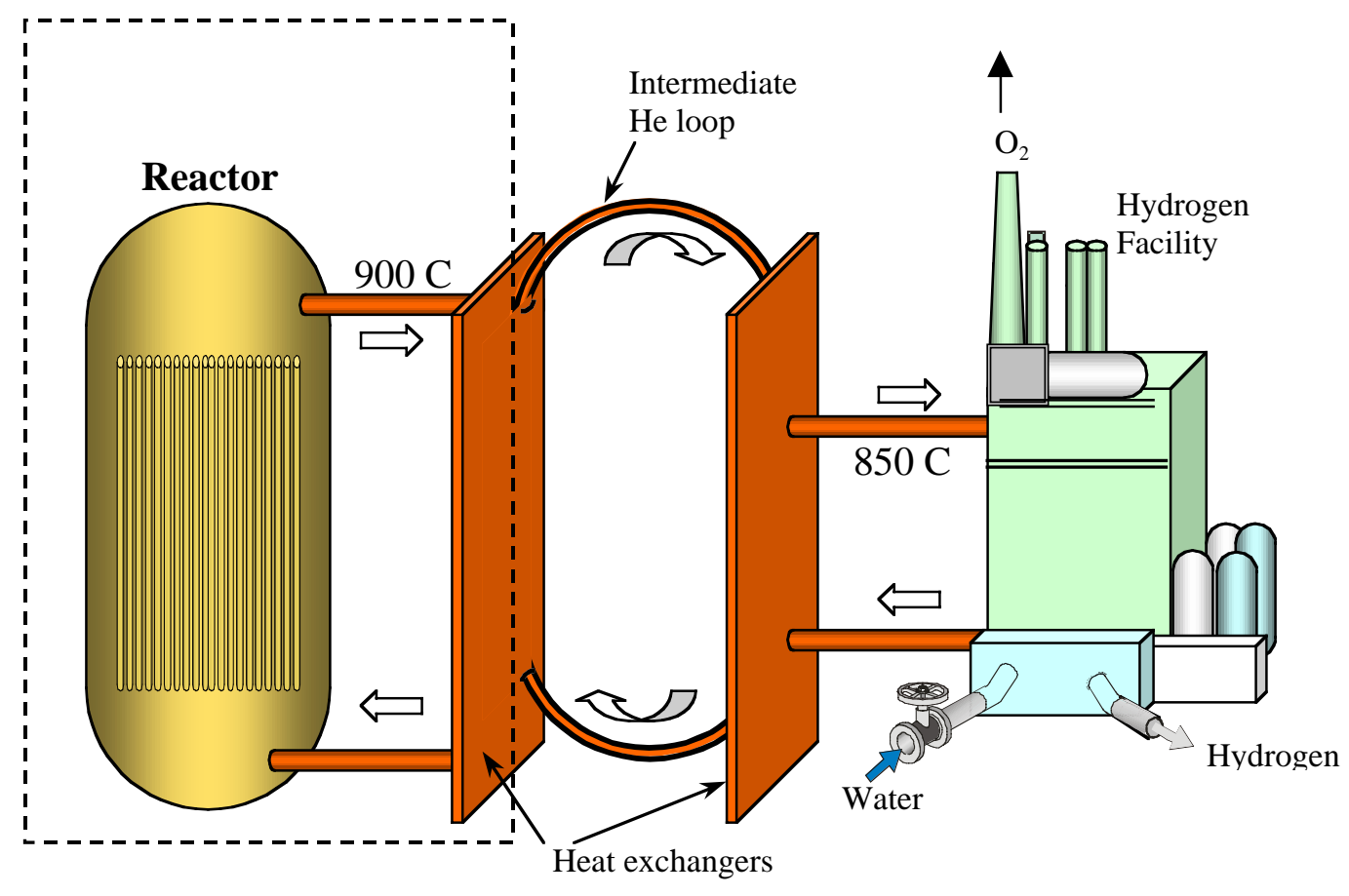

Figure 2 Schematic of nuclear reactor heat source with a water/thermochemical hydrogen production system. 


\subsection{Approach}

The focus for this project is the integration of a reactor system with a chemical plant for the production of hydrogen from water. This challenging goal is in itself an innovative application of nuclear power. Ideally, the recommended reactor technology would require minimal technology development to meet the high temperature requirement. Furthermore, the reactor system should not present any significant design, safety, operational, or economic issues. In other words, the focus of this DOE project should be on the integration and development of a reactor-based hydrogen production plant, rather on a major development of the reactor itself.

The reactor heat source can be conceptually decoupled from the hydrogen production plant, with a heat exchanger providing the interface between the two systems. At present, the plan is to use an intermediate helium loop between the reactor coolant loop and the hydrogen production system. The intermediate helium loop assures that any leakage from the reactor coolant loop will not contaminate the hydrogen production system or expose plant personnel to radiation from the primary loop coolant. The intermediate helium loop also assures that corrosive process chemicals cannot enter the core of the nuclear reactor. Thus, the heat exchanger interface, to a large extent, sets the boundary conditions for selection of the reactor system. The principal requirement set by the interface is the temperature requirement for the decomposition of $\mathrm{H}_{2} \mathrm{SO}_{4}$. General Atomics estimates a $50 \mathrm{C}$ drop from the core outlet to the point of application [2]; thus, in order to deliver $850 \mathrm{C}$ to the hydrogen production system, the required core outlet temperature is $900 \mathrm{C}$.

The project objectives and reactor operational requirements suggest a logical approach for reviewing and assessing potentially applicable reactor system options. Given the basic requirements of coolant temperature, and the potential effect of leakage into the coolant loop, the reactor coolant becomes a primary consideration for determining which concepts are most appropriate. Furthermore, the basic reactor types are generally classified by the coolant type. Given these considerations, reactor categories can be delineated by nine basic coolant types identified in Table 1. In order to aid the discussion, a number of sub-categories are also defined in Table 1. The reactor/coolant types include pressurized water-cooled reactors, boiling water-cooled reactors, alkali liquid metal-cooled reactors, heavy liquid metal-cooled reactors, gas-cooled reactors, organic-cooled reactors, molten salt-cooled reactors, liquid-core reactors, and gas-core reactors.

Four assessment stages are used in this study:

STAGE 1: The basic reactor types are reviewed to provide perspective on the development level of candidate reactor systems. Speculative concepts with extreme developmental requirements may be eliminated at this stage. Coolant limitations and concept attributes are not assessed at this stage 
STAGE 2: For the second stage, coolant properties are examined to identify merits, issues, and limitations. Fundamental limitations of coolant choices may result in the elimination of some reactor types. At this stage, specific coolant options for each reactor type are examined to select a baseline coolant option; e.g., $\mathrm{Li}$ may be selected from the options of $\mathrm{Na}, \mathrm{Li}, \mathrm{NaK}$, and $\mathrm{K}$ for alkali metal-cooled reactors.

STAGE 3: For the third stage, the reactor types are subjectively assessed based on the five requirements and five important criteria given in Table 2. A subjective grade is given for each reactor type ( 0 through 4$)$ for each assessment criterion.

STAGE 4: For the final stage, the relative development costs are reviewed for the top remaining candidates. A subjective score for development costs (0 through 4) are awarded to each reactor type for five development categories. Based on this analysis a baseline concept is recommended as a heat source for the sulfur-iodine cycle.

From the preceding discussion of the assessment approach, it should be clear that conclusions from this study are based on subjective assessments and the study is limited in both scope and detail. Nonetheless, for the purpose of selecting a baseline approach for system analysis of a sulfur-iodine hydrogen production facility, the conclusions from this study should provide adequate guidance. 
Table 1 Reactor Types Considered in the Assessment

1. Pressurized Water Reactors

- Pressurized Water Reactors (light and heavy water)

- Supercritical-Phase Pressurized Water Reactors

2. Boiling Water Reactors

- Boiling Water Reactors (light and heavy water)

- Boiling Water Reactors with Superheat

3. Organic-Cooled Reactors

- Diphenyl

- Other organic coolants

4. Alkali Liquid Metal-Cooled reactors

- Lithium-cooled

- Other (Na, K, NaK)

5. Heavy Liquid Metal-Cooled Reactors

- Lead-bismuth

- Other (Pb, Bi, Sn, Hg)

6. Gas-Cooled Reactors

- Noble gasses (He, Ar)

- Other gasses $\left(\mathrm{CO}_{2}, \mathrm{H}_{2}, \mathrm{~N}_{2}\right.$, Air, Ar, Steam)

7. Molten Salt-Cooled Reactors

- $2 \mathrm{LiF}-\mathrm{BeF}_{2}$

- Other salts

8. Liquid-Core Reactors

- Molten Salt-Core

- Liquid Metal-Core

- Aqueous-Core

9. Gas-Core Reactors

- $\mathrm{UF}_{6}$

- Other gas/fuel ( $\mathrm{UF}_{4}, \mathrm{U}$-plasma) 
Table 2 Attribute Requirements and Criteria

\section{(a) Basic Requirements}

1. Chemical compatibility

- Compatibility of coolant with primary loop materials and fuel.

2. Coolant Stability

- Molecular stability of coolant at operating temperatures and in a radiation environment.

3. Pressure requirements

- Pressure limitations for primary loop.

4. Nuclear requirements

- Issues associated with nuclear aspects of the reactor type.

5. Feasibility

- Basic feasibility, development requirements, and development risk.

1. Safety

(b) Important Criteria

2. Operational Issues

3. Capital Costs

4. Intermediate Loop Compatibility

5. Other merits and Issues 


\subsection{Stage 1: Status of Reactor Types}

Before embarking on an in-depth study of a specific reactor concept for hydrogen production, an assessment of all possible reactor candidates should be carried out to determine the best choices. This study explores a broad range of reactor concepts and options, from the highly conventional to the highly speculative. The basic reactor types and the principal concepts in each category are briefly reviewed in this section. The principal reactor categories include pressurized water reactors, boiling water reactors, alkali liquid metal-cooled reactors, heavy liquid metal-cooled reactors, gas-cooled reactors, organiccooled reactors, molten salt-cooled reactors, liquid-core reactors, and gas-core reactors.

\subsection{Pressurized Water-Cooled Reactors}

Pressurized water reactors (PWRs) are used extensively for commercial production of electricity. A typical PWR reactor system design is illustrated in Fig. 3. The basic design of a PWR core consists of bundles of approximately one $\mathrm{cm}$ in diameter, $3.6 \mathrm{~m}$ long zircaloy clad fuel rods. Each fuel rod contains stacks of $\mathrm{UO}_{2}$ fuel pellets. The moderator/coolant/heat transfer medium is water. Water in the primary cooling loop is pressurized to about $15.5 \mathrm{MPa}(2,250 \mathrm{psi})$ and remains in the liquid phase. A heat exchanger is used to transfer heat to a low-pressure secondary loop. The working fluid in the secondary loop is also water. Steam is formed in the secondary loop and used in a Rankine cycle to drive a turbine-generator. The core outlet coolant temperature is about $325 \mathrm{C}$. The nominal fuel centerline temperature and cladding temperature are $2280 \mathrm{C}$ and $347 \mathrm{C}$, respectively. A typical large PWR produces $3,400 \mathrm{MW}_{\text {th }}$ to provide $1,100 \mathrm{MW}_{\mathrm{e}}$ at $32 \%$ efficiency. The total coolant flow rate is about $1.7 \times 10^{4} \mathrm{~kg} / \mathrm{sec}(19 \mathrm{tons} / \mathrm{sec})$ [3]. 


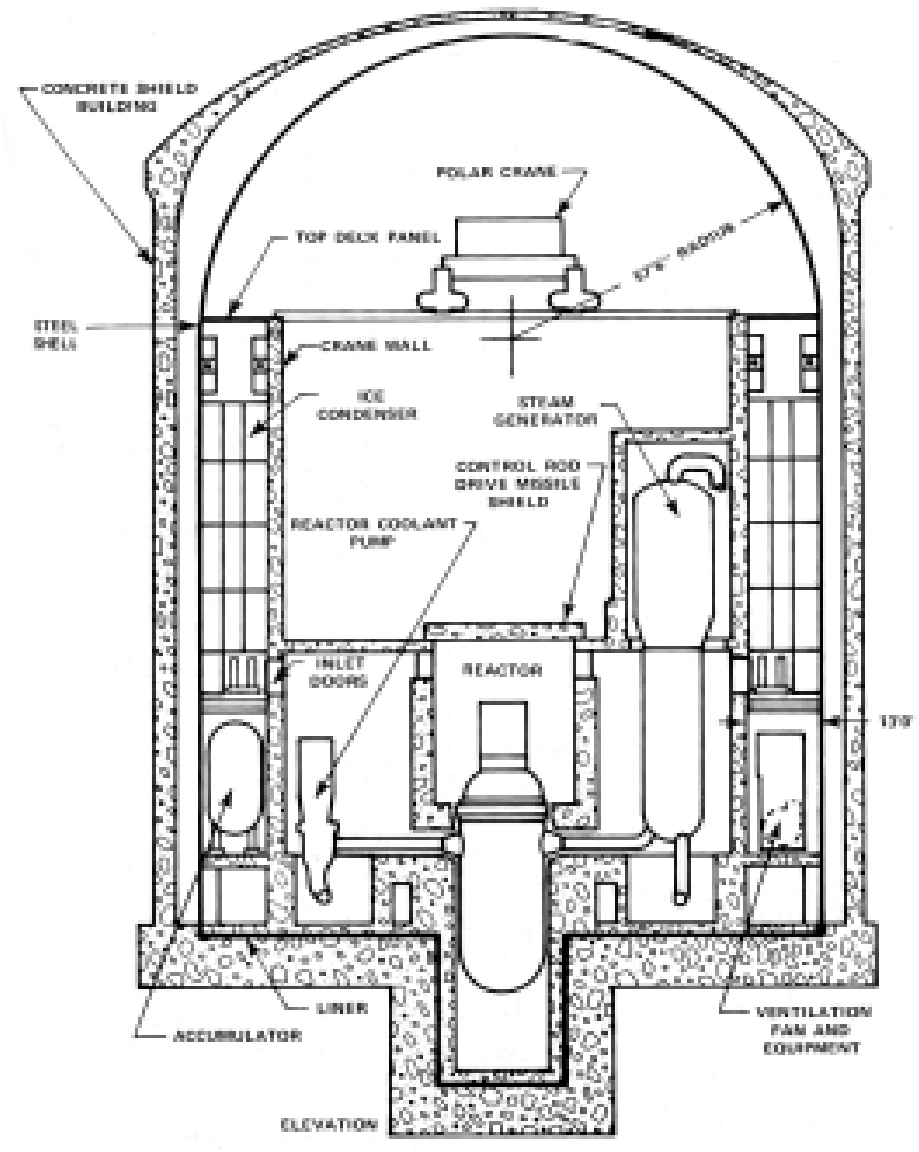

Figure 3 PWR containment building and system components 
A number of variations on the basic pressurized water reactor design are available. The Canadian CANDU pressurized water reactors use heavy water, rather than light water, as the moderator. Heavy water $\left(\mathrm{D}_{2} \mathrm{O}\right)$ absorbs fewer neutrons, thus permitting the use of natural uranium rather than enriched uranium. Advanced PWR concepts, including both evolutionary and revolutionary designs, are under development. These advanced designs are primarily focused on providing passive safety features [4]. Although PWRs are fully mature and they are among the most prolific reactor types, none of the PWRs described in the preceding discussion can achieve the temperature required for the sulfur-iodine cycle using liquid water. In order to provide thermal energy at $900 \mathrm{C}$ with a pressurized watercooled reactor, the water coolant must be in the supercritical state. The supercritical state of water refers to water above 374C; above this temperature water cannot exist in the liquid state (supercritical water is unrelated to neutronic supercriticality). So-called supercritical pressurized water-cooled reactors (high temperature water-cooled reactors in the supercritical phase) have been proposed [5].

\subsection{Boiling Water-Cooled Reactors}

In the United States, about one-third of operating water-cooled power reactors are boiling water reactors (BWRs). Fuel rods in BWRs are similar to PWR fuel rods. The coolant in a BWR, however, is maintained at lower pressure (7.2 MPa) and steam is formed in the primary loop. For the BWR, water in the primary loop serves as the moderator, coolant, and working fluid. This design eliminates the need for a secondary loop. The coolant temperature is $290 \mathrm{C}$, and the maximum fuel centerline temperature and average cladding temperatures are $1830 \mathrm{C}$ and $300 \mathrm{C}$, respectively. A typical large BWR produces 3,579 MWth to provide 1,220 MWe at 34\% efficiency. Current U.S. reactors provide steam at saturation conditions; consequently, current design BWRs are incapable of providing steam at the required temperature. If the reactor is used to superheat the steam, however, it may be possible to provide thermal energy at $900 \mathrm{C}$. BWRs employing nuclear superheat have been operated in the 1950s and 1960s, with reactor outlet steam temperatures up to $500 \mathrm{C}$. Nuclear Superheated BWRs present a number of problems, such as severe corrosion of fuel elements exposed to superheated steam and shutdown cooling of fuel zones used for superheating [3, 6, 7]. The British have developed boiling heavy water-cooled reactor designs [7].

\subsection{Organic-Cooled Reactors}

Organic liquid coolants, such as diphenyl, have been developed as an alternative to water coolants for power reactors. The principle advantages of organic coolants are the relatively low vapor pressure and low corrosion characteristics. The low vapor pressure leads to low pressure system designs, compared to water-cooled reactors, resulting in a potentially significant capital cost reduction. An experimental organic-cooled reactor was designed, built, and operated at Oak Ridge National Laboratories in the 1950s. A small U.S. organic-cooled reactor commercial power plant and a Soviet transportable organiccooled reactor were built and operated in the 1960s. Coolant dissociation in radiation and 
high temperature environments resulted in virtual abandonment of the organic-cooled reactor option $[6,7]$.

\subsection{Alkali Metal-Cooled Reactors}

Alkali liquid metal-cooled Reactor development has focused on sodium-cooled breeder reactor systems. The French have built and operated a large-scale sodium-cooled breeder reactor. In the United States several breeder-prototype liquid metal-cooled reactors were developed. The United States also began construction (subsequently terminated) on a $975 \mathrm{MW}_{\text {th }}$ Clinch River Breeder Reactor (CRBR). The CRBR basic design is presented in Fig. 4. Typical reactor outlet temperatures are about $530 \mathrm{C}$, and the coolant is maintained at a very low operating pressure. For the CRBR system, the flow rate of the sodium coolant was designed to be approximately $2.3 \times 10^{3} \mathrm{~kg} / \mathrm{sec}(2.5$ tons per sec $)$. For liquid metal-cooled power reactors, heat from the primary liquid metal cooling loop is transferred to a water loop using a heat exchanger. Steam is generated in the secondary loop for use in Rankine cycle to produce electrical power [3]. Fast breeder reactor core designs usually consist of uranium and plutonium oxide pellets contained in steel-clad fuel pins. An advanced liquid metal cooled reactor concept has been proposed that uses a ternary metallic fuel consisting of uranium, plutonium, and zirconium [8]. Other fuel types have been studied and used in alkali liquid metal-cooled reactor designs. Most liquid metalcooled reactors are fast reactors; however, some designs have been developed that utilize graphite or other materials to moderate (slow down) neutrons.

Although sodium is usually selected as the coolant for liquid metal-cooled breeder reactor system designs, space reactor systems have been developed in the United States and the former Soviet Union that utilize other liquid metal coolants. In the United States, sodium-potassium $(\mathrm{NaK})$ eutectic, potassium, and lithium coolant technology have been developed for space reactors. For the proposed lithium-cooled SP-100 reactor, the fuel was uranium nitride and the design temperature of the coolant outlet was 1,120 C [8].

\subsection{Heavy Metal-Cooled Reactors}

Heavy liquid metals considered for both terrestrial and space reactors include mercury, bismuth, lead, tin, and lead-bismuth eutectics [7, 9, 10]. The United States developed and tested a small reactor with a mercury Rankine cycle in a secondary-side loop. Lead-bismuth reactors were developed and used in the Russian nuclear-powered submarine program [10]. Heavy metal-coolants are not fire or chemical explosive hazards, and exhibit very low vapor pressures. Furthermore, heavy metal cooled reactors have negative void coefficients of reactivity. For one proposed $\mathrm{PbBi}$ power reactor system, the coolant outlet temperature and pressure are $439 \mathrm{C}$ and $0.5 \mathrm{MPa}$, respectively. For this design, the fuel is $\mathrm{UO}_{2}$, and the core diameter and length are $1.65 \mathrm{~m}$ and $0.9 \mathrm{~m}$, respectively [11]. A variety of other fuels have been proposed for heavy metal-cooled reactors; e.g., UZr, UPuZr, and UPuN. 


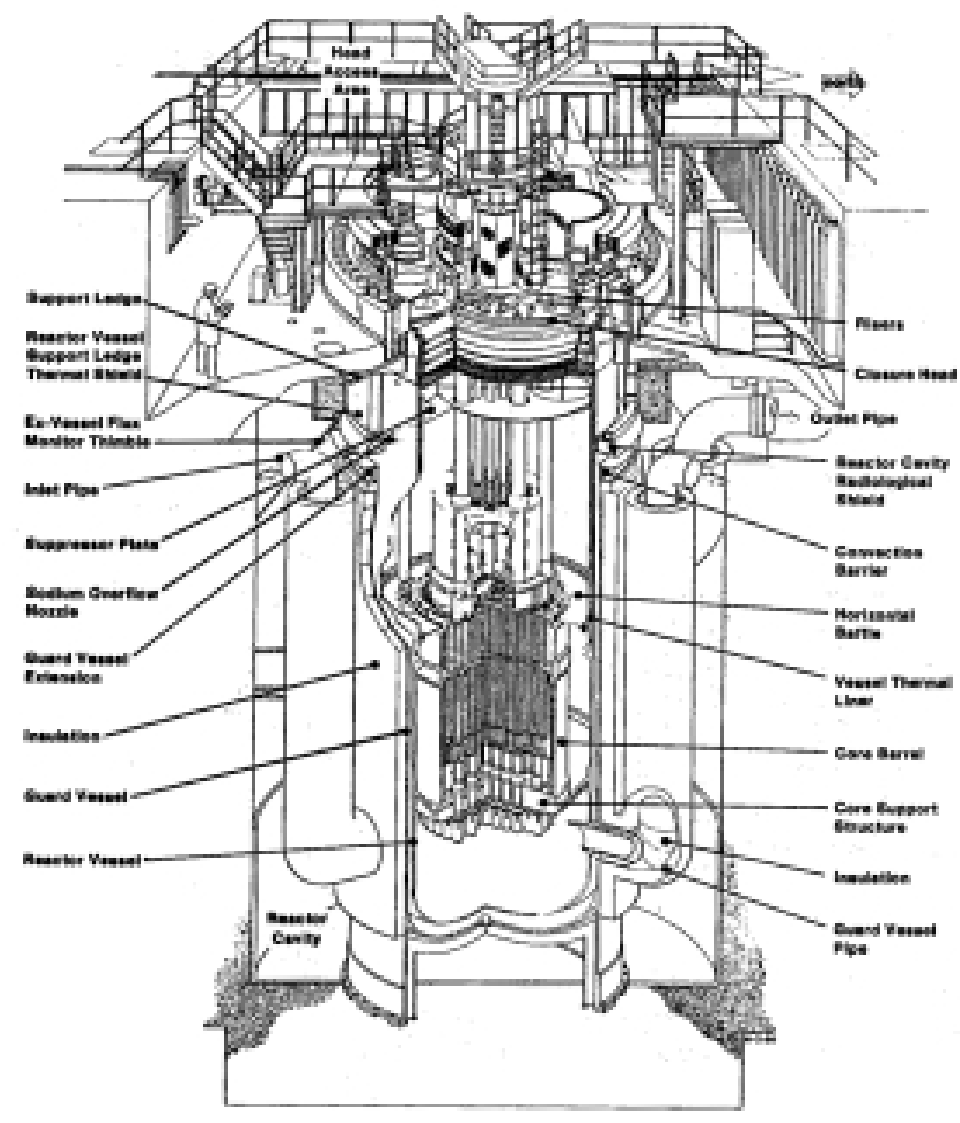

Figure 4 Clinch River Breeder Reactor liquid metal-cooled reactor. 


\subsection{Gas-Cooled Reactors}

Potential gas coolants for reactors include hydrogen, helium, nitrogen, $\mathrm{CO}_{2}$, argon, air, and steam. A number of large gas-cooled reactors (GCRs) have been developed and operated worldwide. Gas-cooled reactor designs are usually moderated, and graphite is commonly selected as the moderator. However, gas-cooled reactors have been studied and developed that employ other moderators or no moderator. A broad variety of fuel element geometries and fuel types have been used in gas-cooled reactors [6].

The first gas-cooled reactors developed in the United Kingdom were air-cooled reactors. By the late 1950s, gas-cooled reactor development in the United Kingdom and France was based on a $\mathrm{CO}_{2}$ coolant. Oxidation and dissociation issues, however, have limited $\mathrm{CO}_{2}$ coolant temperatures to less than $600 \mathrm{C}$. Fuel element designs for these reactors included uranium metal and uranium dioxide clad in magnesium alloy and other metals. The $\mathrm{CO}_{2}$-cooled reactor approach proved successful, but these systems did not produce electricity as cheaply as PWRs. In 1979, Great Britain abandoned $\mathrm{CO}_{2}$-cooled reactors in favor of the more economical PWR approach [6, 7]. In the United States, nitrogen-cooled reactors were once studied for remote power sources, and hydrogencooled reactors were developed for space applications. However, nitrogen and hydrogencooled reactors were never developed for commercial power applications. The use of steam as a coolant/working fluid has been limited to nuclear superheat in BWR reactors.

Developers in the United States, Germany, and Japan eventually selected helium as an attractive coolant for gas-cooled reactors. Helium is chemically inert, exhibits good heat transfer properties (among gasses), and has a very small neutron capture cross section. In the 1960s, a small high temperature, graphite moderated, helium-cooled reactor plant (Peach Bottom) was built and operated in the United States, and in the 1970s the Fort St. Vrain (FSV) commercial High Temperature Gas Cooled Reactor (HTGR) went into operation. The Fort St. Vrain system was a mid-sized power plant with the basic design features of current-design HTGRs. The FSV core consists of stacks of hexagonal graphite blocks. Each graphite block is $78.7 \mathrm{~cm}$ high and $35.6 \mathrm{~cm}$ across flats. Fuel rods are contained within the graphite blocks and helium flows through internal coolant channels in the blocks. The fuel rods consist of coated uranium carbide microspheres embedded in a graphitic binder. Maximum fuel temperatures were < $1260 \mathrm{C}$, and the coolant outlet temperature was $785 \mathrm{C}$. The primary system for an HTGR design is shown in Fig. 5. For a 2,900 MWth HTGR design, the coolant pressure and flow rate are about 4.8 MPa (700 psi) and $1.3 \times 10^{3} \mathrm{~kg} / \mathrm{sec}$ (1.4 tons per sec), respectively [6, 7]. The recently completed Japanese 30 MWth test reactor, which uses HTGR technology, is designed to achieve an outlet temperature of about $900 \mathrm{C}$ [1]. 
In the late 1960s, the Germans developed and operated the AVR helium-cooled Pebble Bed Reactor with coolant operating conditions similar to an HTGR, but with a radically different core configuration. Rather than hexagonal fuel elements, the AVR used 6-cm diameter graphite balls containing coated uranium carbide microparticles embedded in the graphite matrix of the ball. The AVR pebble bed reactor core, illustrated in Fig. 6, consists of several hundred thousand fuel balls and over one hundred thousand pure graphite moderator balls. The fuel and moderator balls are continuously recirculated through the core. "Spent" fuel balls are removed from the circulating loop and fresh fuel balls are added as needed to maintain criticality. The outlet coolant temperatures ranged between 850 and $950 \mathrm{C}$. The Germans also built a $746 \mathrm{MW}_{\text {th }}$ prototype power plant pebble bed reactor system; the plant was operated from 1983 to 1988 [6, 7]. The maximum permitted fuel temperature for current generation PBRs (as for HTGRs) is $1260 \mathrm{C}$ [2]. A pebble bed reactor is now under development in South Africa [12].

Currently, the United States has no operating Gas-Cooled Reactors but interest is growing worldwide. The U.S. GCR technology is being updated for use in burning plutonium in Russia. One utility has announced that they will build the Pebble Bed version of GCR in the United States. Development on GCRs is being carried out in the United States, Russia, Japan, China, Germany, and South Africa.

\subsection{Molten Salt-Cooled Reactors}

Molten Salt-Cooled Reactors have been recently proposed that combine features of the HTGR and Molten Salt Core Reactor concepts [13]. For this concept, the coolant is a molten salt, such as $2 \mathrm{Li}-\mathrm{BeF}_{2}$ and the core resembles the core of a prismatic HTGR. This approach can permit high temperature operation at low pressure, with the possibility of low corrosion. Molten salt-cooled reactors avoid most of the issues associated with the flowing fuel of the molten salt-core reactors (discussed subsequently). Molten salts exhibit very low vapor pressures and are stable in radiation and high temperature environments. Although the molten salt-cooled approach appears to be entirely feasible, it must be emphasized that this approach is only in the early conceptual stage.

\section{$2.8 \quad$ Liquid-Core Reactors}

One novel approach to reactor design uses reactor fuel in the liquid phase. The liquid fuel is pumped through the reactor system. Fuel entering the core region supports criticality and the liquid fuel is heated by nuclear fission of its fissile constituents. The hot liquid fuel then exits the core and passes through a heat exchanger, where heat is extracted for use in a power cycle. Liquid-core reactors offer a number of potential advantages. For example, because the fuel is also the fluid heat transfer medium, no thermodynamic losses result from temperature differences between the fuel and coolant. As a consequence, very high efficiencies are possible with liquid-core reactor systems. Furthermore, liquid-core reactors eliminate fuel fabrication costs and eliminate fuel damage concerns. Fluid cores also permit on-line refueling and removal of fission products. The low fission product inventory and low excess reactivity, made possible by on-line fuel processing and fuel resupply, result in potential safety advantages. 


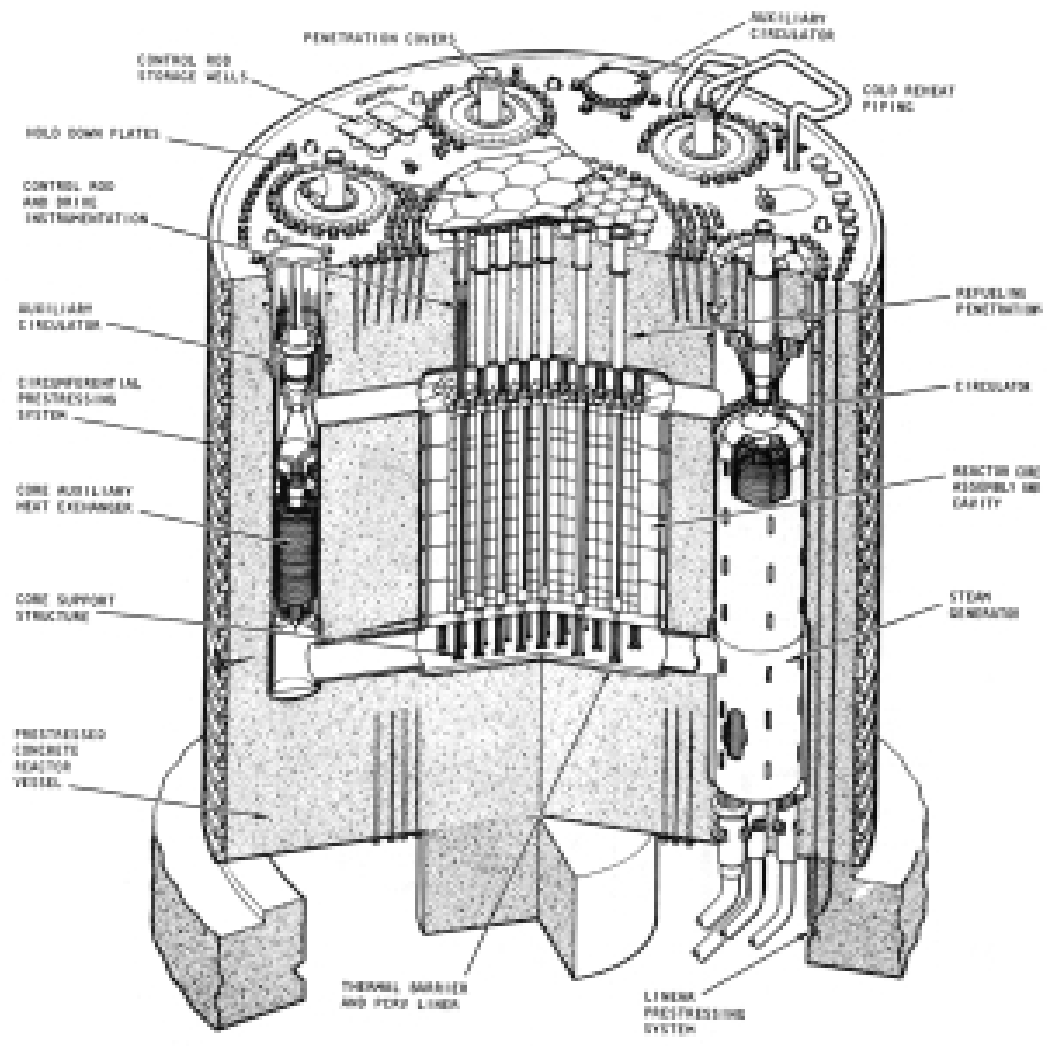

Figure 5 HTGR primary system cross section. 


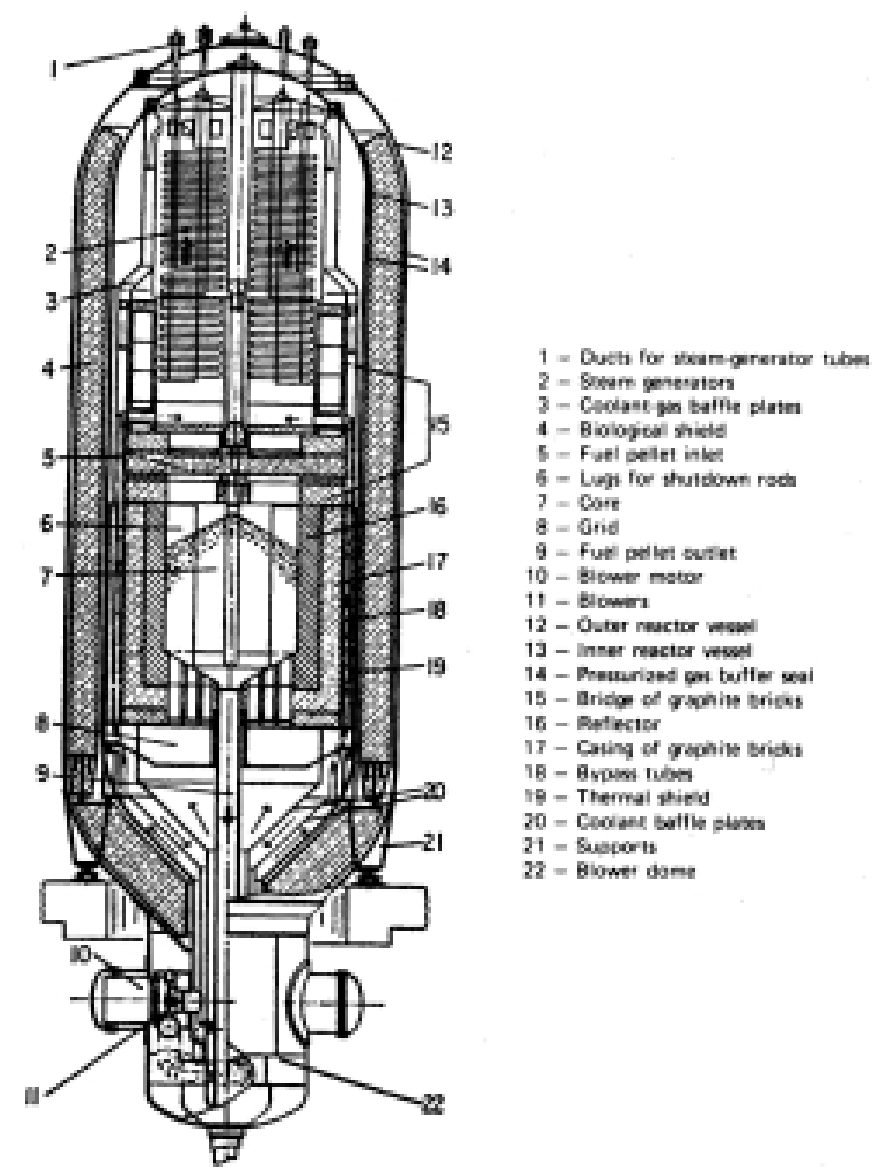

Figure 6 Pebble Bed Reactor vessel cross section. 
Aqueous, liquid metal, and molten salt liquid-core reactors have been studied. Aqueous-core reactors include fuel solutions and slurries. Several uranium salts, such as uranyl sulfate $\left(\mathrm{UO}_{2} \mathrm{SO}_{4}\right)$ have been studied for solution-type aqueous-core reactors. For slurry-type aqueous-core reactors, uranium compounds (e.g., UO2) are suspended in water. Aqueous-core reactor experiments were conducted in the United States in the 1950s [7].

Liquid metal-core reactors were extensively studied in the 1950s and early 1960s at Brookhaven and Los Alamos National Laboratories. As for aqueous fuel reactors, liquidmetal-fuel reactors include both fuel solutions and slurries. For this approach, uranium or plutonium is maintained in solution in a liquid metal, such as bismuth or lead, or in suspension in a liquid metal, such as sodium. Both moderated and unmoderated systems have been studied. Liquid metal core reactors are not limited by the high vapor pressure difficulties found in aqueous-fuel approaches. Fluid operating temperatures of > $500 \mathrm{C}$ were planned for some designs [7].

Molten salt-core reactors have been more extensively developed than other liquid core concepts. For this approach, the reactor fluid consists of uranium tetrafluoride dissolved in a carrier salt, such as lithium fluoride and beryllium fluoride. Both moderated and unmoderated reactor systems have been designed. A test reactor was operated in the United States in the 1960s [6, 7], and commercial scale designs have been developed in the United States, Russia, and Japan. Molten salts are stable to both radiation and high temperature, and exhibit low vapor pressures. The fuel-fluid operating temperature for one molten salt reactor concept is $700 \mathrm{C}$ [3]. The system pressure for this design is about 0.5 $\mathrm{MPa}$. As for other liquid core designs, the use of a radioactive fluid in the primary loop presents a number of design and operational difficulties. The entire loop is a source of intense radiation fields, requiring shielding-exclusion areas, remote maintenance, containment, and decay-heat removal capability $[6,7,14]$.

\subsection{Gas-Core Reactors}

Gas-core reactors are unquestionably the least developed of all the reactor types studied in this assessment. The fuel for this concept is typically a uranium compound in gaseous form, such as $\mathrm{UF}_{6}, \mathrm{UF}_{4}$, or uranium plasma. Similar to the liquid-core approach, the gaseous fuel is circulated through the reactor system. Fuel entering the core region supports criticality and the gaseous fuel is heated by nuclear fission. The principal advantage of this approach is that very high temperatures are possible. For gaseous fuel compounds, a typical design would provide gas outlet temperatures of several thousand C. Plasma core reactors are projected to produce gas exit temperatures in excess of 10,000 C. The very high temperature of the gaseous fuel presents serious materials and design challenges. One design approach for protection of core boundary materials includes cooling the pressure vessel and surrounding reflector by a flowing low temperature gas. Most of the work on gas core reactors has focused on nuclear rockets, where very high temperatures are an important advantage. Many operational and design issues must be resolved for gas-core reactors. Although some low power testing of gas core reactors was successfully carried out in the 1970s [15], the gas core approach is basically unproven 
technology. The required development work and the development risk for gas core reactors are too significant to merit further consideration for this study.

\subsection{Stage 2: Coolant Properties}

Reactor coolants and heat transport fluids should have low melting points, good heat transport properties, and low potential for chemical attack on vessels and piping. Reasonable operating pressures and compositional stability at operating temperature are also important characteristics. Other desirable properties include low toxicity and low fire and explosion hazard. Reactor coolants must also possess desirable nuclear properties, such as radiation stability and low neutron activation. For thermal reactors, low parasitic capture cross sections are required. If the coolant is to serve as a moderator, low atomic weight constituents are desirable. Property values and characteristics for potential reactor coolants are presented in Tables 3 and 4, and discussed in the following [7- 35]:

\subsection{Pressurized Water}

The low atomic weight constituents of water (hydrogen) and heavy water (deuterium) make these coolants desirable as moderators. Water has good heat transport properties and a low melting point, but its very low boiling point implies high vapor pressures at high temperatures. At only $327 \mathrm{C}(600 \mathrm{~K})$ the vapor pressure is $135 \mathrm{~atm}$, requiring massive high-pressure coolant pipes and vessels. The critical point for water occurs at $374 \mathrm{C}$ and a pressure of $22.1 \mathrm{MPa}$ (218 atm) [14]. At the $900 \mathrm{C}$ temperature required for the sulfur-iodine cycle, the coolant would be required to operate in a supercritical state. So-called supercritical water-cooled reactors have been proposed [5]; however, at only $500 \mathrm{C}$, operating pressures are $25 \mathrm{MPa}$. For the required cycle operating temperatures, pressures become extreme, and structural requirements are enormous. Furthermore, the potential energy stored in water at these temperatures and pressures is very large; safety issues associated with large breaks at these extreme pressures present additional concerns. Supercritical water is also highly corrosive and heat transfer capability is degraded relative to water in the purely liquid phase. Thus, at the required temperature for the sulfur-iodine cycle, pressurized water-cooled reactors are not feasible.

\subsection{Boiling Water}

Steam produced at saturation conditions in a BWR cannot provide heat at the high temperature required for the sulfur-iodine cycle. Water-cooled reactors producing superheated steam could, in principle, achieve the required $900 \mathrm{C}$ operating temperature. Although boiling water reactors producing superheated steam at $537 \mathrm{C}$ have been developed, nuclear superheated steam options are no longer actively pursued. High temperature oxidation in a superheated steam environment was one of the main reasons for abandoning this approach. At $900 \mathrm{C}$, the temperature required for the sulfur-iodine cycle, steam is highly corrosive; consequently, the boiling water-cooled reactor approach is not a feasible option. 
Table 3 Reactor Coolant Basic Properties

\begin{tabular}{|c|c|c|c|c|c|c|}
\hline Coolant & $\begin{array}{c}\text { Molecular } \\
\text { Weight }\end{array}$ & $\begin{array}{c}\text { Density* } \\
(\mathrm{g} / \mathrm{cc})\end{array}$ & $\begin{array}{c}\sigma_{\mathrm{th}}{ }^{* *} \\
\text { parasitic (b) }\end{array}$ & $\begin{array}{c}\text { Neutron } \\
\text { activation }\end{array}$ & $\begin{array}{c}\text { Radiolytic } \\
\text { Decomposition }\end{array}$ & $\begin{array}{c}\text { Hazards } \\
\text { Toxic }\end{array}$ Fire Explosion \\
\hline
\end{tabular}

Water

\begin{tabular}{|r|c|c|c|c|c|c|c|c|}
\hline $\mathrm{H}_{2} \mathrm{O}$ & 18 & 1 & 0.66 & & & N0 & No & No \\
\hline $\mathrm{D}_{2} \mathrm{O}$ & 20 & 1.1 & 0.001 & Some & Some & & & \\
\hline
\end{tabular}

Organic

\begin{tabular}{|r|c|c|c|c|c|c|c|c|}
\hline Diphenyl & 154 & 0.86 & 0.33 & low & Yes & No & No & No \\
\hline
\end{tabular}

Alkali Metal

\begin{tabular}{|r|c|c|c|c|c|c|c|l|}
\hline (natural) $\mathrm{Li}$ & 7 & 0.53 & 71 & & & & \\
\hline $\mathrm{Na}$ & 23 & 0.82 & 0.525 & \multirow{3}{*}{ High } & \multirow{2}{*}{ Stable } & Yes & Yes & Yes \\
\hline $\mathrm{NaK}$ & - & 0.74 & $\sim 0.5$ & & & & \\
\hline $\mathrm{K}$ & 39 & 0.70 & 2.07 & & & & & \\
\hline
\end{tabular}

Heavy Metal

\begin{tabular}{|c|c|c|c|c|c|c|c|c|}
\hline $\mathrm{Sn}$ & 118 & 6.5 & 0.625 & \multirow{5}{*}{ High } & \multirow{5}{*}{ Stable } & No & \multirow{5}{*}{ N0 } & \multirow{5}{*}{ No } \\
\hline $\mathrm{Hg}$ & 200 & 13.6 & 380 & & & High & & \\
\hline $\mathrm{Pb}$ & 207 & 11.4 & 0.17 & & & Yes & & \\
\hline $\mathrm{Bi}$ & 209 & 9.75 & 0.034 & & & No & & \\
\hline $\mathrm{PbBi}$ & - & $\sim 10$ & $\sim 0.1$ & & & Yes & & \\
\hline
\end{tabular}

Gases

\begin{tabular}{|c|c|c|c|c|c|c|c|c|}
\hline $\mathrm{H}_{2}$ & 2 & 0.00009 & 0.332 & Low & Stable & $\mathrm{No}$ & High & High \\
\hline $\mathrm{He}$ & 4 & 0.00018 & 0.007 & No & Stable & \multirow{6}{*}{ No } & \multirow{6}{*}{ No } & \multirow{6}{*}{ No } \\
\hline $\mathrm{N}_{2}$ & 14 & 0.0013 & 1.88 & No & Stable & & & \\
\hline $\mathrm{Ar}$ & 40 & 0.0018 & 0.66 & Yes & Stable & & & \\
\hline $\mathrm{CO}_{2}$ & 44 & 0.0015 & 0.0038 & Some & & & & \\
\hline Air & - & 0.0013 & $\sim 1.3$ & Yes & & & & \\
\hline Steam & 18 & 0.00056 & 0.66 & Some & Some & & & \\
\hline
\end{tabular}

Molten Salt

\begin{tabular}{|l|l|l|l|l|l|l|l|l|}
$2 \mathrm{LiF}_{-}-\mathrm{BeF}_{2}$ & - & $\sim 2$ & - & Yes & Stable & Yes & No & No \\
\hline
\end{tabular}

\section{Liquid Core}

\begin{tabular}{|c|c|c|c|c|c|c|c|c|}
\hline Aqueous & - & $\sim 1$ & - & \multirow{3}{*}{$\begin{array}{c}\text { Fission } \\
\text { products } \\
\text { Very high }\end{array}$} & Some & Yes & No & No \\
\hline Liquid Metal & - & $\sim 10$ & - & & Stable & Yes & Yes & Yes \\
\hline Molten Salt & - & $\sim 2.5$ & - & & Stable & Yes & No & No \\
\hline
\end{tabular}

*@ ambient temperature $\quad * *$ neutron capture cross section in barns $\left(\mathrm{b}=10^{-24} \mathrm{~cm}^{2}\right)$ 
Table 4 Reactor Coolant Thermal and Chemical Properties

\begin{tabular}{|c|c|c|c|c|c|c|}
\hline Coolant & $\begin{array}{r}\text { Melting } \\
\text { Point (C) }\end{array}$ & $\begin{array}{c}\text { Boiling } \\
\text { Point (C) }\end{array}$ & $\begin{array}{c}\text { Vapor } \\
\text { Pressure } \\
\text { (MPa)* }\end{array}$ & $\begin{array}{l}\text { Heat } \\
\text { transport } \\
\text { properties }\end{array}$ & $\begin{array}{c}\text { Thermal } \\
\text { stability } \\
\text { Limit (K) }\end{array}$ & $\begin{array}{c}\text { Chemical attack } \\
@ 900 \mathrm{C}\end{array}$ \\
\hline
\end{tabular}

Water

\begin{tabular}{|r|l|l|l|l|l|l|}
\hline $\mathrm{H}_{2} \mathrm{O}$ & 0 & 100 & 13.7 & Very & Stable & Yes \\
\cline { 1 - 2 } & good & 13.7 & Stable & \\
\hline
\end{tabular}

Organic

Diphenyl

\begin{tabular}{|c|c|c|}
\hline 69 & 255 & 0.2 \\
\hline al & & \\
\hline 181 & 1331 & $<10^{-9}$ \\
\hline 98 & 881 & $5 \times 10^{-6}$ \\
\hline-11 & 784 & $\sim 10^{-4}$ \\
\hline 64 & 761 & $10^{-4}$ \\
\hline
\end{tabular}

\begin{tabular}{|c|c|c|}
\hline Excellent & Stable & $\begin{array}{c}\text { Yes } \\
\text { (Nb alloys may be } \\
\text { suitable })\end{array}$ \\
\hline
\end{tabular}

\section{Heavy Metal}

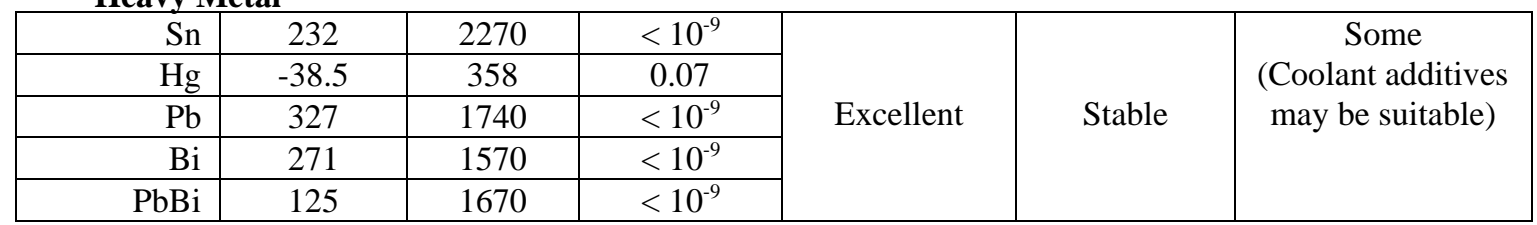

Gas

\begin{tabular}{|c|c|c|c|c|c|c|}
\hline $\mathrm{H}_{2}$ & - & - & - & \multirow{7}{*}{ Poor } & Stable & Yes \\
\hline $\mathrm{He}$ & - & - & - & & Stable & No \\
\hline $\mathrm{N}_{2}$ & - & - & - & & Stable & Yes \\
\hline $\mathrm{Ar}$ & - & - & - & & Stable & No \\
\hline $\mathrm{CO}_{2}$ & - & - & - & & $<850$ & Yes \\
\hline Air & - & - & - & & $<850$ & Yes \\
\hline Steam & 0 & 100 & - & & - & High \\
\hline
\end{tabular}

Molten Salt

\begin{tabular}{|l|l|l|l|l|l|l|}
\hline $2 \mathrm{LiF}_{-} \mathrm{BeF}_{2}$ & 457 & 1397 & $<10^{-9}$ & Excellent & Stable & Some \\
\hline
\end{tabular}

\section{Liquid Core}

\begin{tabular}{|l|c|c|c|c|c|c|}
\hline Aqueous & - & - & $\sim 10$ & \multirow{2}{*}{ Excellent } & $\begin{array}{c}\text { Some fuel } \\
\text { precipitation }\end{array}$ & Yes \\
\cline { 1 - 4 } Liquid metal & $\sim 300$ & $\sim 1500$ & Low & & $\begin{array}{c}\text { Some fuel } \\
\text { precipitation }\end{array}$ & Yes \\
\cline { 1 - 2 } Molten Salt & 497 & & $<10^{-9}$ & & Stable? & Yes \\
\hline
\end{tabular}

*@ saturation, 325 C 


\subsection{Organic Coolants}

Organic coolants also contain hydrogen atoms and are good moderators. The vapor pressure for organic coolants, at comparable temperatures, is much lower than for water coolants. Although many organic coolants rapidly decompose in radiation environments, the decomposition of some organic coolants may be manageable [7]. Organic coolant heat transport properties are not as good as water, but the major limitation of organic coolants for high temperature applications is its thermal stability. Thermal decomposition limits organic coolant temperatures to a maximum of about 400 $\mathrm{C}[14,16]$; thus, organic-cooled reactors are not recommended for use as a heat source for the sodium-iodine thermochemical cycle.

\subsection{Alkali-Metal Coolants}

Most of the liquid metal-cooled reactor development in the United States has focused on alkali metal coolants such as sodium. Other possible alkali metal coolants include lithium, potassium, and $\mathrm{NaK}$ eutectic. Alkali metals are generally corrosive at high temperature, exhibit high neutron activation, are typically toxic, and present fire and explosion hazards. Some alkali metal-cooled reactor designs can exhibit positive void coefficients. In addition to sodium-cooled reactors, the United States developed a number of NaK-cooled reactors, mostly for space applications. Although NaK is liquid at ambient temperatures, the heat transport properties of $\mathrm{NaK}$ are not as good as $\mathrm{Na}$. NaK is toxic, flammable, and can be highly explosive. All liquid metal cooled breeder reactor programs selected sodium rather than $\mathrm{NaK}$; apparently $\mathrm{NaK}$ 's ability to remain fluid at ambient temperatures was less important than economic and other benefits of sodium.

The United States carried out significant development work on a potassiumcooled reactor for space applications [15]. Like NaK, potassium is toxic, flammable, and can be highly explosive. For commercial terrestrial power applications, potassium-cooled reactors do not possess any significant advantages over sodium [7]. At the high temperatures of interest to this study, the vapor pressure of most alkali metals is fairly high; lithium, however, is an exception. The low vapor pressure and excellent heat transport properties of lithium are significant advantages. Lithium activation produces helium and radioactive tritium gases. The coolant activity and the quantity of gas produced by activation can be reduced by using depleted lithium. Lithium presents fire and severe chemical explosion hazards, and is solid at ambient temperatures. Life testing of $\mathrm{Nb}$ alloys with lithium coolants have been successful at temperatures above the desired cycle operating range; however, a long-term operational database has not been developed. Furthermore, the development cost and capital costs for candidate materials has not been determined. For this study, lithium is selected as the baseline coolant because it exhibits a low vapor pressure relative to other alkali metals. 


\subsection{Heavy-Metal Coolants}

Possible heavy metal coolant options include tin, mercury, lead, bismuth, and lead-bismuth eutectic. Although tin appears to have a number of desirable features, no significant development work has been carried out for this option. In the United States, mercury was once considered as a working fluid for space reactors. Mercury has a relatively high vapor pressure, but its most significant drawback is its toxicity and a large thermal capture cross section. In the current ES\&H environment, the health risk associated with mercury is too great to merit serious consideration of mercury as a coolant option.

Lead possess excellent heat transfer characteristics and does not present a fire or significant chemical explosion hazard. Lead also exhibits an extremely small vapor pressure, typically possesses a negative void coefficient, and may offer other safety advantages [17]. The Russians have developed and operated PbBi-cooled reactors for naval applications. Lead-bismuth coolants possess the advantage, relative to lead, of a $200 \mathrm{C}$ lower melt temperature. A major disadvantage of $\mathrm{PbBi}$ coolants is the activation product ${ }^{210} \mathrm{Po}$ resulting from an $n, \gamma$ reaction with ${ }^{209} \mathrm{Bi}$ and subsequent beta-decay to ${ }^{210} \mathrm{Po}$. Polonium-210 is very toxic and difficult to contain [7]. Nonetheless, the former Soviet Union developed and used $\mathrm{PbBi}$-cooled reactors, and the $\mathrm{PbBi}$-cooled approach has been proposed by several laboratories as an advanced power production reactor [17-20]. Bismuth possesses a higher melt temperature than the $\mathrm{PbBi}$ eutectic and offers no significant advantages over PbBi-cooled reactors. Compared to the alkali metals, heavy metals may be more compatible with other core materials at very high temperatures. The issue has been raised of a loss of alloying agents in structural materials for high temperature flowing $\mathrm{Pb}$ or $\mathrm{PbBi}$ environments. Supplying appropriate additives to the cooling stream may eliminate this concern. For this study, $\mathrm{PbBi}$ was selected as the baseline heavy metal coolant because of its lower melt temperature, and because the Russians have accumulated significant experience with $\mathrm{PbBi}$ reactor technology.

\subsection{Gas Coolants}

Increasing the flow surface area, as well as operating at high temperatures, high pressures, and high flow rates can compensate for the generally poor heat transport characteristics of gas coolants. Gas coolant operating pressures, however, are far below that for water at required cycle temperatures, and for most gas coolants, no phase change occurs for any postulated accident sequence. Most importantly, noble gases are chemically inert. Gases are too diffuse to serve as effective moderators; consequently, thermal gas-cooled reactors require a separate moderator.

\section{Reactive Gases}

Although considerable $\mathrm{CO}_{2}$-cooled nuclear power plant experience was accrued in the 1960s and 1970s in the UK, the economics of these systems proved unfavorable. More importantly to this study, the corrosiveness and thermal dissociation of $\mathrm{CO}_{2}$ at $>600 \mathrm{C}$ makes this coolant option unacceptable for the proposed cycle. Limited development work has been carried out for nitrogen reactors, and chemical incompatibility of materials with high temperatures nitrogen gas is an issue. In the 
pioneering days of nuclear power, once-through air-cooled reactors were developed and operated (i.e., the air coolant passing through the reactor was released directly into the atmosphere). Air-cooled reactors suffer the same limitations as $\mathrm{CO}_{2}$-cooled reactors and once-through cooling is no longer a viable approach.

Although water-cooled reactors with superheated steam have been developed, nuclear superheated steam options are no longer actively pursued. The high temperature oxidation of superheated steam was one of the main reasons for abandoning this approach. Furthermore, the heat transfer properties of steam are not as good as helium, and steam activation and dissociation are significant. Hydrogen-cooled reactors have been developed in the United States and Russia for nuclear rockets. Although hydrogen possesses the best heat transfer characteristics among gas coolants, the very high fire and explosion hazard of hydrogen rules out its use for terrestrial applications.

\section{Noble Gasses}

Little development has been carried out for argon-cooled reactors. Argon is chemically inert, but heat transfer characteristics for argon are not as good as helium and neutron activation and parasitic capture are disadvantages. Significant experience has been accumulated with helium-cooled reactors. Among gasses, helium exhibits good heat transport properties. Helium is neither a fire or explosion hazard, is non-toxic, is stable in radiation and high temperature environments, has a very small parasitic capture cross section, and neutron activation is extremely small. The most significant and pertinent advantage of helium is its chemical inertness. For these reasons, helium is selected as the baseline coolant for gas-cooled reactors.

\subsection{Molten Salt Coolants}

Molten salt-cooled reactors were recently proposed [13] that combine features of the HTGR and molten salt-core reactor concepts (here we assume that the "G" in HTGR refers to graphite, rather than gas). For this concept a molten salt coolant, such as $2 \mathrm{Li}$ $\mathrm{BeF}_{2}$ is used in place of helium in an HTGR. This approach permits high temperature operation at low pressure, with the possibility of low corrosion. The excellent heat transfer capabilities of molten salt should reduce fuel operating temperatures, relative to HTGR operation using a helium coolant. Molten salt-cooled reactors avoid most of the issues associated with flowing fuel for molten salt-core reactors (discussed subsequently). Molten salt coolants also offer the advantages of thermal and radiation stability, no fire or chemical explosion hazard, and a number of safety advantages. However, molten salts are solid at room temperatures, requiring a high-temperature auxiliary heating system for reactor startup. Depleted lithium $\left(99.999 \%{ }^{7} \mathrm{Li}\right)$ is required because the capture cross section of natural lithium is high. Another consideration is the generation of tritium and helium as a result of neutron capture by ${ }^{6} \mathrm{Li}$. 


\subsection{Liquid Core Coolants}

Heat transfer is excellent for liquid core coolants because the heat source (fuel) and coolant are embodied in the same fluid. The major disadvantage of liquid core coolants is that the primary loop contains radioactive fission products. Even with online fission product removal, the radiation environment of primary loop components is a major issue [7].

\section{Aqueous Core}

The corrosiveness of the uranium salt solutions, the inability to keep uranium compounds in suspension in slurry-type fuels, and a number of other difficulties resulted in a termination in the development of aqueous-fuel liquid core reactors [7]. Furthermore, the vapor pressure for aqueous-core reactors is too high for the required cycle temperature.

\section{Liquid Metal Core}

The vapor pressure for liquid metal core coolants is quite low, and the fluid is stable in high temperature and high radiation field environments. However, liquid metal core reactors have never been built. Furthermore, liquid metal core coolants are highly corrosive and mass transport is an issue for some liquid metal core concepts.

\section{Molten Salt Core}

Molten salt fuel/coolants possess a number of advantages; e.g., low vapor pressures, low corrosion at high temperature, thermal and radiation stability, no fire or chemical explosion hazard, a number of safety advantages, and the possibility of online refueling and fuel processing. Furthermore, a molten salt reactor was successfully operated in the United States in the 1960s. The issues associated with a circulating highly radioactive fuel and on-line fuel processing, however, are substantial. Although molten salt reactors generally exhibit low corrosion at high temperature, long term materials compatibility at the required $900 \mathrm{C}$ cycle temperature has not been demonstrated. If a moderated molten salt-core is proposed, depleted Li must be used to reduce parasitic neutron capture by ${ }^{6} \mathrm{Li}$. Nonetheless, molten salt core reactor technology is more developed and more promising than other liquid core coolants; consequently, molten salt core-coolants are selected as the baseline liquid core reactor category.

\subsection{Stage 3:Attribute Assessments}

Using the requirements and criteria presented in Table 2, a subjective grade was assessed for each of the remaining candidate reactor options. A brief discussion of the assessment basis is presented here, and a summary of the assessment grades for each requirement and criteria is provided in Table 5. For each consideration, reactor concepts were graded using the following rating scheme: 


\section{Grading basis for requirements}

4: - Demonstrated to meet requirements

3: - Expected to meet requirements

2: - Promising, but entails a development risk

1: - Possible, but entails a significant development risk

0: - Not feasible (eliminate from consideration)

\section{Grading basis for criteria}

4: - Excellent

3: - Good, not optimum

2: - Acceptable

1: - Issues or poorly suited

0: - Unacceptable (eliminate from consideration) 
Table 5 Assessment of Reactor Concepts for Sulfur-Iodine Thermochemical Cycle

\begin{tabular}{|l|c|c|c|c|c||c|c|c|c|}
\hline \multicolumn{1}{|c|}{ Coolant } & Gas & Salt & $\begin{array}{c}\text { Heavy } \\
\text { metal }\end{array}$ & $\begin{array}{c}\text { Liquid } \\
\text { core }\end{array}$ & $\begin{array}{c}\text { Alkali } \\
\text { metal }\end{array}$ & PWR & BWR & Org. & $\begin{array}{c}\text { Gas } \\
\text { core }\end{array}$ \\
\hline \hline $\begin{array}{l}\text { 1. Materials } \\
\text { compatibility }\end{array}$ & 4 & 3 & 3 & 3 & 2 & - & 0 & - & - \\
\hline $\begin{array}{l}\text { 2.Coolant } \\
\text { stability }\end{array}$ & 4 & 3 & 4 & 3 & 4 & - & - & 0 & - \\
\hline $\begin{array}{l}\text { 3. Operating } \\
\text { Pressure }\end{array}$ & 4 & 4 & 4 & 4 & 4 & 0 & - & - & - \\
\hline 4.Nuclear issues & 4 & 4 & 4 & 3 & 3 & - & - & - & - \\
\hline 5. Feasibility & 4 & 3 & 2 & 3 & 2 & - & - & - & 0 \\
\hline $\begin{array}{l}\text { 1. Safety } \\
\text { 2. Operations }\end{array}$ & 3 & 3 & 3 & 2 & 3 & - & - & - & - \\
\hline 3. Capital costs & 2 & 3 & 3 & 1 & 1 & & & & \\
\hline $\begin{array}{l}\text { 4. Intermediate loop } \\
\text { compatibility }\end{array}$ & 4 & 3 & 3 & 3 & 3 & - & - & - & - \\
\hline $\begin{array}{l}\text { 5. Other merits and } \\
\text { issues }\end{array}$ & 3 & 3 & 3 & 3 & 3 & - & - & - & - \\
\hline \hline $\begin{array}{l}\text { Unweighted Mean } \\
\text { Score }\end{array}$ & 3.5 & 3.3 & 3.2 & 2.8 & 2.7 & N/A & N/A & N/A & N/A \\
\hline
\end{tabular}




\subsection{Pressurized Water-Cooled Reactors}

- Pressure: 0

The extreme pressure requirements for PWRs eliminate this potential option.

\subsection{Boiling Water-Cooled Reactors}

- Chemical compatibility: 0

Superheated steam at $900 \mathrm{C}$ is highly corrosive; consequently, BWRs are eliminated from consideration.

\subsection{Organic-Cooled Reactors}

\section{- Coolant stability: 0}

Thermal and radiation dissociation issues eliminate organic cooled reactors from consideration.

\subsection{Alkali metal-Cooled Reactors}

The low vapor pressure of lithium and the Li compatibility test data from the SP100 program led to the selection of lithium as a representative coolant for alkali metal coolants.

\section{Assessment:}

- Chemical compatibility: 2

Alkali metals are generally corrosive at high temperatures; nonetheless, limited testing of liquid metals has been carried out at $>900 \mathrm{C}$. For example, the SP-100 space reactor program carried out successful compatibility testing of flowing $\mathrm{Li}$ in $\mathrm{Nb}$ alloy loops for several thousand hours at $1,077 \mathrm{C}$. Test data spanning many years of operation is lacking, and development and fabrication of corrosion resistant components may be very costly.

\section{- Coolant stability: 4}

Liquid metals are stable in high temperature and radiation environments.

- Pressure requirements: 4

The vapor pressure for lithium is very low.

\section{- Nuclear issues: 3}

Neutron capture in lithium-6 results in the formation of lithium-7 in an excited state. Subsequent decay produces tritium and helium.

$$
\mathrm{Li}^{6}+\mathrm{n} \rightarrow\left(\mathrm{Li}^{7}\right)^{*} \rightarrow{ }^{3} \mathrm{H}+{ }^{4} \mathrm{He}
$$


The design of lithium-cooled reactors must accommodate the production of tritium and helium. The use of depleted lithium can reduce tritium and helium production. Of greater concern is the potential for positive void coefficients and its effect on safety.

\section{- Feasibility: 2}

No reactor experience exists for lithium-cooled reactors (although experience exists for sodium cooled reactors, operating pressures for sodium are unacceptable). Compatibility testing of lithium coolants for the SP-100 program is promising; however, operational data for $\mathrm{Li}$ at $900 \mathrm{C}$ was accrued for only a small fraction of the lifetime of a typical terrestrial reactor. Uranium nitride was selected as the fuel for the SP-100 reactor because $\mathrm{UO}_{2}$ was found to dissolve in lithium (in the event of a cladding leak). Uranium nitride

fuel, however, required specially designed fuel elements to deal with thermal dissociation and chemical incompatibility of the Nb alloy with UN fuel (a Re liner was used). The development requirements for a commercial scale lithium based system needs to be assessed.

\section{- Safety: 2}

Lithium's low vapor pressure should prevent rapid coolant evaporation following a postulated primary system breach. On the other hand, liquid metal-cooled reactors are typically fast reactors, raising some concerns relative to reactivity-induced accidents. These issues are more acute when positive void coefficients (coolant void induced reactivity increase) are possible. From the standpoint of positive void coefficients, lithium is probably worse than sodium. Although the United States and other nations have safely operated alkali metal cooled reactors, positive void coefficients, the potential for lithium fires and explosions, and tritium production are important safety considerations.

\section{- Operational issues: 3}

Lithium thaw requirements, fire and explosion safety precautions, and tritium management requirements may present operational issues.

\section{- Capital costs: 1}

High capital costs may result if special alloys and complex fuel element deigns are required (as for the SP-100 design). Low operating pressures may reduce some capital expenditures.

\section{- Intermediate loop compatibility: 3}

Possible reactivity effects of voids introduced by helium leakage from the intermediate loop must be considered. A liquid metal coolant could be used for the intermediate loop; however, compatibility with the thermochemical loop may then present issues for some postulated accidents.

\section{- Other issues and merits 3}


The development of high temperature alkali metal cooled reactors could provide the technology for highly efficient systems for electrical power. A fast reactor design could permit deep fuel-burn to render the fuel proliferation resistant.

\subsection{Heavy Metal-Cooled Reactors}

The lower melt temperature of $\mathrm{PbBi}$, relative to lead, and the extensive Russian experience with $\mathrm{PbBi}$ reactors led to the selection of $\mathrm{PbBi}$ as the representative coolant for heavy metal-cooled reactors.

\section{Assessment:}

\section{- Materials compatibility 3}

Heavy metals are generally less corrosive than alkali metals. Nonetheless, extensive materials testing for liquid heavy metals at $900 \mathrm{C}$ is lacking. Furthermore, issues have been raised concerning the possibility of leaching out alloying agents from structural materials containing very hot flowing lead or lead-bismuth. Coolant additives may result in acceptable materials compatibility at $900 \mathrm{C}$.

\section{- Coolant stability: 4}

Liquid metals are stable in high temperature and radiation environments.

\section{- Pressure requirements: 4}

The vapor pressure for lead-bismuth is very low.

\section{- Nuclear issues: 4}

The major nuclear disadvantage of $\mathrm{PbBi}$ coolants is the activation product ${ }^{210} \mathrm{Po}$ resulting from an $n, \gamma$ reaction with ${ }^{209} \mathrm{Bi}$ (and beta decay). Although polonium-210 is very toxic and difficult to contain, Russian experience suggests that ${ }^{210}$ Po can be safely managed.

\section{- Feasibility: 2}

The United States has little experience with heavy metal reactor coolants. Cooperation with Russian developers could be important if heavy metal cooled reactors are pursued. Reactor experience with heavy metal coolants is limited to temperatures far below $900 \mathrm{C}$. Although promising, this absence of materials and appropriate fuel data for these systems presents appreciable development risk.

\section{- Safety 3}

The low vapor pressure of heavy metal coolants provides the safety advantages of preventing loss of coolant accidents due to rapid coolant evaporation, and precluding explosive release of a high-pressure coolant. Heavy metal-cooled reactors are typically proposed as fast reactors. Reactivity induced accidents are generally more of a concern for fast reactors than for thermal reactors; however, heavy metal coolants possess an advantage over alkali metals in that they do not exhibit positive void coefficients. 
Furthermore, $\mathrm{PbBi}$ does not present fire or chemical explosion hazards. On the other hand, the activation product ${ }^{210} \mathrm{Po}$ resulting from an $n, \gamma$ reaction with ${ }^{209} \mathrm{Bi}$, presents additional considerations.

\section{- Operational issues: 3}

Lead-bismuth thaw requirements may result in added operational complexity.

\section{- Capital costs: 3}

Lead-bismuth thaw requirements may result in additional capital expenditures. Low operating pressures may reduce some capital expenditures.

\section{- Intermediate loop compatibility: 3}

Possible reactivity effects of voids introduced by helium leakage from the intermediate loop must be considered. A liquid metal coolant could be used for the intermediate loop; however, compatibility with the thermochemical loop may then present issues for some postulated accidents.

\section{- Other issues and merits: 3}

The development of high temperature heavy metal-cooled reactors could provide the technology for highly efficient systems for electrical power. A fast reactor design could permit deep fuel-burn to render the fuel proliferation resistant.

\subsection{Gas-Cooled Reactors}

Although the coolant for PBRs and HTGRs is identical (He), the design characteristics of these approaches differ significantly. To simplify the grading of the helium-cooled approach, the HTGR design will be assumed as the representative approach for heliumcooled reactors.

\section{Assessment:}

\section{- Materials compatibility: 4}

Helium is an inert gas and, in its pure state, should be ideal for operation at the required temperature of $900 \mathrm{C}$. Although materials effects can result from impurities in the coolant, operational experience with Fort St. Vrain showed no significant materials issues related to impurities in the coolant. Some graphite transport materials problems were encountered that were associated with water entering the primary loop from the water bearings and Pelton wheel of the compressor. For new HTGR designs, these problems should not arise because the water bearings and Pelton wheels will be replaced by magnetic bearings and electric motors. Fort St. Vrain operated for 15 years at coolant temperatures of $750 \mathrm{C}$. The AVR operated for 21 years, including years of operation at $950 \mathrm{C}$; consequently, gas-cooled reactors have been successfully operated in the desired optimal temperature range. (The Japanese prismatic fuel HTTR will also operate at coolant temperatures $>900 \mathrm{C}$ ). 


\section{- Coolant stability: 4}

Helium is stable in thermal and radiation environments.

\section{- Pressure requirements: 4}

Gas coolant operating pressures are high, but well within the operational envelope for gas cooled reactors. Although high pressure operation implies the possibility of rapid coolant loss, the high heat capacity of the graphite fuel elements mitigates the effects of these types of accidents.

\section{- Nuclear issues: 4}

Activation of $\mathrm{He}$ is insignificant.

\section{- Feasibility: 4}

In general little development work is identified for GCRs. The United States has considerable experience with gas-cooled reactor systems. U.S. industry is not directly engaged in gas-cooled reactor development at present, but U.S. technology is well documented. The U.S. HTGR technology is now being transferred to Russia for the purpose of building an HTGR to burn the plutonium from the Russian plutonium stockpile. Germany is no longer developing gas-cooled reactors but the German pebble bed technology is in the process of being transferred to the South African nuclear program. Japan is actively engaged in development of gas-cooled reactors. The required coolant temperature is a bit higher than the current experience base for U.S. designs; however, the current fuel form is expected to be acceptable for the somewhat higher operating temperatures. The German reactors have been successfully operated at a coolant outlet temperature 950C, and the Japanese are developing higher temperature zirconium carbide coated fuel. Although the United States has experience with zirconium carbide coated fuel, it may be expedient to license the Japanese technology. The U.S. facilities for gas-cooled reactor fuel fabrication have been decommissioned but the technology for making coated particle fuel still exists at facilities that produce Navy reactor fuel.

\section{- Safety: 3}

The high heat capacity of the core for graphite-moderated helium cooled concepts results in very gradual core heating in the event of a loss of flow accident. Furthermore, no coolant phase change occurs for any postulated accident sequence. The high fission product retention ability of the HTGR microsphere fuel provides another safety advantage. Helium is non-toxic and does not present a fire or explosion hazard.

The issue has been raised concerning the possibility of rapid oxidation of the graphite fuel elements in the event of accidental air ingress into the primary system. The proponents of gas-cooled reactors argue that the high-density, high-grade graphite used for the fuel elements does not undergo rapid oxidation for postulated loss-of-coolant accident conditions [36]. The possibility of significant water ingress seems highly 
improbable due to the absence of a high-pressure water interface with the primary loop. Furthermore, magnetic bearings and electric motors will be used for the compressor, rather than using water bearings and steam-driven Pelton wheels (used for FSV).

Nonetheless, independent study of the possibility of rapid oxidation is recommended. Gas cooled reactors, taking advantage of coated particle fuel technology, are sometimes designed without an external containment building. Here we have assumed adequate confinement by either the fuel particle coating, or by a confinement enclosure (reflected in somewhat higher capital costs, as discussed subsequently).

\section{- Operational issues: 3}

Other than the lack of a large base of operational experience (compared to PWRs and BWRs), no significant operational issues are identified. Nonetheless, very high temperature, high pressure operating conditions may present some operational considerations; thus, a score of (3) is awarded for operational issues.

\section{- Capital costs: 2}

The poor heat transfer characteristics of gasses and the large volumes of graphite required for effective moderation generally result is fairly large reactor systems. Furthermore, large reactor systems combined with the need for containing a high-temperature, highpressure coolant may result in increased capital costs. Additional capital costs will result if a containment or confinement building is required. Given all of these considerations, a (2) was awarded for capital costs.

\section{- Intermediate loop compatibility: 4}

The helium coolant is entirely compatible with the intermediate loop.

\section{- Other issues and merits: 3}

The high temperature capability of the helium-cooled reactor can also be used to develop highly efficient systems for electrical power. The possibility of a direct Brayton cycle may result in significant efficiency improvements and reduced capital costs for the production of electricity. (If the PBR is used, online refueling, deep fuel burn, and low excess reactivity operation are feasible).

\subsection{Molten Salt-Cooled Reactors}

Fluoride salts were selected as the representative coolant for molten salt-cooled reactors.

\section{Assessment:}

\section{- Materials compatibility: 3}

Molten fluoride salts exhibit good corrosion resistance at high temperatures; however, the required temperatures are somewhat higher than the existing experience base. Although molten fluoride salts should be compatible with graphite, some evidence of mass transport has been obtained for systems using both metal and graphite components [37]. 
The possible issue of fission product effects for molten salt-core reactors does not apply to molten salt-cooled reactors.

\section{- Coolant stability: 3}

Molten salts are found to be stable in high temperature and radiation environments; however, long-term operation data is lacking.

\section{- Pressure requirements: 4}

The vapor pressure for molten salts is very low.

\section{- Nuclear issues: 4}

Activation of fluoride salts should be modest and the void coefficient is expected to be negative. Lithium fluoride salts will require the use of depleted lithium $\left(99.999 \%{ }^{7} \mathrm{Li}\right)$ to reduce parasitic neutron capture and the generation of tritium and helium.

\section{- Feasibility: 3}

The United States developed molten salt technology for the Molten Salt Reactor Experiment. The United States has also developed HTGR fuel and fuel elements (proposed to be used with a molten salt coolant). Furthermore, the excellent heat transfer capability of molten salts should reduce maximum fuel temperatures relative to gascooled reactors. On the other hand, the differences between molten salt and helium coolants will probably require modification of the core design. The lack of adequate longterm data in the desired temperature range also presents a development risk. MSCR is projected to be feasible, but undemonstrated (3).

\section{- Safety: 4}

Void coefficients for molten salts are expected to be negative. Molten salt coolants possess HTGR safety advantages as well as molten salt advantages. If the basic fuel form of the HTGR is not substantially altered, the high heat capacity of the graphite blocks result in very gradual core heating in the event of a loss of flow accident. The low pressure of molten salts provides the safety advantage of preventing loss-of-coolant accidents due to rapid coolant evaporation and explosive release of a high pressure coolant is precluded. Furthermore, the molten salt coolant can enhance passive heat transfer for some postulated accident conditions. The low-pressure coolant and passive heat removal capability may completely eliminate air ingress issues. The high fission product retention ability of the HTGR microsphere fuel provides another safety advantage. For postulated severe accidents, molten salts can react with some fission products, possibly reducing the source term. In addition, molten salts do not present fire or chemical explosion hazards. The toxicity of molten salts may present safety considerations, but on the whole, MSCRs appear to offer outstanding safety advantages. As a consequence, a score of (4) is awarded.

\section{- Operational issues: 3}


The very high melt temperature for molten salts may present some operational challenges.

\section{- Capital costs: 3}

Low operating pressures may reduce some capital expenditures, but the required high temperature thaw system may present additional capital expenditures.

\section{- Intermediate loop compatibility: 3}

Possible reactivity effects of voids introduced by helium leakage from the intermediate loop must be considered. A molten salt coolant could be used for the intermediate loop; however, compatibility with the thermochemical loop may then present issues for some postulated accidents.

\section{- Other issues and merits: 3}

The development of high temperature molten salt-cooled reactors could provide the technology for highly efficient systems for electrical power.

\subsection{Liquid-Core Reactors}

Liquid-core reactors possess a number of unique features and advantages. Aqueous liquid cores are not recommended, however, because operational pressures would be extreme. Liquid metal-core concepts are not as well developed as molten saltcore reactors and they present mass transport and corrosion issues. Molten salt-core reactors are selected as the lead candidate among molten-core approaches.

\section{Assessment:}

\section{- Materials compatibility: 3}

Molten fluoride salts exhibit good corrosion resistance at high temperatures; however, the required temperatures are somewhat higher than the existing experience base, and operational experience is much shorter than the required lifetime. Although fission products are removed from the coolant during operation, the effect of continued release of fission products into the coolant stream needs to be assessed.

\section{- Coolant stability: 3}

Molten salts are stable in high temperature and radiation environments, however, longterm operational data is lacking. Furthermore, the possibility of precipitation of fuel materials needs to be assessed.

\section{- Pressure requirements: 4}

The vapor pressure for a molten salt core is very low.

\section{- Nuclear issues: 3}


The circulation of hot fuel materials, actinides, and fission products can present significant operational challenges.

\section{- Feasibility: 3}

The United States has developed molten salt core technology with the Molten Salt Reactor Experiment. Nonetheless, long term operational data is lacking, and issues relating to a radiologically hot primary loop and on-line refueling and processing present significant challenges.

\section{- Safety: 3}

Molten core reactors offer significant safety advantages. Online refueling eliminates the need for high excess core reactivity and substantially reduces the risk from reactivityinduced accidents. The online removal of fission products reduces the potential source term for some postulated accidents and removes the decay heat source from the core and primary loop. Furthermore, the coolant is not a fire or chemical explosion hazard. On the other hand, the potentially high activity in the primary loop and the need for on-site fission product processing introduces some additional safety issues.

\section{- Operational issues: 2}

The high melt temperature for molten salts, the limitations on access due to a hot primary loop, and the need for online fuel/coolant processing presents operational challenges.

\section{- Capital costs: 1}

Low operating pressures may reduce some capital expenditures; however, the required high-temperature thaw system, online refueling system, and fission product removal and treatment systems could result in significant capital costs.

\section{- Intermediate loop compatibility: 3}

The radiologically-hot coolant could enter the secondary loop in the event of a heat exchanger leak. Furthermore, if helium is used in the intermediate loop, a leak of helium into the primary loop could create bubbles with possible effects on reactivity. A molten salt coolant could be used for the intermediate loop; however, compatibility with the thermochemical loop may then present issues for some postulated accidents.

\section{- Other issues and merits: 3}

The liquid-core reactor offers the advantages of online refueling, online waste treatment and storage, the ability to use a variety of fuel types (e.g., plutonium, uranium, MOX), and the potential for deep fuel-burn to render the fuel proliferation resistant. The high temperature capability could also be used to develop highly efficient systems for electrical power.

\subsection{Gas-core Reactors \\ - Feasibility: 0}


The required development work and the development risk for gas core reactors are too significant to merit further consideration for this study.

\subsection{Stage 4: Development Costs}

From the preceding analysis, the gas-cooled reactors (GCRs), molten salt-cooled reactors (MSCRs), and heavy metal-cooled reactors (HMRs) appear to be the most promising. A detailed economic analysis of development costs is beyond the scope of this study but an estimate of the relative development cost of the three concepts is instructive. For the purpose of selecting a baseline concept, a simple method for comparing development will be used.

\subsection{Approach}

Expected development cost trends for MSCR and HMR systems will be compared relative to GCR development costs. Gas cooled reactors are chosen as the baseline because GCRs are the most developed of the three promising concepts. If development costs are expected to be significantly greater than for GCRs, then selecting GCRs for the baseline is clearly recommended. The following simple indictors will be used:

$4 \quad$ Lower development cost than for gas-cooled reactors

3 Approximately the same development cost as for gas-cooled reactors

2 Higher development cost than for gas-cooled reactors

$1 \quad$ Significantly higher development costs

$0 \quad$ Prohibitive development costs (eliminate from consideration)

This numbering system is consistent with the numbering system in Section 5, in that higher numbers are favorable. Note that the reference GCR baseline score is always equal to (3).

The following development activities were identified:

- Materials development

- Fuel development

- Component development

- System design

- Fabrication facility development

The results of this assessment are presented in Table 6 . 
Table 6 Development Cost Scores Relative to GCRs.

\begin{tabular}{|l|l|l|l|l|l|l|}
\hline $\begin{array}{l}\text { Reactor } \\
\text { Type }\end{array}$ & $\begin{array}{l}\text { Materials } \\
\text { develop }\end{array}$ & $\begin{array}{l}\text { Fuel } \\
\text { develop }\end{array}$ & $\begin{array}{l}\text { Component } \\
\text { develop }\end{array}$ & $\begin{array}{l}\text { System } \\
\text { develop }\end{array}$ & $\begin{array}{l}\text { Fab. } \\
\text { facility }\end{array}$ & $\begin{array}{l}\text { Unweighted } \\
\text { average }\end{array}$ \\
\hline HMR & 1 & 1 & 2 & 3 & 1 & 1.6 \\
MSCR & 2 & 3 & 2 & 2 & 2 & 2.2 \\
GCR & 3 & 3 & 3 & 3 & 3 & 3.0 \\
\hline
\end{tabular}

\subsection{Materials Development}

Materials development refers to coolant compatibility issues. Gas-cooled reactors have demonstrated acceptable materials compatibility for more than a decade of operation (AVR) in the required temperature regime. Molten salt compatibility looks promising; however, demonstrated molten salt acceptable compatibility close to the desired temperature range was limited to about two years. Given this lack of long-term operational experience, additional materials development is most likely required for the MSCR (2), Heavy metal cooled reactors have not been operated anywhere near the required temperature range, and significant materials development is most likely required for the HMRs (1).

\subsection{Fuel Development}

The required coolant temperature is somewhat higher than that used in the U.S. HTGR program. The required higher coolant temperature could result in higher fuel temperatures than demonstrated for HTGR designs. If higher fuel temperatures are required to achieve $900 \mathrm{C}$ coolant temperatures, fuel development work will be required. The Japanese HTTR, an HTGR-type reactor, is currently ramping up to the expected operating temperature of $>900 \mathrm{C}$, and a significant effort in developing and demonstrating zirconium carbide coated fuel particles is underway in Japan.

The excellent heat transfer characteristics of molten salt cooled coolants may result in less demanding requirements on the fuel; optimistically, the fuel already developed for gas-cooled reactors may be used for the MSCR. The MSCR is a new and undeveloped concept and additional development work cannot be ruled out. At this stage, a significant difference in MSCR fuel development cost, relative to GCRs, is not clearly indicated (3).

Fuel performance for HMRs is totally lacking in the required operational range, and appreciable development work is projected for HMRs. As a consequence, the HMR is scored a (1).

\subsection{Component Development}

Some component development is required for all three concepts. No significant component development issues, relative to GCRs, are identified for the MSCR or the HMR. Nonetheless, the lack of experience with these systems in the required temperature range implies the possibility of unexpected component development costs. Both MSCRs and HMRs are scored a (2). 


\subsection{System Design Development}

Full system designs for high temperature GCRs have been developed; whereas the MSCR is an entirely new concept and significant MSCR system design development is anticipated (2). The Russians have carried out appreciable design development work for a commercial HMR. If the higher temperature capability required for the sulfur-iodine cycle does not alter the HMR design significantly, it is possible that additional system design work will be minimal (3).

\subsection{Fabrication Facility Development}

Internationally, fuel fabrication facilities existed in Germany for the Pebble Bed reactor fuel, and the technology is being transferred to South Africa. Developmental fuel fabrication facilities exist in Japan and facilities are now under development in Russia. Fuel fabrication facilities for production of coated fuel particles that can be used in GCRs exist in the United States at (e.g., Babcock and Wilcox). These facilities have been in operation, producing fuel for the Navy, for more than twenty years. A complete fuel fabrication facility for the HTGR existed at General Atomics. Although the General Atomics fabrication facility has been dismantled, the technology is fully documented and recoverable. Fabrication processes for most major GCR components have been established.

If MSCRs use the same fuel as GCRs, no fabrication development will be necessary. The assumption that MSCRs can use GCR fuel is based on the documented resistance of graphite to $2 \mathrm{LiF}-\mathrm{BF}_{2}$. Although the fuel elements and coated particles are fully graphitized, the fuel compacts are not. Nonetheless, a clear need for greater fuel fabrication development (relative to GCRs) is not identified. Fabrication technology may need to be developed, however, for other MSCR components that will be required to operate at higher temperatures than those required for the molten salt reactor experiment. The fabrication development cost for the MSCR is scored a (2).

Fuel fabrication facilities will need to be developed for the HMR. Some facilities capable of producing HMR fuel probably exist in Russia, but this fuel never operated at the required temperatures. Appreciable fuel fabrication technology development is expected, and other component fabrication technology development is expected as well (1).

\subsection{Development Assessment}

From Table 6 we observe that the GCR approach is expected to result in the lowest development cost and risk. The MSCR and, especially, the HMR approaches are expected to require significantly greater development costs.

\subsection{Conclusions}


Based on the forgoing discussion, the following preliminary conclusions and recommendations are made:

\section{PWR, BWR, Organic-Cooled, and Gas-Core Reactors - Not Recommended}

- From the preceding analysis we conclude that all PWR approaches are impractical in that enormous system pressures are required to obtain $900 \mathrm{C}$ coolant temperatures.

- The highly corrosive nature of $900 \mathrm{C}$ steam eliminates BWRs from consideration.

- Organic-cooled reactors are not recommended as a heat source for the sulfur-iodine thermochemical cycle because organic coolants dissociate at temperatures well below the required cycle temperature.

- Gas core reactors were not considered because the approach requires unproven technology at a fundamental level and the development risk is too great for the goals of this program.

\section{Liquid-Core Reactors and Alkali Metal-Cooled Reactors - Significant development risk}

- Although the liquid-core reactor technology is promising for operation at the required temperatures, the circulation of radiologically hot fuel/coolant presents many operational and developmental issues, as well as high capital costs. At this stage the molten core is judged to be a possible approach, but it is not retained as a strong alternative.

- Alkali metal-cooled reactors are also possible candidates, but the general corrosiveness of alkali metals at very high temperatures is an important issue. At this stage, the technology risk and development cost are judged to be significant. Furthermore, if special alloys and complex fuel elements are required, the capital cost required to produce a system capable of meeting performance requirements may be significant. Positive void coefficients, fire and explosion hazards, coolant activation, and thaw requirements are additional undesirable features of alkali metal coolants. For these reasons, alkali metal-cooled reactors are considered as possibilities, but not a strong alternative.

\section{Heavy Metal and Molten Salt-Cooled Reactors - Promising}

- Both HMRs and MSCRs appear to be promising candidates, but relatively high development costs places these approaches in the promising alternative category.

\section{Gas Cooled Reactors - Baseline choice}


- Based on Table 5, helium gas cooled reactors appear to well suited for the proposed application. From Table 6, GCRs are projected to require substantially lower development costs then alternative approaches. The underlying reasons for the suitability of GCRs for the high temperature sulfur-iodine cycle are: (1) helium is chemically inert, and (2) gas cooled reactors have been successfully operated for a number of years in the required temperature range. Altogether, the GCRs approach appears to be very well suited as a heat source for the intended application, and no major development work is identified. This study recommends using a GasCooled Reactor as the baseline reactor concept for a sulfur-iodine cycle for hydrogen production.

- Although the GCR approach provides a number of important safety advantages, a possible safety issue has been raised associated with postulated accidents leading to air ingress. An independent review of this issue is recommended. 


\section{References:}

1. L. C. Brown, High efficiency Generation of Hydrogen Fuels Using Nuclear Power, NERI Proposal, January 291999.

2. L. C. Brown, General Atomics, personal communication, November 2000.

3. A. V. Nero, Jr., A Guidebook to Nuclear Reactors, U. of Cal. Press, Berkeley, 1979.

4. C. W. Forsberg and A. M. Weinberg, "Advanced Reactors, Passive Safety, and Acceptance of Nuclear Safety," Annu. Rev. Energy, 15, pp. 133-152

5. S. Koshizuka and Y. Oka, "Supercritical-Pressure, Light-Water-Cooled Reactors for Economical Nuclear Power Plants," Prog. Nucl Ener. 32, pp. 547-554, 1998.

6. M. Simnad, Fuel Element Experience in Nuclear Power Reactors, Gordon and Breach Science Publ., NY, 1971.

7. S. Glasstone and A. Sesonske, Nuclear Reactor Engineering, Van Nostrand Reinhold Co., NY, 1967.

8. D. Bleuel, J. Scott, and L. Sevingy, Introduction to the ALMR/PRISM, http://www.nuc.berkeley.edu/ gav/almr/01.intro.html. November 2000.

9. M. S. El-Genk, A Critical Review of Space Nuclear Power and Propulsion 19841993, American Institute of Physics, NY, 1994.

10. M. I. Bugreev, et. Al., Analysis of Risks Associated with Nuclear Submarine Decommissioning, Dismantling, and Disposals, pp. 261-264, A. A. Sarkisov and A. Tournyol du (eds.), Kluver Academic Publishers, Netherlands, 1999.

11. A. V. Zrodnikov, O. G. Grigoriev, A. V. Dedoul, G. I. Toshinsky, V. I. Chitaykin, V. S. Stepanov, "Shore Small Power NPP with Lead-Bismuth cooled Reactor without on-site refueling", International Workshop on Utilization of Nuc;ear Power in Oceans, Tokyo, February, 2000.

12. K. Kemm, Development of the South Africa Pebble Bed Modular Reactor System, http:www.uilondon.org/sym/1999kemm.htm, November, 2000.

13. C. Forsberg and P. Pickard, Advanced High-Temperature Reactor for Hydrgen and Electricity Production, Oak Ridge National Laboratory view graph presentation, May, 2001.

14. M. M. El-Wakil, Nuclear Power Engineering, McGraw-Hill Book Co., NY, 1962.

15. J. A. Angelo and D. Buden, Space Nuclear Power, Orbit Book Co., Malabar, FL, 1985.

16. Coolants for Nuclear Reactors, http://www.nuc.berkeley.edu/thyd/ne161/rahmed/coolants.html. November, 2000.

17. V. V. Orlov and E. O. Adamov, "A radical approach is needed for a nuclear future in Russia,” Nucl. Engr. Inter., pp. 42-44, May, 1992.

18. B. F. Gromov, et al., "Inherently safe lead-bismuth-cooled reactors," Atomic Energy, 76 No. 4, 1984.

19. C. B. Davis and A. S. Shieh, Overview of the use of ATHENA for thermal-hydraulic analysis of systems with lead-bismuth cooling, INEEL/CON-2000-00127, April 2000.

20. H. Sekimoto and Z. Su'ud, "Design of lead and lead-bismuth cooled small long-life nuclear power reactors using metallic and nitride fuel," Nucl. Tech., 109, 307-313, March 1995.

21. J. A. Lane, H. G. MacPherson, and F. Maslan, Fluid Fuel Reactors, Addison-Wesley Publ. Co., Reading MS, 1958. 
22. U. Gat and J. R. Engel, "Non-proliferation attributes of molten salt reactors," Nucl. Engr. \& Des., 201, pp. 327-334, 2000.

23. K. Mitachi, T. Suzki, and K. Furakawa, "A preliminary design of a small molten salt reactor for effective use of thorium resource," proc. $7^{\text {th }}$ International Conf. On Nucl. Engr., Tokyo, Japan, April 1999.

24. A. S. Shenoy, Modular helium reactors for non electric applications of Nuclear energy, GA-A22701, Nov. 1995.

25. K. Onuki, et al., "Studies on water splitting hydrogen production," The third symposium on HTGR Technologies, pp. 262-474, 2000.

26. High temperature engineering test research, http://www.jari.go.jp/nglish/temp, December 2000.

27. A. N. Nesmeyanov, Vapor Pressure of the Chemical Elements, Elsevier Publ. Co., Amsterdam, 1963.

28. B. M. Ma, Nuclear Reactor Materials and Applications, Van Nostrand Reinhold Co., NY, 1983.

29. M. M. El-Wakil, Nuclear Energy Conversion, International Textbook Co., La Grange Park, IL, 1982.

30. A. R. Foster, R. L. Right, Basic Nuclear Engineering, Allyn and Bacon, Inc. Boston, 1974.

31. J. E. Draley and J. R. Weeks, Corrosion by Liquid Metals, Plenum Press, NY, 1970.

32. D. W. Yaun, R. F. Yan, and G. Simkovich, "Rapid oxidation of liquid tin and its alloys at 600 to 800C," Jour. Matls. Sc., 34, pp. 2911-2920, 1999.

33. M. Broc, J. Sannier, and G. Santarini, "Behavior of ferritic steels in the presence of flowing purified liquid lead," proc. Conf. Liquid Metal in Energy Applications, Oxford UK, April 1984.

34. R. C. West, et al. (eds.) CRC Handbook of Chemistry and Physics, $70^{\text {th }}$ Edition, CRC Press Inc., Boca Raton FL, 1989.

35. N. Brown and J. A. Hassberger, "New concept of small power reactor without on-site refueling for non-proliferation," IAEA advisory group meeting on propulsion reactor technologies for civilian applications," Obninsk, Russia, July 1998.

36. A. S. Shenoy, General Atomics, personal communication, September 2001.

37. J. Sannier and G. Santarini, "Studies of materials for molten salt nuclear operations", International Symposium on Molten Salt Chemical and Tecnical, Kyoto, Japan, April, 1983. 